\title{
PRODUTIVIDADE DA CANA-DE-AÇÚCAR EM FUNÇÃO DE ALGUNS MACRONUTRIENTES PRESENTES NO CAIDO E NO SOLO.
}

\author{
EDGAR GOMES FERREIRA DE BEAUCLAIR \\ Engenheiro Agrônomo
}

Orientador: Prof. Dr. VALDOMIRO CORREA DE BITTENCOURT

Tese apresentada à Escola Superior de
Agricultura "Luiz de Queiroz", da
Universidade de săo Paulo, para
obtençăo do título de Doutor em
Agronomia, Área de Concentração: Solos
e Nutriçăo de Plantas.

PIRACICABA

Estado de São Paulo - Brasil

Novembro - 1994 
Ficha catalografica preparada pela beço de Livros da Divisado de Hitilioteca e Documentacta - FCLQ/usF

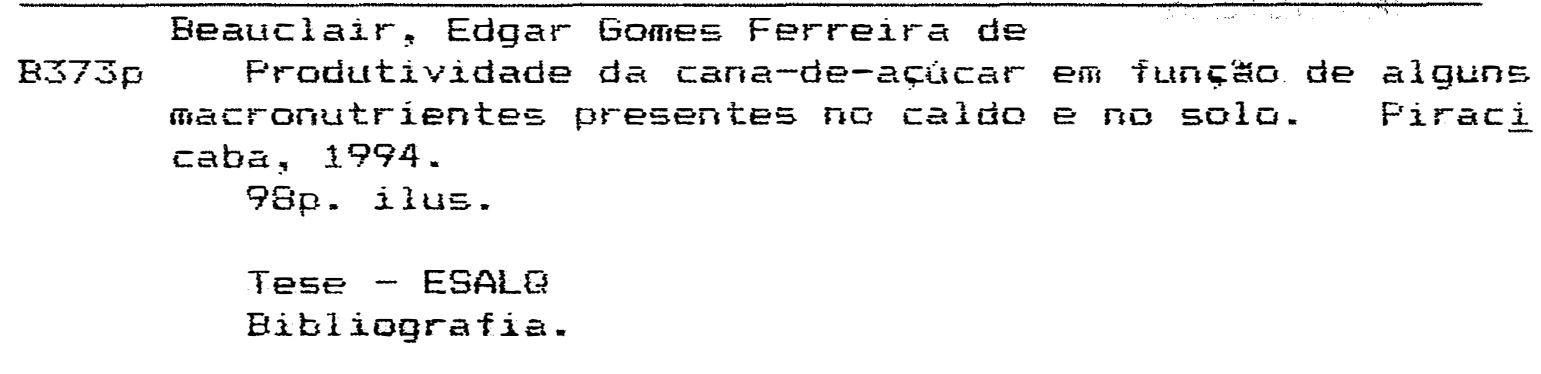

1. Caldo de cana-de-af̧ucar - Anilise Z. Cana-de-açú car - Nutriça I. Eana-de-ackicar - Frodutividade I. EE cula Superiof de Agricultura Luiz de Queirot, Firacicaba

CDD 653.61 


\section{PRODUTIVIDADE DA CANA-DE-AÇÚCAR EM FUNÇÃO DE ALGUNS MACRONUTRIENTES PRESENTES NO CALDO E NO SOLO.}

EDGAR GOMES FERREIRA DE BEAUCLAIR

Aprovada em: 28.11.1994

Comissão julgadora:

Prof. Dr. Valdomiro Corrêa de Bittencourt ESALQ/USP Prof. Dr. José Carlos Chitolina ESALQ/USP Prof. Dr. Gil Miguel de Sousa Câmara ESALQ/USP Prof. Dr. José Orlando Filho UFSCar Prof. Dr. Gaspar Henrique Korndorfer U.F. Uberlândia

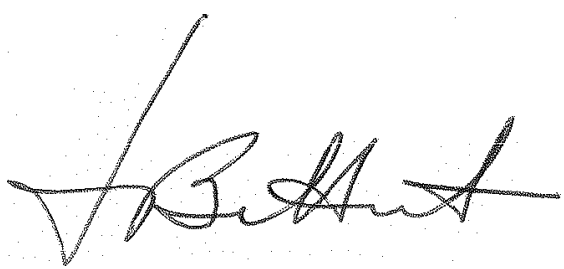

Prof. Dr. VALDOMIRO CORREA DE BITTENCOURT Orientador 
Aos meus pais e irmã ofereço

\author{
À minha esposa Daniela, \\ e meus filhos Camila e Paulo \\ dedico.
}




\section{AGRADECIMENTOS}

Ao Professor Valdomiro Corrêa de Bittencourt pelos ensinamentos, orientação e grande amizade.

Ao Departamento de Química da Escola Superior de Agricultura "Luiz de Queiroz", por permitir e incentivar a realização do Curso de Doutorado.

Aos Professores e Funcionários do Setor de Química Analitica pelo apoio e amizade.

À Diretoria da Usina Santa Adélia, cujo apoio foi fundamental para a realização deste trabalho, permitindo o uso de suas instalações.

Ao colega e Engenheiro Agrônomo Antônio Claret, que garantiu o funcionamento dos trabalhos na Usina Santa Adélia.

A técnica química Rita de C. Vieira, pela ajuda inestimável nas determinações analíticas.

Ao técnico agricola J.W.P. Camba, pela ajuda nos trabalhos de campo.

Aos amigos e familiares que sempre acreditaram em mim.

E a todos que de uma forma ou de outra, contribuiram para este trabalho. 


\section{SUMÁRTO}

Página

RESUMO

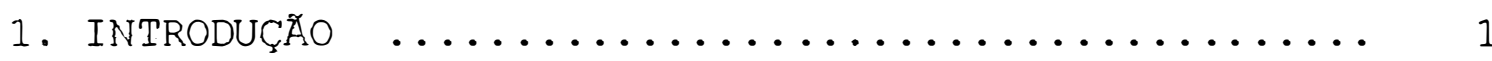

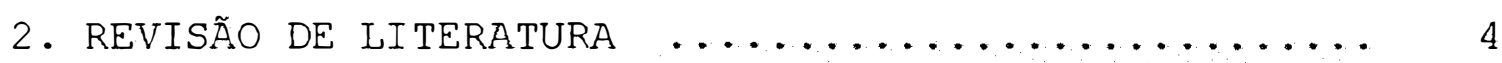

2.1. Análise de solos .................... 5

2.2. Outros métodos de avaliação $\ldots \ldots \ldots \ldots \ldots \ldots \ldots \ldots$

2.2.1. Diagnose foliar $\ldots \ldots \ldots \ldots \ldots \ldots \ldots \ldots \ldots . \ldots$

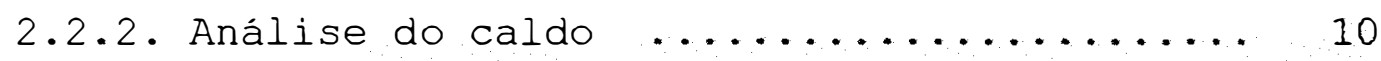

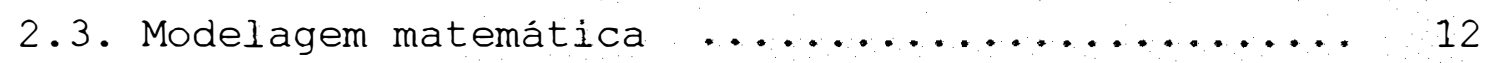

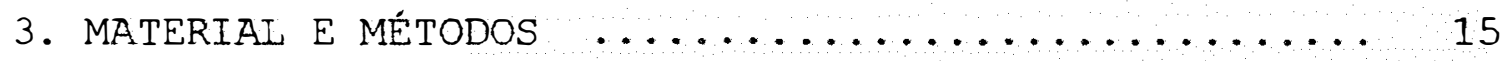

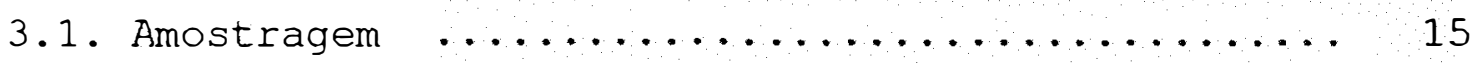

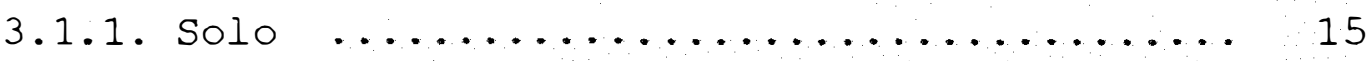

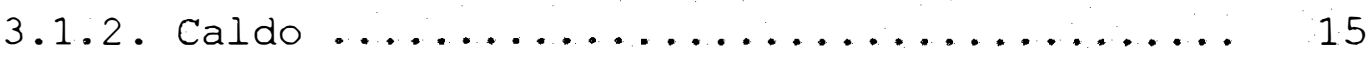

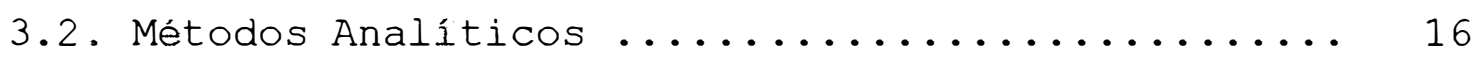

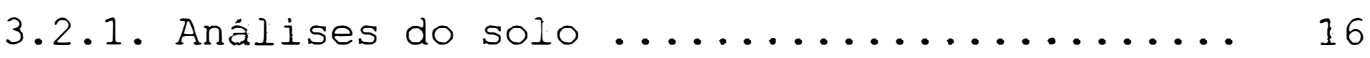

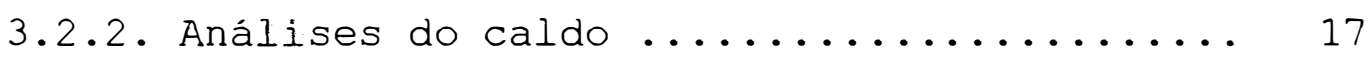

3.2.2.1. Determinação de $\mathrm{N} \ldots \ldots \ldots \ldots \ldots \ldots \ldots . \ldots \ldots 17$

3.2.2.2. Determinação de $\mathrm{K} \ldots \ldots \ldots \ldots \ldots \ldots \ldots . \ldots \ldots$

3.2.2.3. Determinação de $\mathrm{Ca}$ e $\mathrm{Mg} \ldots \ldots \ldots \ldots \ldots . \ldots 18$

3.2.2.4. Determinação de $\mathrm{P} \ldots \ldots \ldots \ldots \ldots \ldots \ldots \ldots \ldots$

3.3. Obtenção dos dados das áreas $\ldots \ldots \ldots \ldots \ldots \ldots \ldots$

3.3.1. Dados cadastrais e de produtividade...... 19

3.3.2. Dados dos insumos aplicados ........... 20

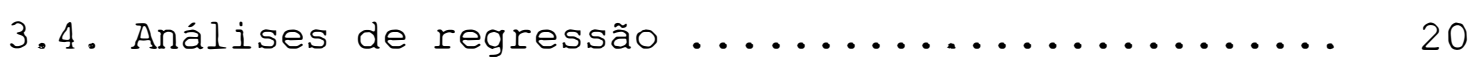

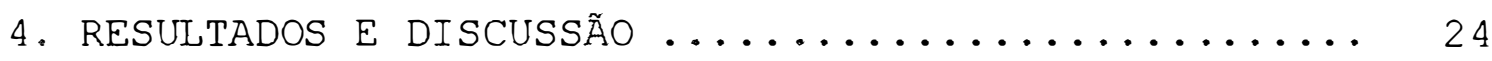

4.1. Resultados gerais de obtenção de dados ........ 24

4.2. Resultado das análises estatísticas ......... 66 
4.2.1. Influência dos nutrientes absorvidos sobre

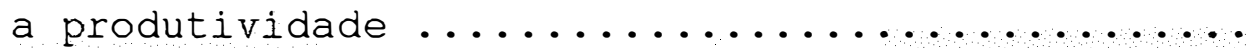

4.2.2. Influência dos nutrientes absorvidos, dos parâmetros do solo e dos fertilizantes aplicados

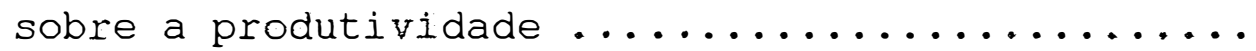
4.2.3. Influência dos nutrientes absorvidos sobre o teor de açúcar expresso em ATR e em PC ........ 69 4.2.4. Influência dos nutrientes absorvidos, dos parâmetros do solo e dos fertilizantes aplicados sobre o teor de açúcar expresso em ATR e em PC .. 4.2.5. Influência dos parâmetros do solo e dos fertilizantes aplicados sobre a quantidade de $\mathrm{N}$

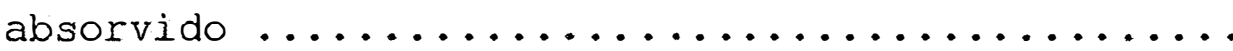

4.2.6. Influência dos parâmetros do solo e dos fertilizantes aplicados sobre a quantidade de $P$

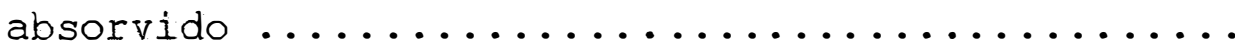

4.2.7. Influência dos parâmetros do solo e dos fertilizantes aplicados sobre a quantidade de $\mathrm{K}$

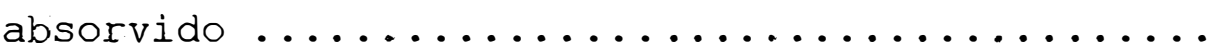

4.2.8. Influência dos parâmetros do solo e dos fertilizantes aplicados sobre a quantidade de $\mathrm{Ca}$

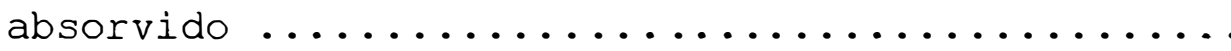
4.2.9. Influência dos parâmetros do solo e dos fertilizantes aplicados sobre a quantidade de $\mathrm{Mg}$ absorvido ........................ 77

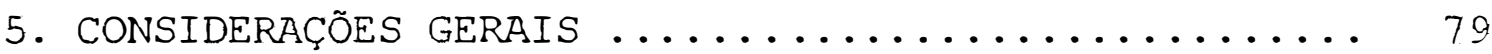

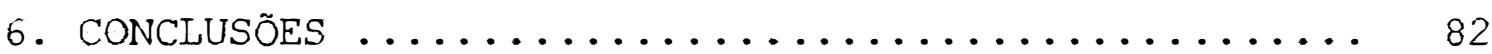

REFERENCIAS BIBLIOGRÁFICAS $\ldots \ldots \ldots \ldots \ldots \ldots \ldots \ldots \ldots . \ldots \ldots$ 


\title{
PRODUTIVIDADE DA CANA-DE-AÇÚCAR EM FUNÇÃO DE ALGUNS MACRONUTRIENTES PRESENTES NO CALDO E NO SOLO.
}

\author{
Autor: EDGAR GOMES FERREIRA DE BEAUCLAIR \\ Orientador: PROF. DR. VALDOMIRO CORREAA DE BITTENCOURT
}

\section{RESUMO}

Com o intuito de verificar a existência de novos indicadores analiticos relacionados com os rendimentos da cana-de-açúcar, procedeu-se à análise de nutrientes no caldo da cana-de-açúcar extraido pelo método utilizado no sistema de pagamento de cana pelo teor de sacarose (PCTS) no Estado de São Paulo, em áreas de cultivo comercial. Foram representados mais de 3200 ha de cana comercial, através das análises de solo e de 178 amostras de caldo. A análise dos nutrientes (N, P, K, Ca e Mg) seguiu uma metodologia analitica simples, sem digestão da matéria orgânica, portanto rápido e não oneroso.

Através de modelos matemáticos de regressão linear múltipla, considerou-se a variação dos rendimentos dependente da variação dos resultados das análises do caldo. Foram ainda incluidas como variáveis independentes, os parâmetros do solo, determinados nas análises químicas de rotina e a quantidade de fertilizantes aplicados.

Os resultados obtidos provaram a existência de relações entre os rendimentos em $t$ de cana/ha e em $\mathrm{Kg}$ de açúcar/t, com os teores de alguns nutrientes no caldo e algumaș propriedades químicas do solo. A grandeza destas relações é compativel com a fração da variabilidade destes rendimentos que não pode ser explicada pelo clima, um dos maiores fatores de produção. Os niveis de fertilizantes 
tiveram pouco efeito, principalmente devido a pequena variação das dosagens realizadas nas áreas comerciais.

A metodologia analitica proposta indica um caminho promissor para novos estudos, visando determinação de niveis criticos ou de relações entre nutrientes (DRIS) no caldo, capazes de realizar a diagnose nutricional da cana-de-açúcar. 


\title{
SUGARCANE YELDS IN FUNCTION OF SOME MAJOR NUTRIENTS DETECTED IN JUICE AND SOIL.
}

\author{
Author: EDGAR GOMES FERREIRA DE BEAUCLAIR \\ Adviser: PROF. DR. VALDOMIRO CORREAA DE BITTENCOURT
}

\section{SOMMARY}

To verify analytical indicators related to cane yields, sugarcane juice, extracted by the methods used in the sugar content payment system (PCTS), were chemically analyzed for some major nutrient content. Over 3200 ha of commercial fields were represented by soil samples and juice analysis.

The analytical methods used to evaluate the nutrients (N, P, K, Ca, Mg) were very simple, fast and cheap, without organic matter digestion.

Mathematical models of multiple linear regression were used to detect relationships with yield. It was also included as independent variables soil parameters, from routine soil analysis, and the amount of fertilizers applied.

The regression results showed there was a relationship between cane yields and nutrient content in sugarcane juice besides some soil chemical properties. The cane yields variability detected in these relationships, agrees with the fraction of total yields which are not explained by climate data, one of most important production factor. The fertilizers levels had a very little effect, mainly due to the short variation of the amounts applied in the fields.

The proposed methodology leads to a promising process for new studies, in a way to determine 
either plant critical levels or relations between sugarcane juice nutrients in a DRIS approach, to achieve a better and easy to use sugarcane nutritional diagnosis for commercial fields. 


\section{INTRODUÇÃO}

A produção agrícola de cana-de-açúcar em escala comercial, envolve uma grande gama de conhecimentos técnicos, ligados às diferentes etapas e fatores de produção. Alguns destes fatores podem ser apenas razoavelmente manejados, como é o caso do clima, da textura do solo, etc. Já outros, por ser viável economicamente a sua modificação, devem ser alterados e manejados de forma a permitir o melhor desempenho técnico-econômico. Nesta última categoria, encontra-se o manejo das propriedades quimicas do solo, ou seja, a correção e recuperação de alguns atributos importantes para 0 desenvolvimento vegetal. Porém, para que as condições desejadas do meio possam ser manejadas adequadamente, é preciso primeiro que elas sejam bem avaliadas.

A análise de amostras de terra é reconhecida pela sua ampla utilização como instrumento de avaliação das propriedades químicas do solo /BUCKMAN \& BRADY, 1976; TISDALE et aIii, 1984; RAIJ, 1991), e portanto de sua capacidade produtiva. Trata-se sem dúvida de uma das mais tradicionais formas de avaliação, mas ainda hoje existem dificuldades em relação a alguns nutrientes e as suas interações (BEAUCLAIR, 1991). Ainda segundo RAIJ (1991), os métodos de avaliação das propriedades químicas do solo podem ser grupados nos seguintes itens: observação de sintomas visuais de deficiência; análise de folhas ou outros tecidos vegetais; ensaios biológicos com plantas e análise química do solo. Como nenhum dos métodos é isento de limitações, a avaliação correta é uma meta importante na pesquisa agricola. 
Portanto, quando não se tem uma avaliação confiável das propriedades químicas do solo, as tomadas de decisão a respeito da aplicação de calcário e da natureza e quantidade dos adubos, tanto a nivel de cana-planta como de soqueiras, é até certo ponto dificil de ser definida pelos técnicos e produtores agricolas. Assim, hoje em dia as decisões relativas à compra e aplicação de fertilizantes e corretivos, são baseadas quase que exclusivamente na amostragem e análise do solo.

Esse processo entretanto, muitas vezes traz dúvidas aos produtores, pois as áreas não se apresentam homogêneas, em razão da própria natureza do solo, das práticas agrícolas de manejo e dos métodos de aplicação dos insumos. Além disso, quando as análises revelam teores médios de nutrientes, também fica difícil se tomar decisões, pois as produtividades nem sempre são as mesmas. Neste sentido, trabalho realizado com dados de lavoura comercial (BEAUCLAIR, 1991), revelou que apesar de existirem relações estatísticamente significativas entre teores no solo e a produtividade, estas são responsáveis por apenas uma pequena parcela da variação encontrada, dificultando a extrapolação dos resultados.

Outra forma importante de avaliação das condições do solo, diz respeito à nutrição da cana-deaçúcar, pois os processos de diagnose são baseados na análise de órgãos das plantas. Nestes casos, a própria planta é utilizada como solução extratora na avaliação das propriedades quimicas do solo, revelando seu estado nutricional através de análises químicas de tecido vegetal (ORIAANDO FILHO \& ZAMBELIO JÚNIOR 1983). Desse modo várias tentativas tem sido feitas, tanto em outros paises como no Brasil, em se determinar as quantidades de nutrientes absorvidas, através da análise das folhas e ou dos colmos, esperando assim definir as condições ideais do solo em relação à cana-de-açúcar e determinar os níveis adequados de cada nutriente para a cultura (BURR, 1955; COURY et 
alii, 1957; CLEMENTS, 1960; GALLO et alii, 1962; SAMUELS, 1969; BEAUFILS \& SUMNER, 1976; ZAMBELLO JÚNIOR \& ORLANDO EILHO, 1979, 1980).

Entretanto apesar dos inümeros trabalhos de pesquisa realizados sobre o assunto, nenhuma dessas técnicas está sendo atualmente usada em escala comercial, pois os dados obtidos não tem se mostrado consistentes e não conseguem esclarecer os aspectos principais da nutrição da cana-de-açúcar. Por outro lado deve ser considerado também, que os sistemas de amostragem propostos nessas metodologias, exigem equipes exclusivas e constituidas de pessoal bem treinado, além de análises químicas demoradas, resultando consequientemente em um procedimento trabalhoso e de alto custo.

Portanto o objetivo deste trabalho foi o de verificar a viabilidade técnica de um novo processo de avaliação das condições nutricionais da cana-de-açúcar e suas relações com os rendimentos de cana e de açúcar, através da análise do caldo, aproveitando a estrutura já existente para a determinação do teor de sacarose, no sistema de pagamento de cana (PCTS). 


\section{REVISÃO DE IITERATURA}

A importância atual de conhecer-se a necessidade de fertilizantes, corretivos e residuos a serem aplicados vem sendo discutida na literatura agronômica, e em especial, na relacionada com cana-de-açúcar (ESPIRONELO \& OLIVEIRA, 1972; ORLANDO FILHO \& RODELLA, 1983; BEAUCLAIR, 1984; BENEDINI, 1988; PENATTI et alii, 1988; BITTENCOURT et alii, 1990a, 1992; ), pois os custos envolvidos pressionam no sentido da melhoria das decisões. Porém, grandes são as dificuldades na avaliação destas necessidades (RAIJ, 1991; BEAUCLAIR, 1991).

A aplicação de residuos na lavoura já é prática rotineira em São Paulo, em especial da vinhaça, que tem portanto uma importância grande na fertilização e caracterização das áreas de cultivo. Tem sido comumente relatado na literatura que aplicação de vinhaça tende a gerar algum ganho na produtividade agrícola (BAPTISTELLA et alii, 1981; ORLANDO FILHO et alii, 1983; COLETI et alii, 1983; BEAUCLAIR, 1984), mas existem relatos de algum prejuizo ou atraso na maturação (STUPIELLO et alii, 1977; COPERSUCAR, 1978; EERNANDES, 1982; SILVA, 1982; ROSSETTO, 1987; KORNDOREER \& MARTINS, 1992). Além de afetar o pH do solo, alguns destes trabalhos também discutem a incorporação de nutrientes, em especial do $K$, que tende $a$ sofrer acréscimos em seus teores no solo, e dos teores e relações de Ca e Mg (COLETI et alii, 1983; ORLANDO FILHO et aiii, 1983).

Em virtude das aplicações muitas vezes aleatórias de vinhaça e das dosagens de fertilizantes, e do pequeno conhecimento a respeito das consequências, há 
necessidade de maiores averiguações para as condições do Estado de São Paulo, como já indicam resultados de estudos de avaliação geral da cultura (BITTENCOURT et alii, 1990a e 1990b).

\subsection{Análise de solo.}

ORLANDO FILHO \& RODELLA (1983) afirmam que a análise do solo é um guia para determinar a fertilidade. É - sistema mais difundido e empregado no Brasil para cana. Apresenta as seguintes vantagens: baixo custo operacional, disponibilidade de laboratórios, rapidez e abrangência geográfica da interpretação dos resultados lestudos de calibração) .

A literatura é vasta em relação aos estudos de calibração em função da análise do solo para a cana-deaçúcar, quando são considerados os macronutrientes isoladamente, mas é bastante restrita no que se refere às interaçóes entre os elementos, tal qual aparecem nas análises de rotina de amostras de terra, e a produtividade final da cultura (BEAUCLAIR, 1991).

As metodologias de análise química das amostras de terra dos estudos que buscam relacionar produção com teores de nutrientes no solo, seguem em sua maior parte, as descritas em outros trabalhos sem especificação da cultura ( RAIJ \& QUAGGIO, 1983; LOPES \& GUIDOLIN, 1987; e QUAGGIO, 1990), mas existem estudos em que estas metodologias de análise química são alteradas, visando aspectos especificos da cultura da cana-de-açúcar (BITTENCOURT et alii, 1978; RODELLA et alli, 1981; BEAUCLAIR, 1991).

No entanto, a análise de amostras de terra é reconhecida pela sua ampla utilização como instrumento de avaliação da fertilidade do solo (BUCKMAN \& BRADY, 1976; TISDALE et alii, 1984; RAIJ, 1991), especificamente para a cana-de-açúcar (ESPIRONELO \& OLIVEIRA, 1972; ORLANDO FILHO 
\& RODELLA, 1983; PENATTI et alii, 1988), e portanto de sua capacidade produtiva.

Trabalho caracterizando as relações existentes entre alguns parâmetros do solo reveladas pelas análises químicas e as produtividades da cana-de-açúcar obtidas em plantios comerciais (BEAUCLAIR, 1991), verificou que ao se considerar as produtividades obtidas nos três cortes, destacaram-se os efeitos do solo nas produtividades do terceiro corte. Outras análises foram feitas considerando-se soma de produtividades e método de análise química de $\mathrm{Ca}$ e $\mathrm{Mg}$. Pelo conjunto de análises estatisticas realizadas, foi possivel concluir que os parâmetros do solo determinados pelas análises químicas, podem ser responsáveis por no máximo $31 \%$ da variação da produtividade, e que a extração do Ca e Mg com $\mathrm{HCl} 0,5 \mathrm{~N}$ foi válida para o estudo e caracterização dos solos cultivados com cana-de-açúcar, visando o ciclo completo da cultura.

Este pequeno efeito dos teores de nutrientes no solo sobre a produtividade agrícola confirma observações de outros autores (OMETTO, 1978 e 1981; IDE \& BANCHI, 1984; MAIA \& BEAUCLAIR, 1984; BITTENCOURT et alii, 1990b) a respeito dos demais fatores de produção, como práticas de adubação e correção do solo, efeitos de épocas de plantio e corte, e portanto do clima na produtividade da cultura, práticas culturais de forma geral, etc, e confirma indiretamente a filosofia dos "blueprints", onde a interação dos fatores assume importância maior do que um efeito ou fator isolado (COOKE, 1982). Além disto, as adubações e correções realizadas ao longo de várias safras, tende a exercer um efeito igualador nas características dos solos, que aliado às práticas culturais e aos conhecidos efeitos do clima, torna-os impotentes para influenciar em mais de 40 s as produtividades agrícolas da cultura (BEAUCLAIR, 1991).

Ainda no mesmo estudo, os teores de $\mathrm{Mg}$ mostraram-se importantes na variação da produtividade, 
contrastando com a pouca atenção dispensada à este nutriente pelos produtores. O Mg apresentou também indicações de estar relacionado com o $\mathrm{P}$ como causa de variação da produtividade. Os valores de $\mathrm{pH}$ também influenciaram em algumas análises na produtividade agricola dos cortes mais avançados da cultura, indicando ser mais um índice para a avaliação do potencial do número de cortes de cada área.

A saturação por bases calculada a partir dos teores de $\mathrm{Ca}$ e Mg potencial, apresentou efeito sobre a produtividade agricola do terceiro corte, indicando ser interessante o conhecimento destes teores na caracterização do solo para a cultura.

\subsection{Outros métodos de avaliaçăo.}

Além da análise do solo, existem outras formas de avaliação das propriedades químicas do solo e da necessidade geral de fertilizantes e corretivos. Segundo RAIJ (1991), a observação dos sintomas visuais de deficiência, a análise de órgãos ou partes da planta e ensaios biológicos completam o rol das técnicas disponíveis para esta avaliação no campo.

ORLANDO FILHO \& ZAMBELLO JÚNIOR (1983), citando vários autores, descrevem também outros métodos especiais de avaliação dos níveis de nutrientes no solo para a cana-de-açúcar além da análise do solo e de tecidos vegetais. São eles:

a) Parcelas diferenciadas, que são microparcelas no campo, que recebem doses extras de fertilizantes, e depois são amostradas. É um método muito utilizado nas avaliações de necessidade de complementação nitrogenada (RODRIGUES et alii, 1983).

b) Análise da seiva da nervura central, utilizada para $K$, compara teor da seiva de folhas +1 em relação às mais velhas. Gradientes altos indicam deficiência. 
c) Indice de crescimento vegetativo, onde o peso de determinadas partes da planta em estágios precoces de desenvolvimento é comparado com a produção final.

\subsubsection{Diagnose foliar.}

Sendo a adubação uma prática fundamental para alcançar maiores produtividades, com o preço dos insumos obrigando a uma avaliação o mais precisa possível das necessidades, a diagnose foliar surge como uma forma importânte de avaliação (ORLANDO FILHO \& ZAMBELLO JÚNIOR, $1983)$.

A expressão diagnose foliar não se limita apenas às análises de folhas, mas a qualquer tecido da planta, desde que o objetivo seja diagnose nutricional. 0 termo correto seria diagnose de tecido ou diagnose de planta SAMUELS, 1969). Existem basicamente dois tipos de diagnose foliar. Um é baseado no estabelecimento de níveis críticos para cada nutriente, e outro, chamado de sistema integrado de diagnose e recomendação (DRIS), nas relações, balanceamentos e interações entre os nutrientes de forma integrada (BEAUFILS, 1973).

Em cana-de-açúcar, o material mais utilizado para as análises é o terço médio das folhas +1 e +3 (ORLANDO EILHO \& ZAMBELLO JÚNIOR, 1983). O colmo da canade-açúcar não tem sido utilizado como material para análise de nutrientes em cana-de-açúcar, com excessão de um sistema de trabalho proposto por BURR (1955). Neste sistema, os internódios superiores $\left(8^{\circ}, 9^{\circ}\right.$ e $\left.10^{\circ}\right)$ são utilizados para análise e diagnose nutricional. Porém o número de colmos amostrados limita-se em 5 para cada talhão.

$$
\text { ORLANDO FILHO \& ZAMBELLO JÚNIOR (1983) }
$$

citando diversos autores, relacionam variedade, solo, época de amostragem e interações de nutrientes como grandes fatores interferêntes da diagnose foliar clássica. Para o DRIS, são relacionados como fatores a posição da folha, idade, época e variedade. Alguns estudos mostram 
independência da variedade e época de amostragem, mas sempre com a necessidade de identificar a população não normal. Além disto, existem dificuldades operacionais para obtenção das amostras, respeitando-se todas limitações.

ORLANDO FILHO \& ZAMBELLO JÚNIOR (1983)

citando vários autores, descrevem que o sistema de diagnose foliar pelo método do nível crítico (diagnose clásica) possui três premissas: Dentro de limites, existe uma relação direta entre o nutriente fornecido pelo solo ou pelo adubo e a produção; dentro de limites, existe uma relação direta entre o nutriente fornecido pelo solo ou pelo adubo e a sua concentração nas folhas; logo existe uma relação direta entre a concentração do nutriente nas folhas e a produção.

BEAUFILS (1973) descreve que o Sistema DRIS é um conjunto de reações de equilíbrio dos constituintes foliares. Assim, toda variação no teor de um elemento mineral, num dado momento, correlaciona-se positiva ou negativamente com um ou vários outros elementos, seja qual for sua importância ponderal relativa. Afirma ainda que a relação de dois elementos antagônicos ( $K$ e $\mathrm{Ca}$ ) pode ser considerada como reflexo, dentro de certos limites, do conjunto de equilibrios químicos ao nível das folhas, pois variações de $\mathrm{N}, \mathrm{S}, \mathrm{P}, \mathrm{Fe}$, e $\mathrm{Cu}$ são relacionadas àquelas do $K$ e variações de $\mathrm{Mg}$ e $\mathrm{Mn}$ são relacionadas às do $\mathrm{Ca}$. Os elementos citados, do primeiro grupo (K), são ligados ao sistema aquoso das folhas; os elementos do segundo grupo (Ca) estão presentes na matéria seca.

Ainda dentro do DRIS, BEAUFILS

determina índices primários para N, P, K. Valores negativos significam deficiência do elemento em relação aos demais, positivos indicam um excesso, e quanto mais próximos de zero, mais próxima estará a planta do equilibrio nutricional. Assim, ele reformulou a diagnose nutricional definindo o DRIS. Produtividade e qualidade do produto em determinada cultura constitui a resposta da planta a vários 
estímulos do ambiente, e não apenas aos estimulos provocados.

Porém na prática, muito pouco uso destas ferramentas tem sido observado nas áreas comerciais em São Paulo. Entre as causas estão a necessidade de equipes especializadas, pouca consistência nos resultados com grande número de interferêntes.

\subsubsection{Anslise do caldo.}

BITTENCOURT et alii (1992) em trabalho preliminar utilizando a análise do caldo, justificaram seu uso ponderando que, sendo a metodologia baseada na análise do caldo de plantas que já completaram o ciclo, admite-se inicialmente que o colmo funciona como um armazenador de nutrientes, sendo que é necessário um teor mínimo, para que as produtividades não sejam afetadas. Assim, se a planta não apresentar nessa fase esse teor mínimo, é suposto que houve durante o seu desenvolvimento, problemas relativos à absorção do nutriente.

A bibliografia relata algumas experiências no sentido de análise de nutrientes no caldo com fins de diagnose (SAMUELS, 1969), mas sem continuidade dos trabalhos. Outros estudos foram realizados, principalmente com vistas a aumentar o teor de $\mathrm{P}$ no caldo, através de uma maior disponibilidade do elemento no solo (SERRA, 1973; SAMPAIO et alii, 1984; CESAR et alii, 1987; PENATTI, 1991). Os dados obtidos entretanto, não foram conclusivos, pois uma série de fatores resultantes das interações dos adubos com o solo interferem na absorção. Quanto ao potássio (SAMPAIO \& SALCEDO, 1991), um estudo relativo a dinâmica do nutriente no sistema solo-clima-planta, não chegou também a esclarecer completamente o processo na sua totalidade. Além disso, a cana-de-açúcar em determinadas condições, apresenta uma absorção de luxo e valores elevados também podem influir no conjunto dos resultados (BITTENCOURT et alii, 1992). 
Para determinar o melhor método de análise dos nutrientes no caldo, BITTENCOURT et alii (1992) observaram que existe uma estreita correlação entre os teores considerados totais e os livres, determinados sem digestão prévia da matéria orgânica. Assim, no caso do N, são observadas as maiores diferenças entre os teores determinados, pois grande parte do elemento no caldo se encontra combinado e na forma orgânica. Para o P também foi observada uma diferença entre os dois teores porém já de menor amplitude do que no caso anterior (MEADE, 1963). Assim admite-se que a fração livre do elemento é mais dinâmica do que a fixada na matéria orgânica e portanto reflete melhor as condições de nutrição num dado momento (SERRA, 1973: SAMPAIO et alii, 1984; CESAR et alii, 1987; PENATTI, 1991). Quanto ao K, Ca e Mg, os valores considerados livres são muito próximos dos teores totais, indicando que grande parte desses elementos não se encontram combinados, ou ainda devido as metodologias analiticas, não necessitam realmente da digestão prévia da matéria orgânica para a sua caracterização.

Para o Mg em particular, BITTENCOURT et alii (1992) mostraram que não existe uma relação maior entre os valores determinados pelos dois procedimentos. Neste trabalho foi sugerido que a propria metodologia analitica de titulação com o EDTA seria inadequada nessas condições. Porém quando foi considerada a soma $\mathrm{Ca}+\mathrm{Mg}$, os dados estatisticos evidenciaram uma alta correlação entre os valores, isto é, 998 do teor livre pode ser explicado pelo teor total.

Por outro lado, a absorção de nutrientes em termos de massa por tonelada de cana industrializável, também não é constante, pois as variedades diferem em seus teores e necessidades, conforme também já foi verificado por ORLANDO EILHO \& HAAG (1976) e por BITTENCOURT et alii (1992). Assim, estes últimos concluiram que 0 comportamento varietal tem influência sobre os resultados, 
podendo ser considerado como básico para qualquer tipo de interpretação. Entretanto foi enfatizado que nas condições em que os estudos foram desenvolvidos, os solos não tiveram qualquer influência sobre as caracteristicas agroindustriais da cana-de-açúcar.

outro importante fator interferente citado no mesmo trabalho foi o número de cortes, indicando que a eficiência dos elementos, é variável durante o ciclo da cultura, de acordo com o que foi verificado para o $N$ (CHUI \& SAMUELS, 1978) e para O K (SAMPAIO \& SALCEDO, 1991).

\subsection{Modelagem matemática.}

MAAS (1993) citando Huschke(*), afirma que a parametrização é uma técnica de modelagem muito útil na aproximação das respostas de um sistema físico à determinadas condições ambientais, e que o uso de equações empiricas simplifica os requerimentos de entrada de dados para fins operacionais.

A análise de regressão, uma das ferramentas estatisticas mais amplamente utilizadas na elaboração de equações empíricas, com aplicações nos mais diversos ramos da ciência, consiste em um conjunto de técnicas para 0 estudo do relacionamento entre variáveis, de grande interesse teórico e também prático pela metodologia relativamente simples (MATTIOLII, 1983). Esta ferramenta vem sendo utilizada nos poucos trabalhos existentes em que se procura relacionar a produtividade de uma cultura com os teores de nutrientes ou propriedades do solo. Estes valores relativos aos solos, por serem variáveis aleatórias, exigem cuidados específicos para serem analisados por análise de regressão (HOFEMAN \& VIEIRA, 1977; EREUND \& MINTON, 1979). Vários procedimentos vem sendo propostos para a seleção do melhor modelo matemático capaz de relacionar estas variáveis, porém segundo DRAPER \& SMITH (1966), as soluções

(*) HUSCHKE, R.E. (Ed.), 1959. Glossary of meteorology. Am. Meteorol. Soc. Boston, MA. 
encontradas são muitas vezes iguais... MATTIOLLI

(1983)

recomendou o procedimento "todas equações possíveis", que tem 0 inconveniente de apresentar muitas equações para a análise final, mas confere maior exatidão ao modelo.

Outra metodologia, o procedimento "stepwise backward" parte de uma equação completa e passa a eliminar as variáveis com significância abaixo de um valor preestabelecido (HOCKING, 1976). O procedimento "stepwise forward" é o inverso do anterior (HOCKING, 1976), e permite que a cada inclusão, sejam avaliadas as variáveis do modelo, permitindo sua eliminação. Nos estudos agronômicos, este procedimento tem tido maior aceitação, como mostram os trabalhos de IAIRD \& CADY (1969) em seu estudo com experimentos de fertilização; SCHOLZ et alii (1983) para estimativa da idade dos solos e da gênese de sedimentos, também estudada por BERG (1980). Por sua vez, também utilizaram esta metodologia LOVEDAY (1964) com alfafa, TOMANENG (1977) e IBRAHIM (1978) com cana-de-açúcar em estudos relacionando produtividade agrícola e parâmetros do solo na África, PAULER \& NEUMANN (1989) para relacionar dados experimentais de trigo com parâmetros fisicos e químicos do solo. Finalmente, CARMELLo (1991) usou o método para selecionar variáveis do solo e da planta (diagnose foliarl que melhor explicam a variação da produtividade de milho e amendoim em experimentos de nutrição e BEAUCLAIR (1991) para relacionar produtividade da cana-de-açúcar com algumas propriedades químicas do solo reveladas pelas análises de amostras de terra.

Em cana-de-açúcar, modelos matemáticos com regressão linear múltipla pelo método "stepwise" já foram utilizados para tentar explicar as variações da produtividade em função de outras variáveis. OMETTO (1978, 1981) obteve bons resultados entre produtividade e evapotranspiração potencial, resultados também obtidos por IDE \& BANCHI (1984) e IDE \& OLIVEIRA (1986) com regressão linear simples. RIBEIRO et alii (1984) também encontraram 
boas relações com o clima, mas incluiram também em seu estudo, resultados das análises de terra nas condições do Nordeste, e conseguiram selecionar a soma de bases (S) como - parâmetro do solo que mais influiu na produtividade. 


\section{MATERIAI E MÉTODOS}

\section{1- Amostragem}

\subsubsection{Solo}

Para a realização deste estudo, foram utilizadas as amostragens de solo normalmente efetuadas na lavoura da Usina Santa Adélia, Localizada no município de Jaboticabal, S.P., realizadas por ocasião da reforma do canavial no caso das áreas de primeiro corte, e após a colheita nas áreas de soqueira, todas no decorrer do ano de 1992. Em todos os casos, a amostragem ocorreu antes da aplicação dos insumos. A profundidade de amostragem foi de 0-25 cm, e a coleta das amostras no campo obedeceu as normas recomendadas (RAIJ, 1991), que foram enviadas para o laboratório da própria usina, para realização das análises químicas. No caso das soqueiras, a amostragem foi feita de acordo com as sugestões apresentadas na literatura, com 4 subamostras na entrelinha e 1 na linha de cana (CLINE, 1944; REED \& RIGNEY, 1947; HAMMOND et alii, 1958; SASA, 1963; ZAMBELLO JR. \& ORLANDO EILHO, 1981).

\subsubsection{Caldo}

- material usado constou do caldo extraido pelo método da prensa hidráulica (COPERSUCAR, 1980), de canas comerciais analisadas pelo laboratório de pagamento de cana (PCTS) na safra 93/94, ou seja, durante o ano civil de 1993. A coleta do material foi feita através da sonda utilizada neste sistema, ou seja, após a colheita, sem a necessidade de nenhuma equipe especialmente treinada. A escolha das cargas a serem amostradas foi aleatória, descartando-se no entanto, as áreas com problemas e 
particularidades conhecidas (alto indice de infestação de mato, incidência de doenças, etc.), assim como todas as áreas com mais de três cortes.

Para a execução deste trabalho, obteve-se um contingente de 178 amostras do caldo, de diferentes variedades e cortes, nos quais foram determinados os teores de $\mathrm{N}, \mathrm{P}, \mathrm{K}, \mathrm{Ca}$ e $\mathrm{Mg}$.

\section{2. - Métodos analiticos}

\subsubsection{Análises do solo.}

Como extrator para as determinações de $\mathrm{P}$ e $\mathrm{K}$, foi utilizado $\mathrm{H}_{2} \mathrm{SO}_{4} 0,5 \mathrm{~N}$, de acordo com metodologia descrita por BITTENCOURT et alii (1977), seguindo-se normalmente as determinações de $\mathrm{P}$ por colorimetria e $\mathrm{K}$ por fotometria de chama. As determinações de H+Al utilizaram como extrator acetato de cálcio $1 \mathrm{~N}, \mathrm{pH} 7$, e de $\mathrm{Ca}$ e $\mathrm{Mg}$ com dois extratores, $\mathrm{KCl} 1 \mathrm{~N}$ e $\mathrm{HCl} 0,5 \mathrm{~N}$, e posterior titulação com EDTA, gerando dois grupos de dados. Este último extrator foi utilizado anteriormente em trabalhos de avaliação do efeito da calagem (RAIJ et alii, 1985; BITTENCOURT et alii, 1988), visando a determinação dos teores totais de $\mathrm{Ca}$ e $\mathrm{Mg}$, e posteriormente, confirmou-se a melhor relação dos valores observados com este extrator e as produtividades de cana-de-açúcar em vários estágios (BEAUCLAIR, 1991). Esta metodologia de determinação do Ca e Mg é a seguinte:

- Transferir $5 \mathrm{~g}$ de terra peneirada e seca ao ar para copo de $250 \mathrm{ml}$, adicionar $10 \mathrm{ml}$ de $\mathrm{HCl} 0,5 \mathrm{~N}$, cobrir com vidro de relógio e ferver por 5 minutos. $O \mathrm{pH}$ deverá estar em torno de 1,5. Adicionar $50 \mathrm{ml}$ de água destilada, esfriar e adicionar solução de $\mathrm{NH}_{4} \mathrm{OH}(1+3)$ até atingir pH 6,5. Eerver por mais 10 minutos, esfriar e filtrar para balão de $100 \mathrm{ml}$, completando-se - volume com água destilada. Transferir alíquotas de $40 \mathrm{ml}$ para as determinações do $\mathrm{Ca}$ e do $\mathrm{Ca}+\mathrm{Mg}$ por titulações com EDTA. 
Einalmente $\circ \mathrm{pH}$ do solo foi determinado em água e o C por volumetria de oxirredução (dicromatometria) .

\subsubsection{Analises do caldo.}

Para este estudo, as amostras não foram digeridas, ou seja, não houve eliminação prévia da matéria orgânica, seguindo a metodologia testada em estudos preliminares (BITTENCOURT et alii, 1992), e foram submetidas a determinação do $\mathrm{N}, \mathrm{P}, \mathrm{K}, \mathrm{Ca}$ e $\mathrm{Mg}$.

A metodologia usada nas análises do caldo para determinação dos teores de nutrientes presentes foram as seguintes:

\subsubsection{1. - Deteminaçăo de $\mathbf{N}$.}

- Transferir $20 \mathrm{ml}$ do caldo "in natura" não digerido para o recipiente removível do microdestilador. Completar com $10 \mathrm{ml}$ de água destilada.

- Transferir $10 \mathrm{ml}$ da solução de ácido bórico a 208 com indicadores para erlenmeyer de $250 \mathrm{ml}$.

- Adicionar água destilada até um volume de aproximadamente $50 \mathrm{ml}$ com água destilada e adaptá-lo ao tubo de saída do condensador do microdestilador.

- Adicionar ao frasco que recebeu o extrato, 5 ml de $\mathrm{NaOH}$ a 458 .

- Ligar a fonte de vapor e proceder a destilação por 5 minutos.

- Retirar o erlenmeyer e titular com solução padronizada de $\mathrm{H}_{2} \mathrm{SO}_{4} 0,05 \mathrm{~N}$ ou $0,1 \mathrm{~N}$.

- Calcular teor de $\mathrm{N}$ no caldo em ppm.

\subsubsection{Determinação de $K$.}

- Pipetar $20 \mathrm{ml}$ do caldo "in natura", transferir para balão volumétrico de $200 \mathrm{ml}$ e 
completar volume com água destilada, formando a solução diluida do caldo. Agitar bem.

- Pipetar $10 \mathrm{ml}$ da solução diluída do caldo para balão de $50 \mathrm{ml}$, completar o volume e agitar bem.

- Acertar o fotômetro de chama com o padrão de 100 ppm de $K$ e fazer as leituras.

- Calcular o teor de $\mathrm{K}_{2} \mathrm{O}$ no caldo em ppm.

\subsubsection{Determinação de Ca e Mg.}

Pipetar $10 \mathrm{ml}$ do caldo "in natura", para balão de $100 \mathrm{ml}$.

- Adicionar 2,5 ml de solução de sulfato de Al (20 g do sal para $100 \mathrm{ml}$ de solução), 1,5 ml de solução de carbonato de sódio $120 \mathrm{~g}$ do sal para $100 \mathrm{ml}$ de soluçãol, completar com água destilada e agitar bem.

- Deixar em repouso por 10 a 15 minutos, e transferir para os tubos da centrifugadora.

- Pesar os tubos com solução de caldo saturado e colocar para centrifugar por 5 minutos.

- Após a centrifugação, retirar uma alíquota para o $\mathrm{Ca}$ e outra para o $\mathrm{Mg}$, e fazer a determinação por quelatometria com EDTA, à semelhança das determinações de $\mathrm{Ca}$ e $\mathrm{Mg}$ em solos. - Calcular os teores de $\mathrm{CaO}$ e $\mathrm{MgO}$ em ppm no caldo.

\subsubsection{Determinação de $\mathrm{P}$.}

Pipetar $10 \mathrm{ml}$ do caldo centrifugado, de acordo com o item anterior, na determinação de $\mathrm{Ca}$ e $\mathrm{Mg}$, em balão volumétrico de $50 \mathrm{ml}$.

- Adicionar $10 \mathrm{ml}$ de solução sulfo molibdato e $5 \mathrm{ml}$ da solução redutora de Elon e completar 0 volume. 
- Homogeneizar e deixar em repouso por 20 minutos no minimo.

- Efetuar a leitura em Espectrofotômetro em $640 \mathrm{~nm}$.

- Calcular teor de $\mathrm{P}_{2} \mathrm{O}_{5}$ em ppm no caldo, de acordo com a curva de calibração.

- Reativos:

Solução sulfo-molibdato 5\%:

- Pesar 50,0 g de molibdato de sódio bi-hidratado

e transferir para balão volumétrico de 1 I e completar.

- Transferir para balão volumétrico de $2000 \mathrm{ml}$ e acrescentar $500 \mathrm{ml}$ de $\mathrm{H}_{2} \mathrm{SO}_{4} \quad 10 \mathrm{~N}$.

- Completar o volume.

Solução redutora de Elon (Photo-Rex).

- Pesar 30,0 g de bissulfito de sódio em aproximadamente $300 \mathrm{ml}$ de água destilada e transferir para balão volumétrico de $1000 \mathrm{ml}$, e agitar.

- Pesar 10,0 g de Elon (Photo-Rex) e dissolver em aproximadamente $300 \mathrm{ml}$ de água destilada e transferir para o balão de $1000 \mathrm{ml}$ juntamente com o bissulfito de sódio. Agitar bem.

- Completar o volume com água destilada.

\subsection{Obtenção dos dados das áreas.}

\subsubsection{Dados cadastrais e de produtividade.}

Com a identificação dos blocos, foi possível recorrer aos dados e informações cadastrais e históricos das áreas no banco de dados agrícolas. Blocos com mais de três cortes foram então descartados, pois a partir deste estádio, ocorre particularização das situações de campo, com efeitos dificeis de serem identificados e representados matematicamente. Na realização deste estudo, as amostras utilizadas representaram mais de 3200 ha de cana comercial. 
A partir dos dados existentes no banco de dados agrícolas da Usina, foram selecionados os registros pertinentes aos blocos que tiveram o caldo analisado para determinação dos nutrientes absorvidos. Desta forma foi obtido o total de cana informado para cada área, permitindo - cálculo das produtividades agrícolas (t/ha).

No caldo obtido para as análises de nutrientes presentes, foram feitas as determinações de rotina do Sistema de Pagamento pelo Teor de Sacarose (PCTS). Com estes valores provenientes da mesma amostra, foram calculados os valores de pol da cana (PC), pureza e fibra, parâmetros utilizados no cálculo do açúcar teoricamente recuperável (ATR). A metodologia de análise e cálculo destes parâmetros foi a mesma descrita por COPERSUCAR (1980) e FERNANDES (1981).

\subsubsection{Dados dos insumos aplicados.}

A calagem foi feita após a amostragem do solo, durante as operações de preparo do solo, seguindo o critério de recomendação da Copersucar (BENEDINI, 1988), até o máximo de $2 t /$ ha.

A quantidade de fertilizante aplicada, assim como de vinhaça, foi obtida em pesquisa direta ao banco de dados da Usina, selecionando-se as áreas amostradas para análise do caldo, no mesmo procedimento adotado na recuperação dos dados de produtividade.

\subsection{Análises de regressão}

Para a realização das análises estatísticas, aplicando-se um modelo de regressão linear múltipla, foi utilizado o procedimento "stepwise" do pacote estatistico SAS (Statistical Analysis System) versão 6 , (COUTO \& MATTIOLLI, 1988). Dentro deste procedimento, testou-se o método "forward" e o "backward". Na maioria dos casos, o resultado final foi idêntico, mas em algumas análises, 
houve um melhor desempenho do algoritmo backward, a semelhança do descrito por HOCKING (1976) e MATTIOLLI (1983). Nestas ocasiões, optou-se por apresentar a relação com maior coeficiente de determinação $\left(r^{2}\right)$, indicando a utilização do "stepwise backward". Em todos os procedimentos, a análise de variância da regressão linear múltipla foi testada com o teste F (SPIEGEL, 1972), até o nível de 108 de probabilidade de erro, na rejeição da hipótese nula. Este nível é utilizado normalmente em trabalhos de regressão com variáveis aleatórias (HOFFMAN\& VIEIRA, 1977; FREUND \& MINTON, 1979).

Foram consideradas variáveis dependentes em análises individuais, as produtividades de cana (t/ha) e açúcar (ATR em kg/t e PC em \%), nutrientes absorvidos e alguns parâmetros do solo determinados nas análises químicas. Como variáveis independentes, considerou-se os nutrientes no caldo (em relação às produtividades), parâmetros do solo (nas análises das produtividades e dos nutrientes absorvidos), nutrientes aplicados através de fertilizantes e da vinhaça 〈nas análises das produtividades, dos nutrientes absorvidos presentes no caldo e teores de nutrientes no solo).

Algumas análises foram descartadas por serem redundantes, ou seja, após a avaliação da relação de nutrientes absorvidos e parâmetros do solo com a produtividade, a análise da relação da produtividade com o solo passa a ser parte da análise anterior, perdendo importância.

Nas análises em que os nutrientes absorvidos foram testados como variáveis independentes, incluiu-se no modelo as relações entre eles. Assim, criou-se variáveis que representavam as relações $\mathrm{N} / \mathrm{P}, \mathrm{N} / \mathrm{K}, \mathrm{P} / \mathrm{K}, \mathrm{P} / \mathrm{Ca}+\mathrm{Mg} e$ $\mathrm{K} / \mathrm{Ca}+\mathrm{Mg}$.

Para a realização das análises, foram identificadas as variáveis utilizadas da seguinte forma: Pdt $v=$ produtividade de cana em $t /$ ha. 
ATR = açúcar teoricamente recuperável (COPERSUCAR, 1980), em kg/t.

$\mathrm{PC}=$ pol da cana.

EST = estádio da cana, em número de cortes.

$I D=$ idade da cana em meses entre plantio ou corte anterior e a data do corte.

$N A B=N$ presente no caldo, detectado na análise, em $g / t$.

$\mathrm{PAB}=\mathrm{P}$ presente no caldo, detectado na análise, em $g / t$

$K A B=K$ presente no caldo, detectado na análise, em $\mathrm{kg} / \mathrm{t}$.

$C A A B=C a$ presente no caldo, detectado na análise, em $g / t$.

MGAB = Mg presente no caldo, detectado na análise, em $g / t$.

$\mathrm{NP}=$ relação entre $\mathrm{N}$ e $\mathrm{P}$, obtida pela divisão $\mathrm{NAB} /$ $\mathrm{PAB}$.

$\mathrm{NK}=$ relação entre $\mathrm{N}$ e $\mathrm{K}$, obtida pela divisão NAB / $\mathrm{KAB}$.

$\mathrm{PK}=$ relação entre $\mathrm{P}$ e $K$, obtida pela divisão $\mathrm{PAB} /$ $\mathrm{KAB}$.

$\mathrm{CM}=$ soma dos teores de $\mathrm{Ca}$ e Mg (CAB + MGAB).

PCM = relação entre $\mathrm{P}$ e a soma de $\mathrm{Ca}$ e $\mathrm{Mg}$, obtida pela divisão $\mathrm{PAB} / \mathrm{CM}$.

KCM = relação entre $\mathrm{K}$ e a soma de Ca e Mg, obtida pela divisão $\mathrm{KAB} / \mathrm{CM}$.

$\mathrm{PH}=\mathrm{pH}$ do solo.

$C$ = carbono orgânico do solo, em 8 .

$\mathrm{PO} 4=\mathrm{P}$ do solo em meq de $\mathrm{PO}_{4}{ }^{3-} / 100 \mathrm{~g}$ de solo.

$\mathrm{KS}=\mathrm{K}$ do solo em meq de $\mathrm{K}^{+} / 100 \mathrm{~g}$ de solo.

$C A K=C a$ trocável do solo em meq de $\mathrm{Ca}^{++} / 100 \mathrm{~g}$ de solo.

MGK = Mg trocável do solo em meq de $\mathrm{Mg}^{++} / 100 \mathrm{~g}$ de solo. 
$\mathrm{CAH}=\mathrm{Ca}$ potencial do solo em meq de $\mathrm{Ca}^{++} / 100 \mathrm{~g}$ de solo.

$\mathrm{MGH}=\mathrm{Mg}$ potencial do solo em meq de $\mathrm{Mg}^{++} / 100 \mathrm{~g}$ de solo.

$A I=A l$ trocável do solo em meq de $A^{+++} / 100 \mathrm{~g}$ de solo.

$\mathrm{HAL}=$ soma de hidrogênio e Al trocáveis do solo em meq de $\mathrm{H}^{+}+\mathrm{Al}^{+++} / 100 \mathrm{~g}$ de solo.

$\mathrm{TK}=$ capacidade de troca catiônica (CTC) do solo, utilizando no cálculo os valores trocáveis de Ca e Mg, em meq / $100 \mathrm{~g}$ de solo.

$\mathrm{TH}=$ capacidade de troca catiônica (CTC) "potencial" do solo, utilizando no cálculo os valores potenciais de Ca e Mg, em meq / $100 \mathrm{~g}$ de solo.

$\mathrm{SK}=$ soma de bases do solo, utilizando no cálculo os valores de Ca e Mg trocáveis, em meq / $100 \mathrm{~g}$ de solo. $\mathrm{SH}=$ soma de bases "potencial" do solo, utilizando no cálculo os valores potenciais de Ca e Mg, em meq / 100 $g$ de solo.

$\mathrm{VK}=$ saturação por bases, utilizando no cálculo os valores trocáveis, em 8

$\mathrm{VH}=$ saturação por bases "potencial", utilizando no cálculo os valores potenciais, em 8 .

$M=$ saturação de Al em relação ao trocável, em \&. $N F=N$ aplicado no fertilizante, em $\mathrm{kg}$ de $\mathrm{N} / \mathrm{ha}$. $\mathrm{PF}=\mathrm{P}$ aplicado no fertilizante, em $\mathrm{kg}$ de $\mathrm{P}_{2} \mathrm{O}_{5} / \mathrm{ha}$. $K F=K$ aplicado no fertilizante, em $\mathrm{kg}$ de $\mathrm{K}_{2} \mathrm{O} / \mathrm{ha}$. $K V=K$ aplicado em área total através da vinhaça, em $\mathrm{kg}$ de $\mathrm{K}_{2} \mathrm{O} / \mathrm{ha}$. 


\section{RESULTADOS E DISCUSSÃO}

\subsection{Resultados gerais de obtenção de dados}

A pesquisa no banco de dados da Usina, revelou os dados referentes às caracteristicas gerais dos blocos amostrados. Assim, pode-se observar na Tabela 1 a relação dos blocos amostrados, a área, o tipo de solo segundo grande grupo, a variedade plantada, a data do corte na safra, o estádio correspondente e a produtividade observada.

Tabela 1. Dados cadastrais e da produtividade observada dos blocos amostrados.

\begin{tabular}{lrrrrrr} 
BLOCO & ÁREA & SOLO & VARIEDADE & DATA & EST. & \multicolumn{1}{c}{ PDTV } \\
& ha & & & CORTE & & t/ha \\
01D & 3,29 & LE & RB765418 & $10 / \mathrm{Mai}$ & 2 & 100,79 \\
01E & 9,61 & LE & RB765418 & $10 / \mathrm{Mai}$ & 2 & 94,38 \\
01F & 22,85 & LE & RB765418 & $10 / \mathrm{Mai}$ & 2 & 93,68 \\
01G & 6,25 & LE & SP71-6163 & $10 / \mathrm{Mai}$ & 2 & 79,63 \\
01H & 16,71 & LE & SP71-6163 & $18 / \mathrm{Mai}$ & 2 & 90,08 \\
01I & 23,89 & LE & SP71-6163 & $18 / \mathrm{Mai}$ & 2 & 160,41 \\
01J & 6,76 & LE & SP71-6163 & $18 / \mathrm{Mai}$ & 2 & 96,32 \\
01K & 4,83 & LE & SP71-6163 & $18 / \mathrm{Mai}$ & 2 & 137,48 \\
01L & 8,21 & LE & RB765418 & $12 / \mathrm{Mai}$ & 1 & 160,41 \\
01M & 6,32 & LE & RB765418 & $10 / \mathrm{Mai}$ & 2 & 104,21 \\
01N & 26,52 & LE & RB765418 & $10 / \mathrm{Mai}$ & 2 & 97,52 \\
010 & 10,68 & LE & RB765418 & $12 / \mathrm{Mai}$ & 1 & 149,63 \\
01P & 16,87 & LE & SP71-6163 & $6 / \mathrm{Mai}$ & 1 & 129,59 \\
02A & 8,43 & LR & SP71-6163 & $28 / \mathrm{Set}$ & 3 & 64,05 \\
02B & 17,63 & LR & SP71-6163 & $28 / \mathrm{Set}$ & 3 & 76,82
\end{tabular}


Tabela 1. Dados cadastrais e da produtividade observada dos blocos amostrados (continuação).

$\begin{array}{ccccc}\text { BLOCO ÁREA SOLO VARIEDADE } & \text { DATA EST. } & \text { PDTV } \\ \text { ha } & & & \text { CORTE } & \text { tha }\end{array}$

\begin{tabular}{|c|c|c|c|c|c|c|}
\hline $02 \mathrm{C}$ & 21,39 & LR & SP71-6163 & $28 /$ Set & 3 & 66,16 \\
\hline $02 \mathrm{D}$ & 4,71 & LE & SP71-6163 & $28 /$ Set & 3 & 67,56 \\
\hline $02 \mathrm{E}$ & 6,72 & LE & SP71-6163 & $28 /$ Set & 3 & 72,81 \\
\hline $02 \mathrm{~F}$ & 4,40 & LE & SP71- 6163 & $28 /$ set & 3 & 70,37 \\
\hline $03 C$ & 7,71 & LE & SP79-1011 & $14 /$ out & 1 & 141,57 \\
\hline O3D & 3,39 & LE & DIVERSAS & $2 / J u n$ & 3 & 77,31 \\
\hline $03 \mathrm{~F}$ & 14,25 & LE & SP79-1011 & $14 /$ out & 1 & 144,83 \\
\hline $05 B$ & 31,69 & LE & SP79-1011 & $14 /$ out & 1 & 133,22 \\
\hline $06 \mathrm{~A}$ & 25,85 & LE & SP71-1406 & $16 / J u n$ & 1 & 106,94 \\
\hline 06D & 43,13 & LE & SP71-1406 & $16 /$ Jun & 1 & 99,34 \\
\hline $06 \mathrm{E}$ & 43,58 & LE & SP71-1406 & $16 / J u n$ & 1 & 117,73 \\
\hline $08 \mathrm{~A}$ & 31,36 & PV & DIVERSAS & $2 /$ Set & 3 & 80,58 \\
\hline 08B & 26,51 & PV & SP71-6163 & $2 /$ Set & 3 & 66,53 \\
\hline $08 \mathrm{C}$ & 20,45 & PV & DIVERSAS & $2 /$ set & 3 & 81,12 \\
\hline $08 D$ & 32,92 & PV & SP71-1406 & $2 /$ Set & 3 & 67,15 \\
\hline $08 \mathrm{E}$ & 1,96 & PV & SP71-6163 & $2 /$ set & 3 & 40,62 \\
\hline $08 \mathrm{~F}$ & 11,13 & PV & RB765418 & $3 /$ Jun & 3 & 106,98 \\
\hline $08 \mathrm{G}$ & 1,57 & PV & SP71-6163 & $3 /$ Jun & 3 & 58,68 \\
\hline $08 \mathrm{H}$ & 11,11 & PV & SP71-6163 & $3 / J u n$ & 3 & 54,13 \\
\hline $08 \mathrm{I}$ & 8,67 & PV & SP70-1143 & $11 /$ out & 3 & 97,73 \\
\hline 08J & 19,04 & PV & SP71- 6163 & $3 / J u n$ & 3 & 57,85 \\
\hline O9A & 18,25 & $\mathrm{LE}$ & DIVERSAS & $13 /$ out & 2 & 95,21 \\
\hline $09 G$ & 12,05 & LE & SP71-1081 & $1 / \mathrm{MaI}$ & 1 & 82,85 \\
\hline $10 B$ & 15,89 & LE & DIVERSAS & $15 / \mathrm{Mai}$ & 2 & 95,21 \\
\hline $10 \mathrm{C}$ & 23,63 & LE & SP71-6163 & $2 /$ out & 2 & 56,86 \\
\hline $10 \mathrm{E}$ & 5,42 & LE & DIVERSAS & 18/Jul & 2 & 116,20 \\
\hline $10 F$ & 5,43 & LE & DIVERSAS & $18 / J u I$ & 2 & 116,20 \\
\hline $10 \mathrm{G}$ & 6,27 & $\mathrm{LE}$ & DIVERSAS & $19 / J u l$ & 3 & 92,81 \\
\hline $10 I$ & 2,22 & LE & DIVERSAS & $18 / J u l$ & 2 & 51,98 \\
\hline $10 \mathrm{~J}$ & 2,40 & LE & DIVERSAS & 19 /Jul & 3 & 67,98 \\
\hline
\end{tabular}


Tabela 1. Dados cadastrais e da produtividade observada dos blocos amostrados (continuação).

$\begin{array}{cccc}\text { BLOCO ÁREA SOLO VARIEDADE } \\ \text { ha } & & \text { CORTE } & t / h a\end{array}$

$10 \mathrm{~K} \quad 14,89$

$10 \mathrm{~L} \quad 6,96$

$10 \mathrm{M} \quad 17,64$

$10 \mathrm{~N} \quad 22,94$

$100 \quad 17,55$

$11 \mathrm{~A} \quad 30,86$

$11 \mathrm{~B} \quad 18,18$

$12 \mathrm{~A} \quad 16,71$

$12 \mathrm{~B} \quad 64,53$

$12 \mathrm{C} \quad 2,88$

$13 \mathrm{~F} \quad 55,90$

$13 \mathrm{G} \quad 42,94$

$13 \mathrm{H} \quad 9,30$

$13 \mathrm{~K} \quad 13,09$

$\mathrm{ACA} \quad 18,04$

$\mathrm{ACB} \quad 4,21$

AEA 16,45

AEB $\quad 6,79$

ANB $\quad 8,65$

ATA 29,78

ATB $\quad 30,38$

ATC 1,89

BCA 6,05

$\mathrm{BCB} \quad 5,49$

BCC $\quad 7,66$

$\mathrm{BCD} \quad 5,81$

BCE 5,13

BCF 12,90

BGA 25,83

BNA 8,65
LE SP79-1011

LE SP71-1081

LE DIVERSAS

LE DIVERSAS

LE DIVERSAS

PV RB785148

PV SP72-4928

PV SP71-6163

PV SP71-6163

PV SP71-6163

LE

LE

LE

LE

LE

LE

LE

$\mathrm{L}$

LE SP71-6163

PV SP71-6163

PV SP71-6163

PV SP71-6163

LE SP71-6163

PV

PV

RB72454

SP79-1011

LE SP71-6163

PV SP71-6163

LE SP79-1011

LE RB765418

LE SP71-6163
$22 / J u l \quad 3 \quad 98,43$

24/Jul 340,66

$24 / \mathrm{Jul} \quad 3 \quad 71,98$

24/Jul 359,09

24/Jul 396,16

2/Ago 2 114,26

$5 / \mathrm{AgO} \quad 2 \quad 89,46$

$10 /$ Ago 273,93

10/Ago $2 \quad 77,07$

$10 /$ Ago 266,03

$27 /$ Jun 1142,64

$27 /$ Jun $\quad 1143,72$

27 /Jun 1142,81

$31 /$ Ago 376,24

28/Ago 1117,31

22/Out 1135,95

25/Jun 1124,13

$25 /$ Jun 1124,13

$31 / \mathrm{Jul} 1138,35$

$14 /$ set 381,86

$14 /$ set 379,96

$14 /$ set 392,36

$14 / \mathrm{Jul} \quad 3 \quad 46,86$

7 /Ago 228,55

26/Jun $\quad 2 \quad 85,21$

$14 / \mathrm{Jul} \quad 3 \quad 49,55$

$7 /$ Ago 242,11

2/Jun 1111,74

$2 / \mathrm{Mai} 127,98$

$31 /$ Ago 1147,93 
Tabela 1. Dados cadastrais e da produtividade observada dos blocos amostrados (continuação).

$\begin{array}{ccrr}\text { BLOCO ÁREA SOLO VARIEDADE } & \text { DATA EST. } & \text { PDTV } \\ \text { ha } & & \text { CORTE } & \text { t/ha }\end{array}$

\begin{tabular}{|c|c|c|c|c|c|c|}
\hline $\mathrm{BNB}$ & 4,68 & LE & SP71-6163 & $31 /$ Ago & 1 & 161,20 \\
\hline $\mathrm{BSA}$ & 11,14 & PV & SP71- 6163 & $2 / \mathrm{Nov}$ & 2 & 63,18 \\
\hline BSB & 3.78 & LE & SP71-6163 & $3 / \mathrm{NOV}$ & 3 & 63,26 \\
\hline $\mathrm{BSC}$ & 5,11 & LE & SP71- 6163 & $3 / \mathrm{Nov}$ & 3 & 53,02 \\
\hline $\mathrm{CBB}$ & 23,69 & LE & SP79-1011 & $15 /$ Ago & 2 & 102,77 \\
\hline $\mathrm{CBC}$ & 23,80 & LE & SP79-1011 & $15 / \mathrm{Ago}$ & 2 & 103,64 \\
\hline CMA & 13,32 & LE & RB72454 & 27 / Out & 2 & 123,51 \\
\hline $\mathrm{CPA}$ & 25,49 & LE & RB785148 & $29 / \mathrm{Ma} \mathrm{i}$ & 3 & 83,43 \\
\hline $\mathrm{CPB}$ & 30,59 & $\mathrm{LE}$ & RB72 454 & $19 /$ out & 3 & 76,16 \\
\hline DMA & 46,97 & LE & RB7 2454 & $30 /$ out & 3 & 72,98 \\
\hline DMB & 22,18 & LE & RB72454 & $30 / 0 u t$ & 3 & 68,97 \\
\hline DMC & 18,36 & LE & RB72454 & $30 / 0 u t$ & 3 & 64,17 \\
\hline DRA & 7,06 & LE & SP79-1011 & $3 / \mathrm{Nov}$ & 2 & 119,30 \\
\hline EGA & 25,62 & LV & SP71-1406 & $30 /$ set & 3 & 73,97 \\
\hline EGB & 16,44 & LV & SP71-1406 & $30 /$ set & 3 & 72,36 \\
\hline FRA & 26,91 & LE & SP71-1406 & $25 / J u l$ & 2 & 72,77 \\
\hline FRB & 26,35 & LE & SP71-1406 & $25 / J u l$ & 2 & 85,29 \\
\hline FRC & 25,26 & LE & SP7 1-1406 & $25 / J u l$ & 2 & 99,55 \\
\hline ERE & 42,29 & LE & SP71-1406 & $25 / J u l$ & 2 & 68,18 \\
\hline ERE & 46,47 & LE & SP71-140.6 & $25 / J u l$ & 2 & 68,31 \\
\hline FRG & 27,33 & LE & SP71-1406 & $25 /$ Jul & 2 & 66,74 \\
\hline FSA & 20,88 & LE & RB765418 & $10 / \mathrm{Mai}$ & 1 & 146,94 \\
\hline FSB & 46,19 & LE & RB765418 & $10 / \mathrm{Mai}$ & 1 & 139,46 \\
\hline ESC & 33,93 & LE & RB765418 & $10 / \mathrm{Mai}$ & 1 & 142,48 \\
\hline GBA & 23,69 & $L E$ & SP71- 6163 & $7 / \mathrm{Jul}$ & 1 & 113,97 \\
\hline GBB & 4,76 & $\mathrm{LE}$ & SP71-6163 & $7 / J u l$ & 1 & 120,12 \\
\hline GDA & 25,44 & LE & SP71- 1081 & $17 /$ Jun & 3 & 48,60 \\
\hline GDB & 44,48 & LE & SP7 1-1081 & $8 / \mathrm{Ago}$ & 3 & 52,69 \\
\hline DC & 15,04 & LE & SP71-1081 & $11 /$ Jun & 2 & 59,63 \\
\hline & 16,52 & PV & SP71-799 & $24 / \mathrm{Mai}$ & 3 & 64,21 \\
\hline
\end{tabular}


Tabela 1. Dados cadastrais e da produtividade observada dos blocos amostrados (continuação).

\begin{tabular}{|c|c|c|c|c|c|c|}
\hline BLOCO & $\begin{array}{c}\text { ÁREA } \\
\text { ha }\end{array}$ & SOLO & VARIEDADE & $\begin{array}{l}\text { DATA } \\
\text { CORTE }\end{array}$ & EST. & $\begin{array}{l}\text { PDTV } \\
\text { t/ha }\end{array}$ \\
\hline $\mathrm{HBB}$ & 15,54 & LE & $\mathrm{RB} 72454$ & 4 /Out & 2 & 116,74 \\
\hline $\mathrm{HBC}$ & 30,92 & $\mathrm{LE}$ & RB72454 & $4 /$ out & 2 & 116,74 \\
\hline $\mathrm{HGA}$ & 9,80 & PV & SP71-6163 & $4 /$ Set & 3 & 88,72 \\
\hline HGB & 15,29 & PV & SP71-6163 & $4 /$ Set & 3 & 81,24 \\
\hline HGC & 3,27 & PV & SP71-6163 & $4 /$ Set & 3 & 73,68 \\
\hline IGA & 5,09 & LE & SP79-1011 & $9 /$ out & 2 & 109,34 \\
\hline IRA & 26,62 & PV & SP71-6163 & $7 / J u l$ & 3 & 54,79 \\
\hline JLA & 11,08 & LE & NA 56-79 & 25/Mai & 3 & 67,64 \\
\hline JLB & 6,76 & LE & NA5 6-79 & 25/Mai & 3 & 67,64 \\
\hline JMA & 25,08 & $\mathrm{LV}$ & RB 72454 & $20 / \mathrm{Nov}$ & 3 & 77,60 \\
\hline JMB & 11,37 & LV & $\mathrm{RB} 72454$ & $20 / \mathrm{Nov}$ & 3 & 84,09 \\
\hline JMC & 30,33 & LV & SP71-1406 & $25 /$ out & 3 & 63,18 \\
\hline JSA & 10,46 & LE & RB72454 & $21 / \mathrm{Mai}$ & 1 & 121,03 \\
\hline JSB & 5,02 & LE & VIVEIRO & $22 / \mathrm{Mai}$ & 1 & 108,93 \\
\hline JSC & 2,56 & LE & SP70-1284 & $22 / \mathrm{Mai}$ & 1 & 116,03 \\
\hline JSD & 1,62 & LE & SP71-6163 & $22 / \mathrm{MaI}$ & 1 & 117,69 \\
\hline JSE & 7,23 & LE & RB72 454 & $22 / \mathrm{Mai}$ & 1 & 66,24 \\
\hline JSG & 18,32 & $\mathrm{LE}$ & SP71-1406 & $21 / \mathrm{Mai}$ & 1 & 106,03 \\
\hline JSH & 23,34 & LE & RB765418 & $21 / \mathrm{Mai}$ & 1 & 123,26 \\
\hline LGA & 24,84 & LE & DIVERSAS & $10 / J u l$ & 2 & 108,88 \\
\hline LGC & 3,76 & LE & SP79-1230 & $10 / J u I$ & 2 & 67,77 \\
\hline LZA & 7,36 & LE & SP71-1081 & $26 / J u n$ & 2 & 65,37 \\
\hline LZB & 15,66 & PV & RB7 65418 & $26 / J u n$ & 2 & 108,55 \\
\hline LZC & 3,73 & PV & SP71-1406 & 19 /Jun & 2 & 106,49 \\
\hline LZD & 18,51 & LE & SP71-1406 & 19 / Jun & 2 & 90,08 \\
\hline MAA & 9,51 & LE & RB72454 & $12 / J u n$ & 2 & 119,71 \\
\hline$M A B$ & 32,39 & LE & RB72454 & $12 / J u n$ & 2 & 115,58 \\
\hline MGA & 21,24 & LE & RB72454 & 29 / Ago & 1 & 137,56 \\
\hline MIA & 4,00 & LE & SP79-1011 & 10/Out & 2 & 112,31 \\
\hline MIB & 11,00 & LE & SP79-1011 & $10 /$ out & 2 & 92,36 \\
\hline
\end{tabular}


Tabela 1. Dados cadastrais e da produtividade observada dos blocos amostrados (continuação).

\begin{tabular}{|c|c|c|c|c|c|c|}
\hline BLOCO & $\begin{array}{c}\text { ÁREA } \\
\text { ha }\end{array}$ & SOLO & VARIEDADE & $\begin{array}{l}\text { DATA } \\
\text { CORTE }\end{array}$ & EST. & $\begin{array}{l}\text { PDTV } \\
\text { t/ha }\end{array}$ \\
\hline NRA & 26,57 & LE & SP71-6163 & $24 / \mathrm{JuI}$ & 2 & 96,32 \\
\hline NRB & 5,00 & LE & SP72-4925 & 14 /out & 2 & 95,45 \\
\hline NRC & 25,51 & LE & SP79-1011 & $7 / J u n$ & 1 & 109,92 \\
\hline$N Z A$ & 36,41 & LE & $\mathrm{RB} 72454$ & $4 / \mathrm{Nov}$ & 2 & 95,37 \\
\hline $\mathrm{NZB}$ & 21,96 & LE & $\mathrm{RB} 72454$ & $4 /$ Nov & 2 & 83,84 \\
\hline PDA & 22,95 & LE & SP71-6163 & $10 /$ Ago & 1 & 121,98 \\
\hline $\mathrm{PDB}$ & 37,4 & LE & $\operatorname{SP} 71-6163$ & $10 / \mathrm{Ago}$ & 1 & 120,25 \\
\hline PDC & 38,38 & LE & SP71-6163 & $10 /$ Ago & 1 & 109,38 \\
\hline PLA & 26,52 & LE & SP79-1011 & $21 / \mathrm{Ago}$ & 2 & 118,06 \\
\hline PWA & 34,8 & LE & SP71-6163 & $31 /$ Ago & 3 & 56,32 \\
\hline PXA & 5,00 & LE & SP71-6163 & 11 /out & 2 & 88,10 \\
\hline $\mathrm{RCD}$ & 17,10 & LE & SP79-1011 & $31 / \mathrm{Ago}$ & 2 & 98,93 \\
\hline $\mathrm{RCE}$ & 12,72 & LE & $\mathrm{RB} 785148$ & $1 / \mathrm{Ago}$ & 2 & 103,51 \\
\hline $\mathrm{RPA}$ & 23,58 & PV & RB7 65418 & $21 / \mathrm{Mai}$ & 3 & 89,59 \\
\hline RPB & 27,08 & PV & RB 765418 & $21 / \mathrm{Mai}$ & 3 & 87,93 \\
\hline RVA & 18,71 & LE & SP71-1081 & $1 / \mathrm{Ju} 1$ & 1 & 76,16 \\
\hline$S A A$ & 9,43 & LE & SP71-6163 & $2 /$ set & 1 & 159,79 \\
\hline SFA & 61,34 & LE & SP71-6163 & $4 /$ out & 3 & 69,26 \\
\hline SEB & 33,31 & LE & SP71-6163 & $2 /$ out & 2 & 85,12 \\
\hline $\mathrm{SFC}$ & 24,11 & LE & SP71-6163 & 2 /out & 2 & 90,54 \\
\hline SED & 13,24 & LE & SP71-6163 & $29 /$ Jul & 1 & 137,85 \\
\hline SEE & 12,42 & $\mathrm{LE}$ & SP71-6163 & $2 /$ out & 2 & 63,47 \\
\hline SEF & 13,57 & LE & DIVERSAS & $1 /$ out & 2 & 80,45 \\
\hline SFG & 9,06 & LE & SP79-1011 & $29 / \mathrm{JuI}$ & 1 & 157,40 \\
\hline $\mathrm{SGA}$ & 26,46 & LE & SP70-1143 & $9 /$ Jun & 3 & 85,17 \\
\hline SJA & 7,83 & LE & RB7 65418 & $26 / \mathrm{Mai}$ & 1 & 120,62 \\
\hline SMA & 29,32 & LE & SP71-6163 & $29 / \mathrm{Mai}$ & 1 & 104,13 \\
\hline SMB & 15,44 & LE & SP71-6163 & $29 / \mathrm{Mai}$ & 1 & 104,1 \\
\hline SMD & 11,41 & LE & $\mathrm{RB} 785148$ & $27 / \mathrm{Mai}$ & 1 & 125 \\
\hline SME & 13,43 & LE & SP71-1081 & $17 / \mathrm{Mai}$ & 1 & 105 \\
\hline
\end{tabular}


Tabela 1. Dados cadastrais e da produtividade observada dos blocos amostrados (continuação).

\begin{tabular}{|c|c|c|c|c|c|c|}
\hline BLOCO & $\begin{array}{c}\text { ÁREA } \\
\text { ha }\end{array}$ & SOLO & VARIEDADE & $\begin{array}{l}\text { DATA } \\
\text { CORTE }\end{array}$ & EST. & $\begin{array}{l}\text { PDTV } \\
\text { t/ha }\end{array}$ \\
\hline SPB & 1,78 & LE & $\mathrm{RB} 72454$ & $28 /$ out & 2 & 80,45 \\
\hline STA & 7,50 & LE & SP79-1011 & $21 / \mathrm{AgO}$ & 2 & 68,02 \\
\hline $\mathrm{TAA}$ & 4,45 & PV & SP70-1284 & $25 / \mathrm{Mai}$ & 2 & 83,97 \\
\hline $\mathrm{TAB}$ & 3,54 & $\mathrm{PV}$ & DIVERSAS & $25 / \mathrm{Mai}$ & 2 & 81,86 \\
\hline TLA & 50,16 & PV & SP71-1406 & 20/Jun & 3 & 85,17 \\
\hline TLB & 50,68 & $\mathrm{PV}$ & SP71-1406 & $20 /$ Jun & 3 & 85,17 \\
\hline TLC & 26,29 & PV & SP71-1406 & $22 /$ Jun & 3 & 85,17 \\
\hline TLD & 15,97 & PV & SP71-1406 & $22 /$ Jun & 3 & 85,17 \\
\hline TPA & 6,33 & PV & SP79-1230 & $22 /$ Jun & 3 & 72,81 \\
\hline $\mathrm{VBA}$ & 10,77 & LE & SP71-6163 & $25 /$ Jun & 2 & 78,72 \\
\hline VBB & 33,82 & LE & SP71-6163 & $25 /$ Jun & 2 & 64,88 \\
\hline WA & 12,85 & LE & RB785148 & $21 /$ Jun & 2 & 125,83 \\
\hline WB & 23,95 & LE & RB72454 & $12 /$ Jun & 2 & 121,32 \\
\hline WC & 5,79 & LE & SP71-6163 & $22 /$ Jul & 2 & 121,98 \\
\hline
\end{tabular}

Total 3209,44

Observando os dados expostos na Tabela 1, é possivel perceber que praticamente todo contingente de cana existente comercialmente, esta representado pelas áreas amostradas. As principais variedades encontram-se presentes, assim como áreas de até três cortes, que sem dúvida, representam a maior parte da lavoura comercial. Pelas datas de corte, observa-se que foram feitas amostragens no decorrer de toda a safra, representando assim a variação temporal. Na última coluna da Tabela 1, encontram-se as produtividades observadas, e pelos valores encontrados, pode-se inferir que são áreas "normais" para os padrões da Usina Santa Adélia. 
Os dados referentes às informações acerca da quantidade de insumos (fertilizantes e vinhaça) aplicados em cada bloco encontra-se descrita na Tabela 2 . Os fertilizantes utilizados foram preparados na fábrica de fertilizantes fluidos da Usina. O teor de $K$ na vinhaça é referente ao valor do dia da aplicação.

Tabela 2. Quantidade de fertilizantes e residuos aplicados nos blocos amostrados.

........Eertilizantes...... Vinhaça $\mathrm{K}^{+}$

$\mathrm{BLOCO} \quad \mathrm{N} 8 \quad \mathrm{P}_{2} \mathrm{O}_{5}$ 8 $\quad \mathrm{K}_{2} \mathrm{O}$ 8 $\mathrm{kg} / \mathrm{ha} \quad \mathrm{m}^{3} / \mathrm{ha} \quad \mathrm{kg} / \mathrm{m}^{3}$

\begin{tabular}{|c|c|c|c|c|c|c|}
\hline $01 \mathrm{D}$ & 8,00 & 3,00 & 0,00 & 1240 & 0 & 0,00 \\
\hline OLE & 8,00 & 3,00 & 10,00 & 1240 & 0 & 0,00 \\
\hline $01 \mathrm{~F}$ & 8,00 & 3,00 & 0,00 & 1240 & 256 & 4,01 \\
\hline $01 G$ & 7,00 & 2,33 & 0,00 & 1240 & 63 & 4,01 \\
\hline $01 \mathrm{H}$ & 7,00 & 3,00 & 0,00 & 1240 & 94 & 4,01 \\
\hline $01 I$ & 7,00 & 3,00 & 0,00 & 1240 & 84 & 4,01 \\
\hline $01 \mathrm{~J}$ & 7,00 & 2,33 & 0,00 & 1240 & 160 & 4,01 \\
\hline $01 \mathrm{~K}$ & 8,00 & 3,00 & 0,00 & 1240 & 135 & 4,01 \\
\hline 01L & 8,00 & 0,00 & 9,33 & 1240 & 111 & 4,01 \\
\hline $01 M$ & 8,00 & 3,00 & 9,33 & 1240 & 154 & 4,0 \\
\hline $01 \mathrm{~N}$ & 8,00 & 3,00 & 9,33 & 1240 & 164 & 4,01 \\
\hline 010 & 8,00 & 0,00 & 0,00 & 1240 & 189 & 4,01 \\
\hline $01 \mathrm{P}$ & 18,00 & 0,00 & 0,00 & 554 & 242 & 4,01 \\
\hline $2 \mathrm{~A}$ & 7,00 & 2,33 & 0,00 & 1240 & 161 & 1,56 \\
\hline $02 B$ & 7,00 & 2,33 & 0,00 & 1240 & 181 & 1,5 \\
\hline $02 \mathrm{C}$ & 7,00 & 2,33 & 0,00 & 1240 & 156 & 1,56 \\
\hline $02 \mathrm{D}$ & 7,00 & 2,33 & 0,00 & 1240 & 212 & 1,5 \\
\hline $02 \mathrm{E}$ & 7,00 & 2,33 & 0,00 & 1240 & 202 & 1,5 \\
\hline $02 \mathrm{~F}$ & 7,00 & 2,33 & 0,00 & 1240 & 104 & 1,5 \\
\hline $03 \mathrm{C}$ & 18,00 & 0,00 & 0,00 & 471 & 127 & 1, \\
\hline O3D & 7,00 & 2,33 & 0,00 & 1240 & 212 & 5,3 \\
\hline $3 E$ & 18,00 & 0,00 & 0,00 & 471 & 117 & 4,7 \\
\hline $5 B$ & 18,00 & 0,00 & 0,00 & 471 & 150 & $1, \varepsilon$ \\
\hline
\end{tabular}


Tabela 2. Quantidade de fertilizantes e residuos aplicados nos blocos amostrados (continuação) .

.......Fertilizantes...... Vinhaça

$\mathrm{K}^{+}$

BLOCO No $\quad \mathrm{P}_{2} \mathrm{O}_{5} 8 \quad \mathrm{~K}_{2} \mathrm{O} \quad \mathrm{kg} / \mathrm{ha} \quad \mathrm{m}^{3} / \mathrm{ha} \quad \mathrm{kg} / \mathrm{m}^{3}$

$\begin{array}{rrrrrrr}\text { O6A } & 18,00 & 0,00 & 0,00 & 471 & 193 & 6,57 \\ \text { 06D } & 18,00 & 0,00 & 0,00 & 471 & 283 & 1,87 \\ \text { 06E } & 18,00 & 0,00 & 0,00 & 471 & 247 & 1,90 \\ \text { 08A } & 7,00 & 2,33 & 0,00 & 1240 & 239 & 1,56 \\ \text { 08B } & 7,00 & 2,33 & 0,00 & 1240 & 242 & 5,69 \\ \text { 08C } & 7,00 & 2,33 & 0,00 & 1240 & 130 & 1,87 \\ \text { 08D } & 7,00 & 2,33 & 8,00 & 1240 & 16 & 3,04 \\ \text { 08E } & 7,00 & 2,33 & 8,00 & 1240 & 0 & 0,00 \\ \text { 08F } & 7,00 & 2,33 & 0,00 & 1240 & 215 & 4,19 \\ \text { 08G } & 7,00 & 2,33 & 8,00 & 1240 & 0 & 0,00 \\ \text { 08H } & 7,00 & 2,33 & 0,00 & 1240 & 283 & 3,04 \\ \text { 08I } & 7,00 & 2,33 & 0,00 & 1240 & 226 & 3,04 \\ \text { 08J } & 7,00 & 2,33 & 0,00 & 1240 & 141 & 1,90 \\ \text { 09A } & 7,00 & 2,33 & 9,33 & 1240 & 124 & 4,01 \\ \text { 09G } & 6,33 & 3,00 & 9,33 & 1240 & 0 & 0,00 \\ \text { 10B } & 18,00 & 0,00 & 0,00 & 471 & 139 & 4,01 \\ \text { 10C } & 6,33 & 2,33 & 0,00 & 1240 & 213 & 4,01 \\ \text { 10E } & 6,33 & 2,33 & 0,00 & 1240 & 316 & 4,01 \\ \text { 10F } & 6,33 & 2,33 & 9,33 & 1240 & 68 & 4,01 \\ \text { 10G } & 6,33 & 2,33 & 0,00 & 1240 & 81 & 4,20 \\ \text { 10I } & 6,33 & 2,33 & 0,00 & 1240 & 341 & 4,01 \\ \text { 10J } & 6,33 & 2,33 & 0,00 & 1240 & 254 & 5,22 \\ \text { 10K } & 6,33 & 2,33 & 0,00 & 1240 & 388 & 5,22 \\ \text { 10L } & 6,33 & 2,33 & 0,00 & 1240 & 293 & 5,22 \\ \text { 10M } & 8,00 & 0,00 & 9,33 & 1240 & 0 & 0,00 \\ \text { 10N } & 8,00 & 0,00 & 9,33 & 1240 & 0 & 0,00 \\ \text { 10O } & 6,33 & 2,33 & 4,00 & 1240 & 175 & 4,55 \\ \text { 11A } & 6,33 & 2,33 & 4,00 & 1240 & 131 & 4,01 \\ \text { 11B } & 6,33 & 2,33 & 4,00 & 1240 & 107 & 4,01 \\ \text { 12A } & 8,00 & 3,00 & 10,00 & 1240 & 0 & 0,00 \\ & & & & & & \end{array}$


Tabela 2. Quantidade de fertilizantes e residuos aplicados nos blocos amostrados (continuação).

\begin{tabular}{|c|c|c|c|c|c|c|}
\hline BLOCO & $\begin{array}{r}\cdots \cdot \cdot \\
\text { No }\end{array}$ & $\begin{array}{l}\text { Fertil. } \\
\mathrm{P}_{2} \mathrm{O}_{5} \mathrm{\circ}\end{array}$ & $\begin{array}{l}\text { zantes. } \\
\mathrm{K}_{2} \mathrm{O} \text { \% }\end{array}$ & $\mathrm{kg} / \mathrm{ha}$ & $\begin{array}{c}\text { Vinhaça } \\
\mathrm{m}^{3} / \mathrm{ha}\end{array}$ & $\begin{array}{c}\mathrm{K}^{+} \\
\mathrm{kg} / \mathrm{m}^{3}\end{array}$ \\
\hline $12 \mathrm{~B}$ & 8,00 & 3,00 & 0,00 & 1240 & 263 & 4,01 \\
\hline $12 \mathrm{C}$ & 8,00 & 3,00 & 10,00 & 1240 & 0 & 0,00 \\
\hline $13 \mathrm{~F}$ & 18,00 & 0,00 & 0,00 & 471 & 284 & 4,01 \\
\hline $13 G$ & 18,00 & 0,00 & 0,00 & 471 & 165 & 4,01 \\
\hline $13 \mathrm{H}$ & 8,00 & 0,00 & 9,33 & 1240 & 0 & 0,00 \\
\hline $13 \mathrm{~K}$ & 7,00 & 2,33 & 0,00 & 1240 & 166 & 1,87 \\
\hline $\mathrm{ACA}$ & 18,00 & 0,00 & 0,00 & 471 & 110 & 4,01 \\
\hline $\mathrm{ACB}$ & 18,00 & 0,00 & 0,00 & 471 & 125 & 4,01 \\
\hline $\mathrm{AEA}$ & 18,00 & 0,00 & 0,00 & 471 & 270 & 4,01 \\
\hline $\mathrm{AEB}$ & 7,00 & 0,00 & 9,33 & 1240 & 65 & 4,01 \\
\hline ANB & 8,00 & 0,00 & 9,33 & 1240 & 0 & 0,00 \\
\hline $\mathrm{ATA}$ & 8,00 & 3,00 & 10,00 & 1240 & 0 & 0,00 \\
\hline ATB & 8,00 & 3,00 & 10,00 & 1240 & 0 & 0,00 \\
\hline ATC & 8,00 & 3,00 & 10,00 & 1240 & 0 & 0,00 \\
\hline $\mathrm{BCA}$ & 8,00 & 3,00 & 10,00 & 1240 & 283 & 4,01 \\
\hline $\mathrm{BCB}$ & 8,00 & 3,00 & 9,33 & 1240 & 0 & 0,00 \\
\hline $\mathrm{BCC}$ & 18,00 & 0,00 & 0,00 & 446 & 382 & 4,01 \\
\hline $\mathrm{BCD}$ & 8,00 & 3,00 & 0,00 & 1240 & 183 & 4,01 \\
\hline $\mathrm{BCE}$ & 8,00 & 3,00 & 0,0 & 1240 & 207 & 4,01 \\
\hline $\mathrm{BCF}$ & 18,00 & 0,00 & 0,00 & 446 & 315 & 4,01 \\
\hline $\mathrm{BGA}$ & 18,00 & 0,00 & 0,00 & 438 & 180 & 4,01 \\
\hline BNA & 8,00 & 0,00 & 9,33 & 1240 & 0 & 0,00 \\
\hline BNB & 8,00 & 3,00 & 9,33 & 1240 & 0 & 0,00 \\
\hline $\mathrm{BSA}$ & 8,00 & 3,00 & 9,33 & 1240 & 0 & 0,00 \\
\hline BSB & 7,00 & 3,00 & 9,33 & 1240 & 0 & 0,00 \\
\hline $\mathrm{BSC}$ & 7,00 & 3,00 & 9,33 & 1240 & 0 & 0,00 \\
\hline $\mathrm{CBB}$ & 6,33 & 2,33 & 4,00 & 1240 & 121 & 4,01 \\
\hline $\mathrm{CBC}$ & 6,33 & 2,33 & 4,00 & 1240 & 120 & 4,01 \\
\hline CMA & 7,00 & 2,33 & 9,33 & 1240 & 0 & 0,00 \\
\hline $\mathrm{CPA}$ & 7,00 & 2,33 & 0,00 & 1240 & 195 & 4,01 \\
\hline
\end{tabular}


Tabela 2. Quantidade de fertilizantes e residuos aplicados nos blocos amostrados (continuação).

\begin{tabular}{|c|c|c|c|c|c|c|}
\hline BLOCO & $\begin{array}{c}\cdots \\
\mathrm{N}\end{array}$ & $\begin{array}{l}\text { Tertil } \\
\mathrm{P}_{2} \mathrm{O}_{5} \frac{\mathrm{s}}{8}\end{array}$ & $\begin{array}{c}\text { zantes } \\
\mathrm{K}_{2} \mathrm{O}\end{array}$ & $\begin{array}{l}\ldots . . \\
\mathrm{kg} / \mathrm{ha}\end{array}$ & $\begin{array}{c}\text { Vinhaça } \\
m^{3} / \mathrm{ha}\end{array}$ & $\begin{array}{c}\mathrm{K}^{+} \\
\mathrm{kg} / \mathrm{m}^{3}\end{array}$ \\
\hline $\mathrm{CPB}$ & 7,00 & 2,33 & 10,00 & 1240 & 0 & 0,00 \\
\hline DMA & 7,00 & 2,33 & 10,00 & 1240 & 0 & 0,00 \\
\hline $\mathrm{DMB}$ & 7,00 & 2,33 & 10,00 & 1240 & 0 & 0,00 \\
\hline $\mathrm{DMC}$ & 7,00 & 2,33 & 10,00 & 1240 & 0 & 0,00 \\
\hline DRA & 6,33 & 2,33 & 8,00 & 1240 & 0 & 0,00 \\
\hline $\mathrm{EGA}$ & 7,00 & 2,33 & 8,00 & 1240 & 0 & 0,00 \\
\hline EGB & 7,00 & 2,33 & 8,00 & 1240 & 203 & 4,01 \\
\hline FRA & 7,00 & 2,33 & 4,60 & 1240 & 116 & 4,35 \\
\hline $\mathrm{FRB}$ & 7,00 & 2,33 & 4,60 & 1240 & 11 & 4,30 \\
\hline $\mathrm{FRC}$ & 7,00 & 2,33 & 9,33 & 1240 & 0 & 0,00 \\
\hline $\mathrm{FRE}$ & 7,00 & 2,33 & 10,00 & 1240 & 0 & 0,00 \\
\hline FRF & 7,00 & 2,33 & 9,33 & 1240 & 0 & 0,00 \\
\hline FRG & 7,00 & 2,33 & 9,33 & 1240 & 0 & 0,00 \\
\hline FSA & 6,33 & 2,33 & 10,00 & 1240 & 0 & 0,00 \\
\hline ESB & 0,00 & 3,00 & 9,30 & 1240 & 0 & 0,00 \\
\hline FSC & 6,33 & 9,33 & 3,00 & 1240 & 0 & 0,00 \\
\hline GBA & 18,00 & 0,00 & 0,00 & 471 & 248 & 4,01 \\
\hline GBB & 8,00 & 0,00 & 9,33 & 1240 & 0 & 0,00 \\
\hline GDA & 8,00 & 0,00 & 9,33 & 1240 & 0 & 0,00 \\
\hline GDB & 7,00 & 3,00 & 9,33 & 1240 & 0 & 0,00 \\
\hline GDC & 6,33 & 2,33 & 0,00 & 1240 & 184 & 6,13 \\
\hline GIA & 6,33 & 2,33 & 9,33 & 1240 & 0 & 0,00 \\
\hline $\mathrm{HBB}$ & 7,00 & 2,33 & 9,33 & 1240 & 0 & 0,00 \\
\hline $\mathrm{HBC}$ & 7,00 & 2,33 & 9,33 & 1240 & 0 & 0,00 \\
\hline HGA & 8,00 & 3,00 & 10,00 & 1240 & 0 & 0,00 \\
\hline HGB & 8,00 & 3,00 & 10,00 & 1240 & 0 & 0,00 \\
\hline $\mathrm{HGC}$ & 8,00 & 3,00 & 10,00 & 1240 & 0 & 0,00 \\
\hline IGA & 6,30 & 2,33 & 8,00 & 1240 & 0 & 0,00 \\
\hline IRA & 7,00 & 2,33 & 10,00 & 1240 & 54 & 4,01 \\
\hline JLA & 6,33 & 2,33 & 0,00 & 1240 & 246 & 4,01 \\
\hline
\end{tabular}


Tabela 2. Quantidade de fertilizantes e residuos aplicados nos blocos amostrados (continuação).

\begin{tabular}{|c|c|c|c|c|c|}
\hline N\& & $\begin{array}{l}\text { Eertil } \\
\mathrm{P}_{2} \mathrm{O}_{5}^{\circ}\end{array}$ & $\begin{array}{l}\text { zantes } \\
\mathrm{K}_{2} \mathrm{O} \%\end{array}$ & $\begin{array}{c}\cdots \cdot \cdot \cdot \\
\mathrm{kg} / \mathrm{ha}\end{array}$ & $\begin{array}{c}\text { Jinhaça } \\
m^{3} / \mathrm{ha}\end{array}$ & $\mathrm{K}^{+}$ \\
\hline 6,33 & 2,33 & 0,00 & 1240 & 204 & 4,01 \\
\hline 7,00 & 2,33 & 8,00 & 1240 & 33 & 4,01 \\
\hline 7,00 & 2,33 & 8,00 & 1240 & 21 & 4,01 \\
\hline 7,00 & 2,33 & 8,00 & 1240 & 52 & 4,01 \\
\hline 8,00 & 0,00 & 9,33 & 1240 & 0 & 0,00 \\
\hline 8,00 & 0,00 & 9,33 & 1240 & 44 & 4,01 \\
\hline 8,00 & 0,00 & 9,33 & 1240 & 121 & 4,01 \\
\hline 8,00 & 0,00 & 9,33 & 1240 & 289 & 4,01 \\
\hline 8,00 & 0,00 & 9,33 & 1240 & 146 & 4,01 \\
\hline 8,00 & 0,00 & 9,33 & 1240 & 117 & 4,01 \\
\hline 18,00 & 0,00 & 0,00 & 471 & 166 & 4,01 \\
\hline 6,33 & 2,33 & 0,00 & 1240 & 674 & 4,01 \\
\hline 6,33 & 2,33 & 0,00 & 1240 & 487 & 4,01 \\
\hline 6,33 & 2,33 & 0,00 & 1240 & 214 & 4,01 \\
\hline 6,33 & 2,33 & 0,00 & 1240 & 189 & 4,01 \\
\hline 6,33 & 2,33 & 0,00 & 1240 & 257 & 4,01 \\
\hline 6,33 & 2,33 & 0,00 & 1240 & 253 & 4,01 \\
\hline 7,00 & 2,33 & 9,33 & 1240 & 0 & 0,00 \\
\hline 7,00 & 2,33 & 9,33 & 1240 & 24 & 1,56 \\
\hline 8,00 & 0,00 & 9,33 & 1240 & 0 & 0,00 \\
\hline 6,33 & 2,33 & 8,00 & 1240 & 0 & 0,00 \\
\hline 6,33 & 2,33 & 8,00 & 1240 & 0 & 0,00 \\
\hline 8,00 & 3,00 & 4,60 & 1240 & 180 & 4,01 \\
\hline 8,00 & 3,00 & 9,33 & 1240 & 0 & 0,00 \\
\hline 8,00 & 9,33 & 10,00 & 1240 & 0 & 0,00 \\
\hline 7,00 & 2,33 & 8,00 & 1240 & 0 & 0,00 \\
\hline 7,00 & 2,33 & 8,00 & 1240 & 0 & 0,00 \\
\hline 8,00 & 0,00 & 9,33 & 1240 & 0 & 0,00 \\
\hline 8,00 & 3,00 & 9,33 & 1240 & 0 & 0,00 \\
\hline 8,00 & 3,00 & 9,33 & 1240 & 0 & 0,00 \\
\hline
\end{tabular}


Tabela 2. Quantidade de fertilizantes e resíduos aplicados nos blocos amostrados (continuação).

\begin{tabular}{|c|c|c|c|c|c|c|}
\hline BLOCO & No & $\begin{array}{c}\text { Fertil } \\
\mathrm{P}_{2} \mathrm{O}_{5} 8 \\
\end{array}$ & $\begin{array}{l}\text { zantes. } \\
\mathrm{K}_{2} \mathrm{O} \%\end{array}$ & $\begin{array}{c}\cdots \\
\mathrm{kg} / \mathrm{ha}\end{array}$ & $\begin{array}{c}\text { Vinhaça } \\
m^{3} / \mathrm{ha}\end{array}$ & $\begin{array}{r}\mathrm{K}^{+} \\
\mathrm{kg} / \mathrm{m}^{3}\end{array}$ \\
\hline PLA & 6,33 & 2,33 & 4,00 & 1240 & 121 & 4,01 \\
\hline PWA & 7,00 & 2,33 & 0,00 & 1240 & 107 & 1,87 \\
\hline PXA & 7,00 & 2,33 & 8,00 & 1240 & 0 & 0,00 \\
\hline $\mathrm{RCD}$ & 6,33 & 2,33 & 4,00 & 1240 & 136 & 4,01 \\
\hline $\mathrm{RCE}$ & 6,33 & 2,33 & 4,00 & 1240 & 205 & 4,01 \\
\hline $\mathrm{RPA}$ & 6,33 & 2,33 & 9,33 & 1240 & 0 & 0,00 \\
\hline RPB & 6,33 & 2,33 & 9,33 & 1240 & 0 & 0,00 \\
\hline RVA & 18,00 & 0,00 & 0,00 & 471 & 353 & 4,01 \\
\hline$S A A$ & 8,00 & 0,00 & 9,33 & 1240 & 0 & 0,00 \\
\hline SFA & 8,00 & 3,00 & 9,33 & 1240 & 0 & 0,00 \\
\hline SFB & 8,00 & 3,00 & 9,33 & 1240 & 0 & 0,00 \\
\hline SFC & 8,00 & 3,00 & 9,33 & 1240 & 0 & 0,00 \\
\hline SFD & 8,00 & 2,33 & 9,33 & 1240 & 0 & 0,00 \\
\hline SFE & 8,00 & 3,00 & 9,33 & 1240 & 0 & 0,00 \\
\hline $\mathrm{SFF}$ & 8,00 & 0,00 & 9,33 & 1240 & 0 & 0,00 \\
\hline SFG & 6,33 & 2,33 & 10,00 & 1240 & 0 & 0,00 \\
\hline SGA & 6,33 & 2,33 & 0,00 & 1240 & 198 & 4,01 \\
\hline SJA & 6,33 & 0,00 & 9,33 & 1240 & 55 & 5,69 \\
\hline SMA & 8,00 & 0,00 & 9,33 & 1240 & 44 & 4,01 \\
\hline SMB & 8,00 & 0,00 & 9,33 & 1240 & 41 & 4,01 \\
\hline SMD & 18,00 & 0,00 & 0,00 & 471 & 182 & 4,01 \\
\hline SME & 18,00 & 0,00 & 0,00 & 471 & 123 & 4,01 \\
\hline SPB & 7,00 & 2,33 & 9,33 & 1240 & 0 & 0,00 \\
\hline STA & 6,33 & 2,33 & 8,00 & 1240 & 0 & 0,00 \\
\hline TAA. & 6,33 & 2,33 & 0,00 & 1240 & 209 & 4,01 \\
\hline$T A B$ & 6,33 & 2,33 & 0,00 & 1240 & 203 & 4,01 \\
\hline TLA & 7,00 & 2,33 & 0,00 & 1240 & 368 & 4,01 \\
\hline TLB & 7,00 & 2,33 & 0,00 & 1240 & 486 & 4,01 \\
\hline TLC & 7,00 & 2,33 & 0,00 & 1240 & 302 & 4,01 \\
\hline TLD & 7,00 & 2,33 & 0,00 & 1240 & 65 & 4,01 \\
\hline
\end{tabular}


Tabela 2. Quantidade de fertilizantes e resíduos aplicados nos blocos amostrados (continuação).

..............Vinhaça $\mathrm{K}^{+}$

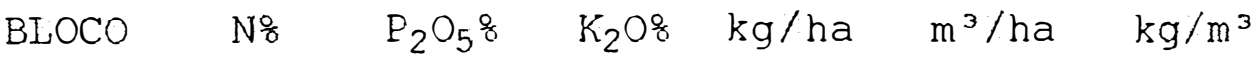

$\begin{array}{rrrrrrr}\text { TPA } & 6,33 & 2,33 & 8,00 & 1240 & 0 & 0,00 \\ \text { VBA } & 7,00 & 2,33 & 0,00 & 1240 & 251 & 5,11 \\ \text { VBB } & 7,00 & 2,33 & 0,00 & 1240 & 143 & 4,98 \\ \text { WA } & 7,00 & 2,33 & 0,00 & 1240 & 260 & 4,01 \\ \text { WB } & 7,00 & 2,33 & 0,00 & 1240 & 233 & 4,01 \\ \text { WC } & 7,00 & 2,33 & 4,06 & 1240 & 120 & 4,01\end{array}$

De forma geral, a aplicação dos fertilizantes fol de acordo com os resultados das análises de solo, e com as recomendações experimentais. Os teores de NPK das formulações fluidas é controlado rotineiramente pelos responsáveis pela operacionalização da fábrica de adubos líquidos da empresa.

A vinhaça é aplicada na maioria das vezes por aspersão, com equipamento bomba-canhão de montagem direta. Isto explica a grande variação nas dosagens de vinhaça, conforme pode ser observado na Tabela 2, pois as dosagens são calculadas em função do tempo de operação do equipamento, que tem vazão definida. Estes sistemas de aplicação encontram-se bem descritos na literatura /GLóRIA, 1976; GLÓRIA \& MAGRO, 1976; COPERSUCAR, 1979, 1981; GLÓRIA \& ORLANDO FILHO, 1983; FURLANI NETO et alii, 1985; COELHO \& AZEVEDO, 1986; MATIOLI et alii, 1988). As áreas com dosagens mais baixas correspondem a áreas onde ainda é feita aplicação da vinhaça por caminhão. Pode-se notar ainda que nem todas as áreas estudadas receberam vinhaça, independente do número de cortes. Nestes casos, houve complementação da adubação com fertilizantes minerais, conforme recomendado na literatura /RODELIA \& FERRARI, 
1977; ESPIRONELO et alii, 1981; GLÓRIA et alii, 1984; PENNA \& FIGUEIREDO, 1984; RODRIGUES et alii, 1984; TRIVELIN et alii, 1986)

Os resultados referentes às análises de solo efetuadas, com extrator $\mathrm{KCl} 1 \mathrm{~N}$ para $\mathrm{Ca}$ e $\mathrm{Mg}$ (teores trocáveis) e 0 extrator $\mathrm{HCl} 0,5 \mathrm{~N}$ (teor potencial), encontram-se na Tabela 3. As colunas correspondentes aos valores obtidos com extrator $\mathrm{KCl} 1 \mathrm{~N}$ estão identificadas pelas letra $\mathrm{CaK}$ e MgK, ou seja, teores de $\mathrm{Ca}$ e Mg respectivamente, obtidos com este extrator. De forma semelhante, $\mathrm{CaH}$ e $\mathrm{MgH}$ indicam valores obtidos de $\mathrm{Ca}$ e $\mathrm{Mg}$ com extrator $\mathrm{HCl} 0,5 \mathrm{~N}$. Vale observar que este extrator revela naturalmente teores mais elevados. Estes teores podem ser considerados teores potenciais, e tem maior relação com a produtividade considerando-se vários cortes (BEAUCLAIR, 1991). Esta diferença também é refletida no cálculo dos parâmetros de CTC, soma e saturação por bases.

Tabela 3: Resultado das análises de solo correspondentes aos blocos amostrados.

BLOCO $\quad \mathrm{pH} \quad \mathrm{C} \quad \mathrm{PO}_{4} \quad \mathrm{CaH} \quad \mathrm{MgH} \quad \mathrm{CaK} \quad \mathrm{MgK} \quad \mathrm{Al} H+\mathrm{Al} \quad \mathrm{K}$ \& $\quad \ldots \ldots \ldots$....meq. $/ 100 \mathrm{~g}$ solo.

$\begin{array}{lllllllllll}\text { OID } & 6,0 & 1,67 & 0,14 & 3,23 & 3,09 & 1,56 & 1,21 & 0,12 & 1,45 & 0,24 \\ \text { OIE } & 6,0 & 1,67 & 0,14 & 3,23 & 3,09 & 1,56 & 1,21 & 0,12 & 1,45 & 0,24 \\ 01 \mathrm{E} & 6,0 & 1,67 & 0,24 & 4,89 & 3,09 & 2,09 & 1,21 & 0,12 & 1,45 & 0,44 \\ 01 \mathrm{G} & 6,0 & 1,67 & 0,14 & 3,23 & 3,09 & 1,56 & 1,21 & 0,12 & 1,45 & 0,34 \\ 01 \mathrm{H} & 6,3 & 1,90 & 0,05 & 3,12 & 3,01 & 1,34 & 1,12 & 0,16 & 1,32 & 0,66 \\ 01 \mathrm{I} & 6,1 & 1,84 & 0,21 & 3,22 & 2,81 & 2,09 & 0,92 & 0,12 & 3,96 & 0,35 \\ 01 \mathrm{~J} & 6,2 & 1,74 & 0,16 & 4,67 & 2,81 & 2,37 & 1,60 & 0,08 & 3,92 & 0,51 \\ 01 \mathrm{~K} & 6,3 & 1,67 & 0,26 & 3,78 & 2,97 & 3,67 & 1,78 & 0,14 & 3,67 & 0,37 \\ 01 \mathrm{~L} & 6,2 & 1,70 & 0,25 & 3,42 & 2,87 & 1,48 & 1,75 & 0,12 & 3,45 & 0,29 \\ 01 \mathrm{M} & 6,5 & 1,68 & 0,16 & 4,36 & 2,88 & 2,07 & 1,75 & 0,10 & 3,54 & 0,29 \\ 01 \mathrm{~N} & 6,2 & 1,87 & 0,17 & 4,09 & 2,91 & 3,08 & 1,77 & 0,11 & 3,47 & 0,28 \\ 010 & 6,3 & 1,65 & 0,14 & 4,23 & 2,94 & 2,24 & 1,77 & 0,13 & 3,56 & 0,37\end{array}$


Tabela 3: Resultado das análises de solo correspondentes aos blocos amostrados (continuação).

$\begin{array}{lllllllllllllll}B L O C O & \mathrm{pH} & \mathrm{C} & \mathrm{PO}_{4} & \mathrm{CaH} & \mathrm{MgH} & \mathrm{CaK} & \mathrm{MgK} & \mathrm{A} I \mathrm{H}+\mathrm{A} & \mathrm{K}\end{array}$

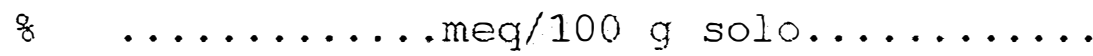

O1P $\quad 6,3 \quad 1,690,25 \quad 4,41 \quad 2,94 \quad 3,10 \quad 1,78 \quad 0,09 \quad 3,67 \quad 0,39$

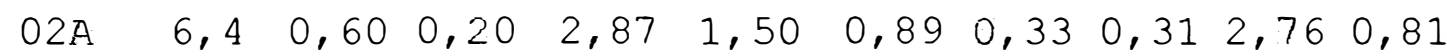

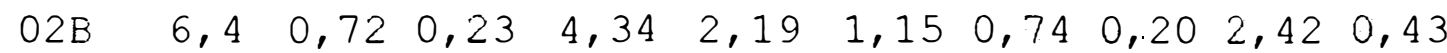

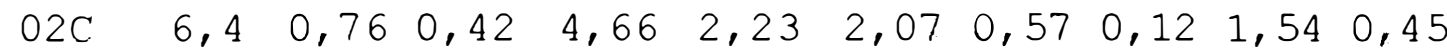

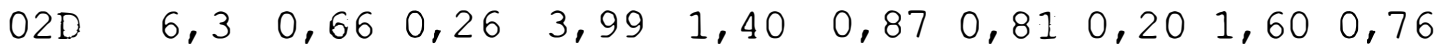
$\begin{array}{lllllllllll}02 \mathrm{E} & 6,4 & 0,70 & 0,23 & 2,98 & 1,46 & 0,98 & 0,67 & 0,19 & 2,34 & 0,23\end{array}$ $\begin{array}{lllllllllll}02 \mathrm{~F} & 6,3 & 0,82 & 0,24 & 3,05 & 1,56 & 0,87 & 0,78 & 0,18 & 2,45 & 0,34\end{array}$

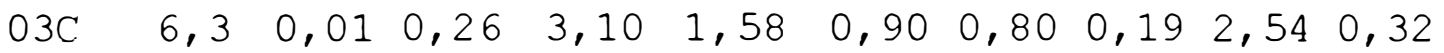

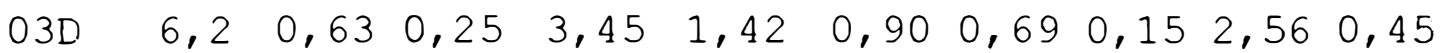

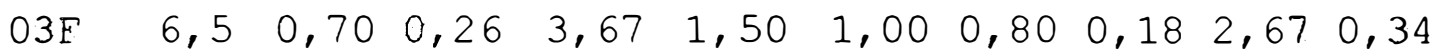

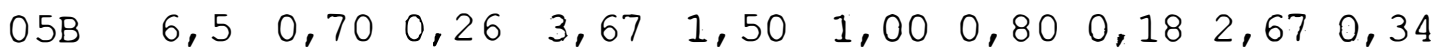
$06 \mathrm{~A} \quad 6,4 \quad 1,02 \quad 0,25 \quad 3,45 \quad 2,17 \quad 2,32 \quad 1,50 \quad 0,12 \quad 1,92 \quad 0,42$ 06D $\quad 6,6 \quad 1,020,28 \quad 3,45 \quad 2,17 \quad 2,32 \quad 1,50 \quad 0,12 \quad 1,94 \quad 0,47$ 06E $\quad 6,6 \quad 0,93 \quad 0,27 \quad 3,64 \quad 2,82 \quad 1,510,890,28 \quad 1,20 \quad 0,43$

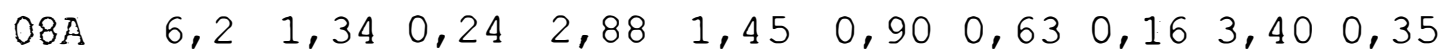
08B $\quad 6,3 \quad 1,250,20 \quad 4,36 \quad 2,35 \quad 0,96 \quad 0,610,12 \quad 3,120,48$ 08C $\quad 6,0 \quad 1,490,24 \quad 4,59 \quad 2,04 \quad 1,07 \quad 0,64 \quad 0,20 \quad 3,32 \quad 0,44$

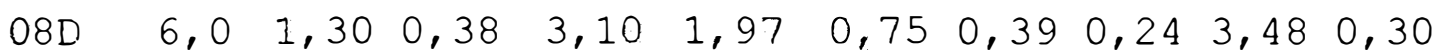
$08 \mathrm{E} \quad 6,0 \quad 1,30 \quad 0,38 \quad 3,10 \quad 1,97 \quad 0,75 \quad 0,390,24 \quad 3,48 \quad 0,21$ $08 \mathrm{~F} \quad 6,2 \quad 1,130,26 \quad 4,96 \quad 1,85 \quad 1,410,810,12 \quad 3,56 \quad 0,44$ O8G $\quad 6,2 \quad 1,130,15 \quad 3,78 \quad 1,85 \quad 1,410,810,12 \quad 3,56 \quad 0,20$ $08 \mathrm{H} \quad 6,2 \quad 1,130,29 \quad 4,96 \quad 1,85 \quad 1,410,810,12 \quad 3,56 \quad 0,44$ $08 \mathrm{I} \quad 6,1 \quad 1,250,24 \quad 4,29 \quad 1,98 \quad 1,110,630,17 \quad 3,440,48$ 08J $\quad 6,1 \quad 1,250,24 \quad 4,29 \quad 1,98 \quad 1,110,630,17 \quad 3,440,48$ 09A $\quad 6,2 \quad 1,30 \quad 0,24 \quad 4,30 \quad 1,99 \quad 1,120,640,18 \quad 3,54 \quad 0,49$ O9G $\quad 6,2 \quad 1,30 \quad 0,24 \quad 3,30 \quad 1,99 \quad 1,12 \quad 0,64 \quad 0,18 \quad 3,54 \quad 0,19$ $10 \mathrm{~B} \quad 6,2 \quad 1,34 \quad 0,25 \quad 4,42 \quad 2,01 \quad 1,230,67 \quad 0,20 \quad 3,630,43$

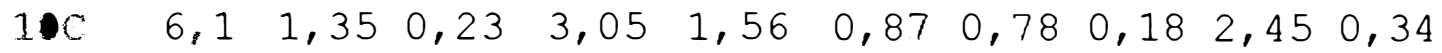
IOE $\quad 6,2 \quad 1,320,30 \quad 3,10 \quad 1,58 \quad 0,90 \quad 0,80 \quad 0,192,54 \quad 0,53$ $1.0 \mathrm{~F} \quad 6,5 \quad 1,230,17 \quad 3,45 \quad 1,42 \quad 0,90 \quad 0,690,15 \quad 2,56 \quad 0,45$ 
Tabela 3: Resultado das análises de solo correspondentes aos blocos amostrados (continuação).

BLOCO $\mathrm{pH} \quad \mathrm{C} \quad \mathrm{PO}_{4} \quad \mathrm{CaH} \quad \mathrm{MgH} \quad \mathrm{CaK}$ MgK Al $\mathrm{H}+\mathrm{Al} \quad \mathrm{K}$

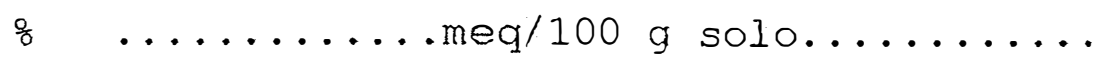

IOG $\quad 6,2 \quad 0,99 \quad 0,18 \quad 3,67 \quad 1,50 \quad 1,00 \quad 0,80 \quad 0,18 \quad 2,67 \quad 0,34$ $10 I \quad 6,1 \quad 1,0100,32 \quad 3,67 \quad 1,50 \quad 1,00 \quad 0,800,18 \quad 2,67 \quad 0,54$ 10J $\quad 6,2 \quad 1,03 \quad 0,20 \quad 3,45 \quad 2,17 \quad 2,32 \quad 1,50 \quad 0,120,920,46$ $10 \mathrm{~K} \quad 6,0 \quad 1,04 \quad 0,31 \quad 3,45 \quad 2,17 \quad 2,32 \quad 1,50 \quad 0,12 \quad 0,92 \quad 0,52$ 10I $\quad 6,5 \quad 1,000,26 \quad 3,54 \quad 1,99 \quad 2,451,450,102,450,40$ $10 \mathrm{M} \quad 6,0 \quad 0,990,14 \quad 3,24 \quad 1,99 \quad 2,34 \quad 1,54 \quad 0,34 \quad 2,09 \quad 0,22$

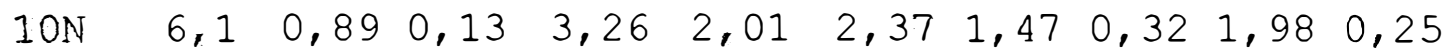
$100 \quad 6,2 \quad 0,890,17 \quad 3,42 \quad 1,56 \quad 1,54 \quad 1,37 \quad 0,12 \quad 1,990,29$ $11 \mathrm{~A} \quad 6,3 \quad 0,97 \quad 0,23 \quad 3,10 \quad 1,58 \quad 2,22 \quad 1,21 \quad 0,17 \quad 2,07 \quad 0,30$ $11 \mathrm{~B} \quad 6,2 \quad 1,03 \quad 0,15 \quad 3,07 \quad 1,42 \quad 1,651,02 \quad 0,29 \quad 2,350,34$ $12 \mathrm{~A} \quad 5,7 \quad 0,830,12 \quad 3,14 \quad 1,50 \quad 2,22 \quad 0,92 \quad 0,14 \quad 1,66 \quad 0,21$ $12 \mathrm{~B} \quad 6,6 \quad 0,92 \quad 0,12 \quad 2,65 \quad 1,60 \quad 1,030,58 \quad 0,24 \quad 2,11 \quad 0,49$ $\begin{array}{llllllllllll}12 \mathrm{C} & 5,7 & 0,88 & 0,12 & 2,90 & 1,55 & 1,63 & 0,75 & 0,19 & 1,89 & 0,18\end{array}$ $\begin{array}{llllllllllll}13 \mathrm{~F} & 6,7 & 0,88 & 0,32 & 2,90 & 1,55 & 1,63 & 0,75 & 0,19 & 1,89 & 0,45\end{array}$

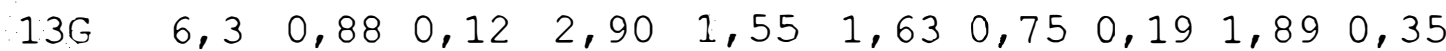
$\begin{array}{llllllllllll}13 \mathrm{H} & 5,7 & 0,88 & 0,12 & 2,90 & 1,55 & 1,63 & 0,75 & 0,19 & 1,89 & 0,18\end{array}$ $\begin{array}{lllllllllll}13 \mathrm{~K} & 6,3 & 0,88 & 0,12 & 2,90 & 1,55 & 1,63 & 0,75 & 0,19 & 1,89 & 0,35\end{array}$

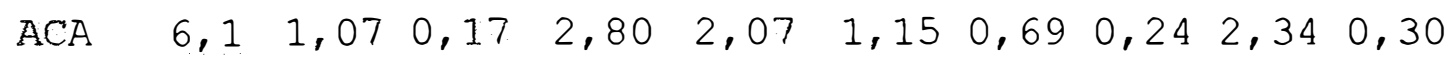
$\begin{array}{lllllllllllll}A C B & 6,3 & 1,07 & 0,21 & 2,80 & 2,07 & 1,15 & 0,69 & 0,24 & 2,34 & 0,30\end{array}$

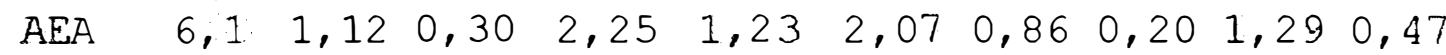
$\begin{array}{llllllllllll}A E B & 6,1 & 1,12 & 0,16 & 2,25 & 1,23 & 0,97 & 0,86 & 0,20 & 1,29 & 0,27\end{array}$ $\mathrm{ANB} \quad 5,9 \quad 0,66 \quad 0,12 \quad 3,03 \quad 1,67 \quad 1,44 \quad 0,70 \quad 0,44 \quad 1,73 \quad 0,21$ ATA $\quad 6,2 \quad 0,980,05 \quad 3,94 \quad 2,02 \quad 1,42 \quad 0,990,100,890,24$ Aтв $\quad 6,2 \quad 0,980,05 \quad 3,94 \quad 2,02 \quad 1,420,990,100,890,24$ ATC $\quad 6,2.0,980,05 \quad 3,94 \quad 2,02 \quad 1,420,990,100,890,24$ $\mathrm{BCA} \quad 6,5 \quad 1,190,29 \quad 4,20 \quad 3,29 \quad 1,50 \quad 1,24 \quad 0,40 \quad 2,26 \quad 0,43$ $\mathrm{BCB} \quad 5,3 \quad 1,190,19 \quad 3,67 \quad 2,91 \quad 1,50 \quad 1,24 \quad 0,40 \quad 2,26 \quad 0,14$ BCC $\quad 6,6 \quad 1,190,29 \quad 4,20 \quad 3,29 \quad 1,50 \quad 1,240,40 \quad 2,26 \quad 0,54$ $\mathrm{BCD} \quad 6,5 \quad 1,20 \quad 0,26 \quad 4,58 \quad 2,93 \quad 1,640,930,42 \quad 5,200,41$ $\mathrm{BCE} \quad 6,2 \quad 1,20 \quad 0,24 \quad 4,58 \quad 2,93 \quad 1,640,930,80 \quad 5,20 \quad 0,41$ 
Tabela 3: Resultado das análises de solo correspondentes aos blocos amostrados (continuação) .

$\begin{array}{llllllllllllllll}B L O C O & \mathrm{pH} & \mathrm{C} & \mathrm{PO}_{4} & \mathrm{CaH} & \mathrm{MgH} & \mathrm{CaK} & \mathrm{MgK} & \mathrm{Al} & \mathrm{H}+\mathrm{Al} & \mathrm{K}\end{array}$

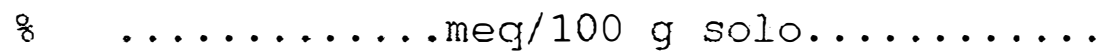

$\mathrm{BCF} \quad 6,5 \quad 1,20 \quad 0,27 \quad 4,58 \quad 2,93 \quad 1,64 \quad 0,93 \quad 0,40 \quad 5,20 \quad 0,43$ BGA $\quad 6,4 \quad 1,23 \quad 0,18 \quad 4,34 \quad 2,97 \quad 1,76 \quad 1,00 \quad 0,41 \quad 4,34 \quad 0,23$ BNA $\quad 6,1 \quad 1,12,0,08 \quad 2,25 \quad 1,23 \quad 1,02 \quad 0,86 \quad 0,201,290,27$ BNB $\quad 6,2 \quad 0,98 \quad 0,05 \quad 3,94 \quad 2,02 \quad 1,42 \quad 0,990,10 \quad 0,890,24$ BSA $\quad 5,4 \quad 1,37 \quad 0,09 \quad 3,80 \quad 2,64 \quad 3,05 \quad 1,090,201,960,09$ BSB $\quad 5,8 \quad 1,41 \quad 0,25 \quad 3,90 \quad 2,78 \quad 2,23 \quad 1,290,16 \quad 1,40 \quad 0,26$ $\mathrm{BSC} \quad 5,6 \quad 1,310,21 \quad 3,78 \quad 2,66 \quad 1,680,910,201,36 \quad 0,14$ $\mathrm{CBB} \quad 6,2 \quad 1,240,25 \quad 3,94 \quad 2,34 \quad 1,651,100,21 \quad 1,450,37$ $\mathrm{CBC} \quad 6,1 \quad 1,24 \quad 0,24 \quad 3,97 \quad 2,34 \quad 1,65 \quad 1,10 \quad 0,21 \quad 1,450,37$ CMA $\quad 5,6 \quad 1,34 \quad 0,20 \quad 3,79 \quad 2,43 \quad 1,70 \quad 1,08 \quad 0,201,490,19$ CPA $\quad 6,7 \quad 1,290,30 \quad 4,42 \quad 1,54 \quad 1,79 \quad 1,10 \quad 0,191,550,44$ $\mathrm{CPB} \quad 5,7 \quad 1,290,18 \quad 3,42 \quad 1,54 \quad 1,791,100,191,550,19$

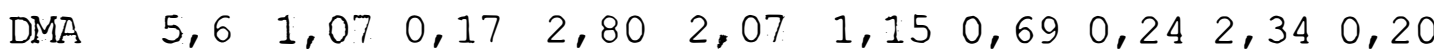
DMB $\quad 5,6 \quad 1,07 \quad 0,17 \quad 2,80 \quad 2,07 \quad 1,150,690,24 \quad 2,34 \quad 0,20$

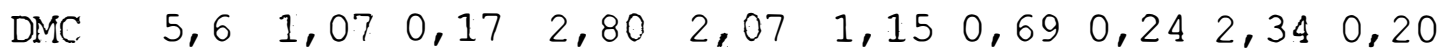
DRA $\quad 6,1 \quad 1,120,08 \quad 2,25 \quad 1,23 \quad 2,07 \quad 0,86 \quad 0,201,290,27$

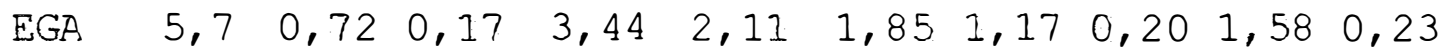
EGB $\quad 6,6 \quad 0,72 \quad 0,21 \quad 3,44 \quad 2,11 \quad 1,85 \quad 1,17 \quad 0,201,58 \quad 0,39$ ERA $\quad 6,2 \quad 0,98 \quad 0,26 \quad 2,98 \quad 2,23 \quad 1,90 \quad 1,24 \quad 0,23 \quad 1,67 \quad 0,29$ FRB $\quad 5,7 \quad 0,98 \quad 0,19 \quad 2,98 \quad 2,23 \quad 1,90 \quad 1,24 \quad 0,231,67 \quad 0,29$ FRC $\quad 5,7 \quad 0,98 \quad 0,19 \quad 2,98 \quad 2,23 \quad 1,90 \quad 1,24 \quad 0,23 \quad 1,67 \quad 0,29$

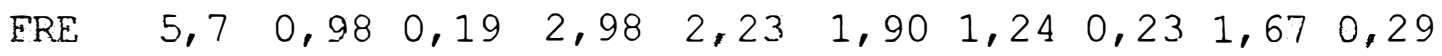
ERE $\quad 5,7 \quad 0,98 \quad 0,19 \quad 2,98 \quad 2,23 \quad 1,90 \quad 1,24 \quad 0,231,67 \quad 0,29$ FRG $\quad 5,7 \quad 0,98 \quad 0,19 \quad 2,98 \quad 2,23 \quad 1,90 \quad 1,24 \quad 0,23 \quad 1,67 \quad 0,29$ FSA $\quad 6,3 \quad 1,650,14 \quad 3,41 \quad 2,94 \quad 1,78 \quad 1,77 \quad 0,13 \quad 3,56 \quad 0,27$ FSB $\quad 6,3 \quad 1,650,14 \quad 3,41 \quad 2,94 \quad 1,78 \quad 1,77 \quad 0,13 \quad 3,56 \quad 0,27$ ESC $\quad 5,4 \quad 0,96 \quad 0,10 \quad 1,83 \quad 1,52 \quad 1,451,010,280,920,16$ GBA $\quad 6,5 \quad 0,96 \quad 0,24 \quad 1,83 \quad 1,52 \quad 0,78 \quad 1,01 \quad 0,38 \quad 0,92 \quad 0,49$ GBB $\quad 5,6 \quad 0,84 \quad 0,11 \quad 1,91 \quad 1,52 \quad 1,57 \quad 1,130,24 \quad 3,64 \quad 0,17$ GDA $\quad 5,7 \quad 0,88 \quad 0,12 \quad 2,90 \quad 1,55 \quad 1,63 \quad 0,750,19 \quad 1,890,25$ 
Tabela 3: Resultado das análises de solo correspondentes aos blocos amostrados (continuação).

$\begin{array}{llllllllllll}\text { BLOCO } & \mathrm{pH} & \mathrm{C} & \mathrm{PO}_{4} & \mathrm{CaH} & \mathrm{MgH} & \mathrm{CaK} & \mathrm{MgK} & \mathrm{Al} & \mathrm{H}+\mathrm{Al} & \mathrm{K}\end{array}$

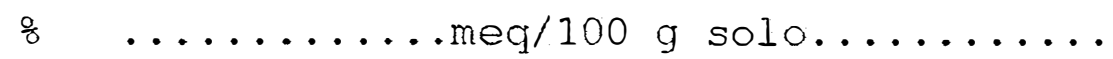

GDB $\quad 5,7 \quad 0,88 \quad 0,12 \quad 2,90 \quad 1,55 \quad 1,63 \quad 0,75 \quad 0,19 \quad 1,890,25$ GDC $\quad 6,7 \quad 0,88 \quad 0,12 \quad 2,90 \quad 1,55 \quad 1,63 \quad 0,75 \quad 0,191,890,35$ GIA $\quad 5,8 \quad 0,98 \quad 0,14 \quad 2,90 \quad 1,60 \quad 1,76 \quad 0,98 \quad 0,201,98 \quad 0,24$ HBB $\quad 5,6 \quad 1,00 \quad 0,15 \quad 2,97 \quad 1,67 \quad 1,82 \quad 1,010,231,990,32$ HBC $\quad 5,6 \quad 1,00 \quad 0,15 \quad 2,97 \quad 1,67 \quad 1,82 \quad 1,01 \quad 0,23 \quad 1,990,32$ HGA $\quad 5,8 \quad 1,01 \quad 0,19 \quad 3,21 \quad 1,43 \quad 1,451,020,404,00 \quad 0,17$ HGB $\quad 5,8 \quad 0,98 \quad 0,16 \quad 2,52 \quad 1,92 \quad 0,98 \quad 1,23 \quad 0,20 \quad 2,04 \quad 0,13$ HGC $\quad 5,4 \quad 0,990,16 \quad 3,74 \quad 2,45 \quad 1,73 \quad 1,70 \quad 0,21 \quad 2,120,08$ IGA $\quad 6,3 \quad 1,01 \quad 0,27 \quad 3,46 \quad 2,21 \quad 1,78 \quad 1,92 \quad 0,25 \quad 2,52 \quad 0,06$ IRA $\quad 5,91,200,21 \quad 3,98 \quad 3,16 \quad 1,892,06 \quad 0,21 \quad 2,120,23$ JLA $\quad 6,4 \quad 1,120,26 \quad 4,78 \quad 2,93 \quad 2,48 \quad 1,950,36 \quad 3,56 \quad 0,43$ $\begin{array}{llllllllllll}\pi B & 6,7 & 1,15 & 0,23 & 4,06 & 3,64 & 3,57 & 2,19 & 0,32 & 3,20 & 0,37\end{array}$ JMA $\quad 5,3 \quad 1,06 \quad 0,12 \quad 3,55 \quad 1,52 \quad 1,540,90 \quad 0,35 \quad 3,54 \quad 0,24$ JMB $\quad 5,5 \quad 1,090,06 \quad 3,37 \quad 1,99 \quad 1,92 \quad 1,290,19 \quad 1,88 \quad 0,26$ JMC $\quad 5,9 \quad 1,17 \quad 0,22 \quad 3,55 \quad 1,39 \quad 1,65 \quad 1,180,27 \quad 2,68 \quad 0,36$ JSA $\quad 5,8 \quad 1,17 \quad 0,22 \quad 3,55 \quad 1,39 \quad 2,25 \quad 1,18 \quad 0,27 \quad 2,68 \quad 0,26$ JSB $\quad 5,8 \quad 1,16 \quad 0,16 \quad 2,20 \quad 1,53 \quad 1,491,140,151,48 \quad 0,29$ JSC $\quad 6,3 \quad 1,26 \quad 0,26 \quad 3,23 \quad 1,95 \quad 1,48 \quad 1,090,24 \quad 2,40 \quad 0,29$ JSD $\quad 6,5 \quad 1,290,24 \quad 3,69 \quad 2,37 \quad 2,08 \quad 1,46 \quad 0,22 \quad 2,16 \quad 0,43$ JSE $\quad 6,4 \quad 1,280,20 \quad 3,24 \quad 1,96 \quad 1,880,850,08 \quad 0,84 \cdot 0,29$ JSG $\quad 6,3 \quad 1,26 \quad 0,23 \quad 3,69 \quad 2,77 \quad 1,67 \quad 0,850,11 \quad 1,120,34$ JSH $\quad 6,2 \quad 1,250,20 \quad 3,98 \quad 2,40 \quad 1,51 \quad 0,86 \quad 0,23 \quad 2,280,32$ LGA $\quad 6,5 \quad 1,310,34 \quad 3,51 \quad 1,42 \quad 2,120,86 \quad 0,18 \quad 1,840,74$ LGC $\quad 6,6 \quad 1,320,32 \quad 2,56 \quad 1,90 \quad 1,661,190,181,76 \quad 0,70$ IZA $\quad 6,6 \quad 1,31 \quad 0,24 \quad 4,24 \quad 2,69 \quad 2,10 \quad 1,37 \quad 0,18 \quad 1,840,36$ LZB $\quad 6,4 \quad 1,28 \quad 0,19 \quad 4,24 \quad 2,69 \quad 1,12 \quad 1,37 \quad 0,18 \quad 1,84 \quad 0,39$ LZC $\quad 6,1 \quad 1,230,27 \quad 5,03 \quad 2,84 \quad 3,451,56 \quad 0,26 \quad 2,600,45$ LZD $\quad 6,6 \quad 1,310,27 \quad 4,66 \quad 2,97 \quad 2,11 \quad 1,450,22 \quad 2,200,43$

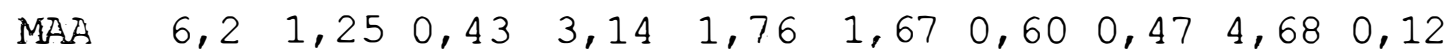
$\begin{array}{llllllllllll}M A B & 5,9 & 1,17 & 0,31 & 3,96 & 1,45 & 1,93 & 0,70 & 0,33 & 3,28 & 0,17\end{array}$ 
Tabela 3: Resultado das análises de solo correspondentes aos blocos amostrados (continuação).

$\begin{array}{lllllllllll}\text { BLOCO } & \mathrm{pH} & \mathrm{C} & \mathrm{PO}_{4} & \mathrm{CaH} & \mathrm{MgH} & \mathrm{CaK} & \mathrm{MgK} & \mathrm{Al} & \mathrm{HI} & \mathrm{K}\end{array}$ o $\ldots \ldots \ldots$........meq/100 g solo.........

MGA $\quad 5,7 \quad 0,72 \quad 0,17 \quad 3,44 \quad 2,11 \quad 1,85 \quad 1,17 \quad 0,201,58 \quad 0,29$ MIA $\quad 5,7 \quad 0,98 \quad 0,19 \quad 3,56 \quad 2,76 \quad 1,98 \quad 1,23 \quad 0,19 \quad 1,67 \quad 0,28$ MIB $\quad 5,7 \quad 0,98 \quad 0,19 \quad 3,56 \quad 2,76 \quad 1,98 \quad 1,23 \quad 0,19 \quad 1,67 \quad 0,28$ NRA $\quad 6,5 \quad 1,050,15 \quad 2,21 \quad 1,22 \quad 0,78 \quad 1,33 \quad 0,201,76 \quad 0,24$ NRB $\quad 5,1 \quad 1,08 \quad 0,27 \quad 3,51 \quad 2,84 \quad 1,45 \quad 1,56 \quad 0,23 \quad 2,60 \quad 0,15$ NRC $\quad 5,6 \quad 1,17 \quad 0,18 \quad 3,87 \quad 2,97 \quad 3,11 \quad 1,45 \quad 0,20 \quad 2,200,06$ NZA $\quad 6,2 \quad 1,31 \quad 0,43 \quad 3,14 \quad 1,76 \quad 1,67 \quad 0,60 \quad 0,42 \quad 4,68 \quad 0,12$ NZB $\quad 5,9 \quad 1,23 \quad 0,31 \quad 3,96 \quad 1,45 \quad 1,930,70 \quad 0,30 \quad 3,280,17$ $\mathrm{PDA} \quad 6,2 \quad 1,30 \quad 0,16 \quad 3,44 \quad 1,42 \quad 1,97 \quad 0,400,32 \quad 3,60 \quad 0,15$ $\mathrm{PDB} \quad 5,91,24 \quad 0,01 \quad 2,72 \quad 1,77 \quad 1,500,91 \quad 0,14 \quad 1,56 \quad 0,11$ $\mathrm{PDC} \quad 5,7 \quad 1,190,09 \quad 3,28 \quad 1,59 \quad 1,380,71 \quad 0,24 \quad 2,720,13$ PLA $\quad 6,3 \quad 1,32 \quad 0,26 \quad 3,68 \quad 1,57 \quad 1,52 \quad 0,78 \quad 0,28 \quad 3,08 \quad 0,36$ PWA $\quad 6,3 \quad 1,200,14 \quad 3,45 \quad 1,43 \quad 1,540,810,20 \quad 3,10 \quad 0,33$ PXA $\quad 6,3 \quad 0,720,11 \quad 2,83 \quad 1,76 \quad 0,90 \quad 0,450,12 \quad 1,48 \quad 0,27$ $\operatorname{RCD} \quad 6,0 \quad 1,67 \quad 0,23 \quad 3,56 \quad 3,09 \quad 1,091,21 \quad 0,12 \quad 1,450,34$ RCE $\quad 6,0 \quad 1,67 \quad 0,24 \quad 4,23 \quad 3,09 \quad 2,091,21 \quad 0,12 \quad 1,450,34$ REA $\quad 6,0 \quad 1,76 \quad 0,13 \quad 3,35 \quad 3,12 \quad 1,34 \quad 1,34 \quad 0,14 \quad 1,54 \quad 0,25$ RPB $\quad 6,0 \quad 1,76 \quad 0,13 \quad 3,25 \quad 3,12 \quad 1,56 \quad 1,34 \quad 0,14 \quad 1,54 \quad 0,25$ RVA $\quad 6,0 \quad 1,80 \quad 0,29 \quad 5,02 \quad 3,20 \quad 3,23 \quad 1,40 \quad 0,151,56 \quad 0,53$ SAA $\quad 6,0 \quad 1,67 \quad 0,12 \quad 3,98 \quad 2,98 \quad 1,12 \quad 1,100,192,03 \quad 0,24$ SFA $\quad 6,0 \quad 1,06 \quad 0,11 \quad 3,26 \quad 2,07 \quad 1,150,690,20 \quad 3,46 \quad 0,22$ SFB $\quad 6,0 \quad 1,06 \quad 0,11 \quad 3,26 \quad 2,07 \quad 1,150,690,20 \quad 3,46 \quad 0,22$ $\mathrm{SFC} \quad 6,5 \quad 1,04 \quad 0,18 \quad 3,33 \quad 2,16 \quad 1,53 \quad 0,90 \quad 0,14 \quad 2,34 \quad 0,23$ SFD $\quad 6,5 \quad 1,04 \quad 0,18 \quad 3,33 \quad 2,16 \quad 1,53 \quad 0,900,142,34 \quad 0,23$ SEE $\quad 6,5 \quad 1,290,03 \quad 3,06 \quad 2,33 \quad 1,440,950,28 \quad 3,640,13$ SFE $\quad 6,5 \quad 1,290,03 \quad 3,06 \quad 2,33 \quad 1,440,950,28 \quad 3,640,13$ SFG $\quad 6,5 \quad 1,290,03 \quad 3,06 \quad 2,33 \quad 1,440,950,28 \quad 3,640,13$ SGA $\quad 6,4 \quad 1,30 \quad 0,24 \quad 3,10 \quad 2,37 \quad 1,56 \quad 1,000,17 \quad 3,78 \quad 0,38$ SJA $\quad 5,91,21 \quad 0,13 \quad 2,98 \quad 2,14 \quad 1,50 \quad 0,980,18 \quad 3,84 \quad 0,25$ SMA $\quad 6,0 \quad 1,30 \quad 0,12 \quad 3,10 \quad 2,45 \quad 1,45 \quad 1,00 \quad 0,24 \quad 3,45 \quad 0,24$ 
Tabela 3: Resultado das análises de solo correspondentes aos blocos amostrados (continuação).

$\begin{array}{lllllllllll}\text { BLOCO } & \mathrm{pH} & \mathrm{C} & \mathrm{PO}_{4} & \mathrm{CaH} & \mathrm{MgH} & \mathrm{CaK} & \mathrm{MgK} & \mathrm{Al} & \mathrm{H}+\mathrm{Al} & \mathrm{K}\end{array}$

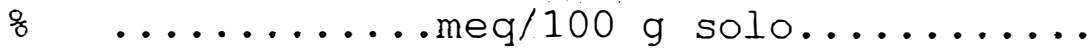

$\begin{array}{llllllllllll}\text { SMB } & 6,0 & 1,30 & 0,12 & 3,10 & 2,45 & 1,45 & 1,00 & 0,24 & 3,45 & 0,24 \\ \text { SMD } & 6,0 & 1,30 & 0,12 & 3,10 & 2,45 & 1,45 & 1,00 & 0,24 & 3,45 & 0,44 \\ \text { SME } & 6,3 & 1,30 & 0,20 & 3,10 & 2,45 & 1,45 & 1,00 & 0,24 & 3,45 & 0,34 \\ \text { SPB } & 5,1 & 1,20 & 0,14 & 3,20 & 2,56 & 1,49 & 1,20 & 0,26 & 3,56 & 0,16 \\ \text { STA } & 5,1 & 1,23 & 0,17 & 3,25 & 2,76 & 1,50 & 1,15 & 0,24 & 3,60 & 0,13 \\ \text { TAA } & 6,6 & 1,20 & 0,25 & 3,17 & 2,65 & 1,78 & 1,13 & 0,29 & 3,67 & 0,42 \\ \text { TAB } & 6,4 & 1,20 & 0,25 & 3,17 & 2,65 & 1,78 & 1,13 & 0,29 & 3,67 & 0,34 \\ \text { TLA } & 6,6 & 1,20 & 0,34 & 3,09 & 2,56 & 1,67 & 1,03 & 0,27 & 3,56 & 0,50 \\ \text { TLB } & 6,6 & 1,20 & 0,34 & 3,09 & 2,56 & 1,67 & 1,03 & 0,27 & 3,56 & 0,67 \\ \text { TLC } & 6,6 & 1,20 & 0,28 & 3,09 & 2,56 & 1,67 & 1,03 & 0,27 & 3,56 & 0,47 \\ \text { TLD } & 5,6 & 1,20 & 0,14 & 3,09 & 2,56 & 1,67 & 1,03 & 0,27 & 3,56 & 0,27 \\ \text { TPA } & 5,3 & 1,13 & 0,15 & 3,10 & 2,67 & 1,47 & 1,23 & 0,28 & 3,45 & 0,14 \\ \text { VBA } & 6,4 & 1,57 & 0,45 & 5,01 & 3,38 & 3,06 & 1,39 & 0,16 & 1,42 & 0,58 \\ \text { VBB } & 6,5 & 0,84 & 0,19 & 2,02 & 1,59 & 1,70 & 0,97 & 0,12 & 1,20 & 0,49 \\ \text { WA } & 6,5 & 1,15 & 0,22 & 1,61 & 1,23 & 1,39 & 0,65 & 0,40 & 2,16 & 0,39 \\ \text { WB } & 6,5 & 1,15 & 0,22 & 1,61 & 1,23 & 1,39 & 0,65 & 0,40 & 2,16 & 0,34 \\ \text { WC } & 6,3 & 1,15 & 0,22 & 3,61 & 1,23 & 1,39 & 0,65 & 0,30 & 2,16 & 0,29\end{array}$

Pelos resultados apresentados, é possível tecer algumas considerações a respeito do manejo geral dos solos. Por exemplo, observando-se $\circ \mathrm{pH}$, nota-se valores relativamente altos, chegando-se mesmo a atingir quase a neutralidade, e o menor valor observado é 5,1. Isto pode indicar que a acidez não é um problema para a produção de cana-de-açúcar, já que este intervalo encontra-se dentro da faixa recomendada (ESPIRONELO \& OLIVEIRA, 1972; ORLANDO FILHO \& RODELLA, 1983; PENATTI et alii, 1988). Por outro lado, mostra também que o critério que vem sendo adotado para a calagem, recomendado pela copersucar (BENEDINI, 
1988), tem se mostrado eficiente na correção da acidez, e sem dúvida de forma muito mais econômica, pois o critério que emprega a saturação por bases, indicaria na maior parte destes dados, ainda necessidade de maior dose de corretivo.

Em relação a matéria orgânica, representada pela análise de $\mathrm{C}$, nota-se que os teores são de forma geral médios e baixos. Isto também ocorre com os teores de $\mathrm{P}$ e de K. Já os teores de $\mathrm{Ca}$ e $\mathrm{Mg}$ trocáveis, indicam que o suprimento destes elementos é médio e algumas vezes alto. A relação entre eles no entanto, merece alguma atenção, pois varia de menos de 1:1 a 4:1, estando a maior parte dos dados na faixa de 1,5:1. A literatura discute esta relação, recomendando a faixa de 3:1 como mais adequada para lavoura e em especial, para a cana-de-açúcar, mas ainda existem dúvidas a este respeito (BEAR, 1967; SANCHEZ \& CLEMENTS, 1974; GOLDEN, 1978; PEIXOTO et alii, 1981; MARINHO \& ALBUQUERQUE, 1981, 1983; RODRIGUES\& PALHARES, 1986; SOLERA, 1988). O teor de Al trocável das amostras revelouse de forma geral baixo, assim como de $\mathrm{H}+\mathrm{Al}$.

$\mathrm{Na}$ Tabela 4, estão expostos os parâmetros complementares aos resultados das análises de solo efetuadas. A soma de bases foi suprimida apenas para facilitar a visualização dos dados.

Tabela 4: Parâmetros calculados referentes às análises de solo dos blocos amostrados.

BLOCO CTC (meq/loog solo)

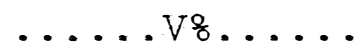

쑹

trocável potencial trocável potencial

$\begin{array}{llllll}\text { OID } & 4,46 & 8,01 & 67 & 82 & 2,7 \\ \text { OIE } & 4,46 & 8,01 & 67 & 82 & 2,7 \\ \text { OIE } & 5,19 & 9,87 & 72 & 85 & 2,3 \\ \text { OIG } & 4,56 & 8,11 & 68 & 82 & 2,6 \\ \text { OIH } & 4,44 & 8,11 & 70 & 84 & 3,6 \\ \text { OII } & 7,32 & 10,34 & 46 & 62 & 1,6\end{array}$


Tabela 4: Parâmetros calculados referentes às análises de solo dos blocos amostrados (continuação).

BLOCO CTC (meq/ $100 \mathrm{~g}$ solo)

......V8......

M요

trocável potencial trocável potencial

$\begin{array}{lrrrrl}\text { 01J } & 8,40 & 11,91 & 53 & 67 & 1,5 \\ \text { 01K } & 9,49 & 10,79 & 61 & 66 & 1,5 \\ \text { 01L } & 6,97 & 10,03 & 51 & 66 & 1,7 \\ \text { 01M } & 7,65 & 11,07 & 54 & 68 & 1,3 \\ \text { 01N } & 8,60 & 10,75 & 60 & 68 & 1,3 \\ \text { 010 } & 7,94 & 11,10 & 55 & 68 & 1,6 \\ \text { 01P } & 8,94 & 11,41 & 59 & 68 & 1,0 \\ \text { 02A } & 4,79 & 7,94 & 42 & 65 & 6,5 \\ \text { 02B } & 4,74 & 9,38 & 49 & 74 & 4,2 \\ \text { 02C } & 4,63 & 8,88 & 67 & 83 & 2,6 \\ \text { 02D } & 4,03 & 7,75 & 60 & 79 & 5,0 \\ \text { 02E } & 4,22 & 7,01 & 45 & 67 & 4,5 \\ \text { 02F } & 4,44 & 7,40 & 45 & 67 & 4,1 \\ \text { 03C } & 4,56 & 7,54 & 44 & 66 & 4,2 \\ \text { 03D } & 4,60 & 7,88 & 44 & 68 & 3,3 \\ \text { 03F } & 4,81 & 8,18 & 44 & 67 & 3,7 \\ \text { 05B } & 4,81 & 8,18 & 44 & 67 & 3,7 \\ \text { 06A } & 6,16 & 7,96 & 69 & 76 & 1,9 \\ \text { 06D } & 6,23 & 8,03 & 69 & 76 & 1,9 \\ \text { 06E } & 4,03 & 8,09 & 70 & 85 & 6,9 \\ \text { 08A } & 5,28 & 8,08 & 36 & 58 & 3,0 \\ \text { 08B } & 5,16 & 10,31 & 40 & 70 & 2,3 \\ \text { 08C } & 5,46 & 10,39 & 39 & 68 & 3,7 \\ \text { 08D } & 4,92 & 8,85 & 29 & 61 & 4,9 \\ \text { 08E } & 4,83 & 8,76 & 28 & 60 & 5,0 \\ \text { 08F } & 6,22 & 10,81 & 43 & 67 & 1,9 \\ \text { 08G } & 5,98 & 9,39 & 40 & 62 & 2,0 \\ \text { 08H } & 6,22 & 10,81 & 43 & 67 & 1,9 \\ \text { 08I } & 5,67 & 10,20 & 39 & 66 & 2,9 \\ \text { 08J } & 5,67 & 10,20 & 39 & 66 & 2,9\end{array}$


Tabela 4: Parâmetros calculados referentes às análises de solo dos biocos amostrados (continuação).

BLOCO CTC (meq/100g solo)

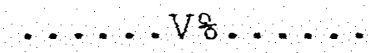

M8

trocável potencial trocável potencial

\begin{tabular}{|c|c|c|c|c|c|}
\hline $09 \mathrm{~A}$ & 5,79 & 10,32 & 39 & 66 & 3,1 \\
\hline $09 \mathrm{G}$ & 5,49 & 9,02 & 36 & 61 & 3,3 \\
\hline $10 B$ & 5,96 & 10,49 & 39 & 65 & 3,4 \\
\hline $10 \mathrm{C}$ & 4,44 & 7,40 & 45 & 67 & 4,1 \\
\hline $10 \mathrm{E}$ & 4,77 & 7,75 & 47 & 67 & 4,0 \\
\hline $10 F$ & 4,60 & 7,88 & 44 & 68 & 3,3 \\
\hline $10 G$ & 4,81 & 8,18 & 44 & 67 & 3,7 \\
\hline $10 I$ & 5,01 & 8,38 & 47 & 68 & 3,6 \\
\hline $10 \mathrm{~J}$ & 5,20 & 7,00 & 82 & 87 & 2,3 \\
\hline $10 \mathrm{~K}$ & 5,26 & 7,06 & 83 & 87 & 2,3 \\
\hline $10 L$ & 6,75 & 8,38 & 64 & 71 & 1,5 \\
\hline $10 \mathrm{M}$ & 6,19 & 7,54 & 66 & 72 & 5,5 \\
\hline $10 \mathrm{~N}$ & 6,07 & 7,50 & 67 & 74 & 5,3 \\
\hline 100 & 5,19 & 7,26 & 62 & 73 & 2,3 \\
\hline $11 \mathrm{~A}$ & 5,80 & 7,05 & 64 & 71 & 2,9 \\
\hline $11 \mathrm{~B}$ & 5,36 & 7,18 & 56 & 67 & 5,4 \\
\hline $12 \mathrm{~A}$ & 5,01 & 6,51 & 67 & 75 & 2,8 \\
\hline $12 \mathrm{~B}$ & 4,21 & 6,85 & 50 & 69 & 5,7 \\
\hline $12 \mathrm{C}$ & 4,44 & 6,51 & 58 & 71 & 4,3 \\
\hline $13 \mathrm{~F}$ & 4,71 & 6,78 & 60 & 72 & 4,0 \\
\hline $13 G$ & 4,61 & 6,68 & 59 & 72 & 4,1 \\
\hline $13 \mathrm{H}$ & 4,44 & 6,51 & 58 & 71 & 4,3 \\
\hline $13 \mathrm{~K}$ & 4,61 & 6,68 & 59 & 72 & 4,1 \\
\hline$A C A$ & 4,48 & 7,51 & 48 & 69 & 5,4 \\
\hline$A C B$ & 4,48 & 7,51 & 48 & 69 & 5,4 \\
\hline AEA & 4,69 & 5,24 & 72 & 75 & 4,3 \\
\hline $\mathrm{AEB}$ & 3,39 & 5,04 & 62 & 74 & 5,9 \\
\hline ANB & 4,08 & 6,64 & 58 & 74 & 10,8 \\
\hline ATA & 3,54 & 7,09 & 75 & 87 & 2,8 \\
\hline ATB & 3,54 & 7,09 & 75 & 87 & 2,8 \\
\hline
\end{tabular}


Tabela 4: Farâmetros calculados referentes às análises de solo dos blocos amostrados (continuação).

BLOCO

CTC (meq/100g solo)

M웅

trocável potencial trocável potencial

\begin{tabular}{|c|c|c|c|c|c|}
\hline $\mathrm{ATC}$ & 3,54 & 7,09 & 75 & 87 & 2,8 \\
\hline $\mathrm{BCA}$ & 5,43 & 10,18 & 58 & 78 & 7,4 \\
\hline $\mathrm{BCB}$ & 5,14 & 8,98 & 56 & 75 & 7,8 \\
\hline $\mathrm{BCC}$ & 5,54 & 10,29 & 59 & 78 & 7,2 \\
\hline $\mathrm{BCD}$ & 8,18 & 13,12 & 36 & 60 & 5,1 \\
\hline $\mathrm{BCE}$ & 8,18 & 13,12 & 36 & 60 & 9,8 \\
\hline $\mathrm{BCF}$ & 8,20 & 13,14 & 37 & 60 & 4,9 \\
\hline BGA & 7,33 & 11,88 & 41 & 63 & 5,6 \\
\hline BNA & 3,44 & 5,04 & 62 & 74 & 5,8 \\
\hline BNB & 3,54 & 7,09 & 75 & 87 & 2,8 \\
\hline$B S A$ & 6,19 & 8,49 & 68 & 77 & 3,2 \\
\hline$B S B$ & 5,18 & 8,34 & 73 & 83 & 3,1 \\
\hline BSC & 4,09 & 7,94 & 67 & 83 & 4,9 \\
\hline $\mathrm{CBB}$ & 4,57 & 8,10 & 68 & 82 & 4,6 \\
\hline $\mathrm{CBC}$ & 4,57 & 8,13 & 68 & 82 & 4,6 \\
\hline CMA & 4,46 & 7,90 & 67 & 81 & 4,5 \\
\hline CPA & 4,88 & 7,95 & 68 & 81 & 3,9 \\
\hline CPB & 4,63 & 6,70 & 67 & 77 & 4,1 \\
\hline$D M A$ & 4,38 & 7,41 & 47 & 68 & 5,5 \\
\hline DMB & 4,38 & 7,41 & 47 & 68 & 5,5 \\
\hline $\mathrm{DMC}$ & 4,38 & 7,41 & 47 & 68 & 5,5 \\
\hline DRA & 4,49 & 5,04 & 71 & 74 & 4,5 \\
\hline EGA & 4,83 & 7,36 & 67 & 79 & 4,1 \\
\hline EGB & 4,99 & 7,52 & 68 & 79 & 4,0 \\
\hline ERA & 5,10 & 7,17 & 67 & 77 & 4,5 \\
\hline ERB & 5,10 & 7,17 & 67 & 77 & 4,5 \\
\hline$E R C$ & 5,10 & 7,17 & 67 & 77 & 4,5 \\
\hline FRE & 5,10 & 7,17 & 67 & 77 & 4,5 \\
\hline ERF & 5,10 & 7,17 & 67 & 77 & 4,5 \\
\hline ERG & 5,10 & 7,17 & 67 & 77 & 4,5 \\
\hline
\end{tabular}


Tabela 4: Parâmetros calculados referentes às análises de solo dos blocos amostrados (continuação).

BLOCO

trocável potencial trocável potencial

\begin{tabular}{|c|c|c|c|c|c|}
\hline FSA & 7,38 & 10,18 & 52 & 65 & 1,8 \\
\hline ESB & 7,38 & 10,18 & 52 & 65 & 1,8 \\
\hline FSC & 3,54 & 4,43 & 74 & 79 & 7,9 \\
\hline GBA & 3,20 & 4,76 & 71 & 81 & 11,9 \\
\hline GBB & 6,51 & 7,24 & 44 & 50 & 3,7 \\
\hline GDA & 4,51 & 6,58 & 58 & 71 & 4,2 \\
\hline GDB & 4,51 & 6,58 & 58 & 71 & 4,2 \\
\hline GDC & 4,61 & 6,68 & 59 & 72 & 4,1 \\
\hline GIA & 4,96 & 6,72 & 60 & 71 & 4,0 \\
\hline $\mathrm{HBB}$ & 5,14 & 6,95 & 61 & 71 & 4,5 \\
\hline $\mathrm{HBC}$ & 5,14 & 6,95 & 61 & 71 & 4,5 \\
\hline HGA & 6,64 & 8,81 & 40 & 55 & 6,0 \\
\hline HGB & 4,38 & 6,61 & 53 & 69 & 4,7 \\
\hline HGC & 5,63 & 8,39 & 62 & 75 & 3,8 \\
\hline IGA & 6,28 & 8,25 & 60 & 69 & 4,0 \\
\hline IRA & 6,30 & 9,49 & 66 & 78 & 3,4 \\
\hline JLA & 8,42 & 11,70 & 58 & 70 & 4,2 \\
\hline JLB & 9,33 & 11,27 & 66 & 72 & 3,4 \\
\hline JMA & 6,22 & 8,85 & 43 & 60 & 5,7 \\
\hline JMB & 5,35 & 7,50 & 65 & 75 & 3,5 \\
\hline$J M C$ & 5,87 & 7,98 & 54 & 66 & 4,6 \\
\hline JSA & 6,37 & 7,88 & 58 & 66 & 4,2 \\
\hline JSB & 4,40 & 5,50 & 66 & 73 & 3,4 \\
\hline JSC & 5,26 & 7,87 & 54 & 70 & 4,6 \\
\hline JSD & 6,13 & 8,65 & 65 & 75 & 3,5 \\
\hline JSE & 3,86 & 6,33 & 78 & 87 & 2,2 \\
\hline JSG & 3,98 & 7,92 & 72 & 86 & 2,8 \\
\hline ISH & 4,97 & 8,98 & 54 & 75 & 4,6 \\
\hline IGA & 5,56 & 7,51 & 67 & 75 & 3,3 \\
\hline LGC & 5,31 & 6,92 & 67 & 75 & 3,3 \\
\hline
\end{tabular}


Tabela 4: Parâmetros calculados referentes às análises de solo dos blocos amostrados (continuação).

$\mathrm{BLOCO}$

$\mathrm{CTC}(\mathrm{meg} / 100 \mathrm{~g}$ solo)

$\mathrm{M} 8$

trocável potencial trocável potencial

\begin{tabular}{|c|c|c|c|c|c|}
\hline LZA & 5,67 & 9,13 & 68 & 80 & 3,2 \\
\hline LZB & 4,72 & 9,16 & 61 & 80 & 3,9 \\
\hline LZC & 8,06 & 10,92 & 68 & 76 & 3,2 \\
\hline LZD & 6,19 & 10,26 & 64 & 79 & 3,6 \\
\hline$M A A$ & 7,07 & 9,70 & 34 & 52 & 6,6 \\
\hline $\mathrm{MAB}$ & 6,08 & 8,86 & 46 & 63 & 5,4 \\
\hline MGA & 4,89 & 7,42 & 68 & 79 & 4,1 \\
\hline MIA & 5,16 & 8,27 & 68 & 80 & 3,7 \\
\hline MIB & 5,16 & 8,27 & 68 & 80 & 3,7 \\
\hline NRA & 4,11 & 5,43 & 57 & 68 & 4,9 \\
\hline NRB & 5,76 & 9,10 & 55 & 71 & 4,1 \\
\hline NRC & 6,82 & 9,10 & 68 & 76 & 2,9 \\
\hline$N Z A$ & 7,07 & 9,70 & 34 & 52 & 6,0 \\
\hline NZB & 6,08 & 8,86 & 46 & 63 & 4,9 \\
\hline $\mathrm{PDA}$ & 6,12 & 8,61 & 41 & 58 & 5,3 \\
\hline $\mathrm{PDB}$ & 4,08 & 6,16 & 62 & 75 & 3,4 \\
\hline $\mathrm{PDC}$ & 4,94 & 7,72 & 45 & 65 & 5,0 \\
\hline PLA & 5,74 & 8,69 & 46 & 65 & 4,8 \\
\hline PWA & 5,78 & 8,31 & 46 & 63 & 3,5 \\
\hline PXA & 3,10 & 6,34 & 52 & 77 & 3,9 \\
\hline $\mathrm{RCD}$ & 4,09 & 8,44 & 65 & 83 & 2,9 \\
\hline $\mathrm{RCE}$ & 5,09 & 9,11 & 72 & 84 & 2,4 \\
\hline RPA & 4,47 & 8,26 & 66 & 81 & 3,1 \\
\hline $\mathrm{RPB}$ & 4,69 & 8,16 & 67 & 81 & 3,0 \\
\hline RVA & 6,72 & 10,31 & 77 & 85 & 2,2 \\
\hline$S A A$ & 4,49 & 9,23 & 55 & 78 & 4,2 \\
\hline SEA & 5,52 & 9,01 & 37 & 62 & 3,6 \\
\hline SEB & 5,52 & 9,01 & 37 & 62 & 3,6 \\
\hline SFC & 5,00 & 8,06 & 53 & 71 & 2,8 \\
\hline SED & 5,00 & 8,06 & 53 & 71 & 2,8 \\
\hline
\end{tabular}


Tabela 4: Parâmetros calculados referentes às análises de solo dos blocos amostrados (continuação).

$\mathrm{BLOCO} \quad \mathrm{CTC}(\mathrm{meg} / \mathrm{loOg} \mathrm{solo})$

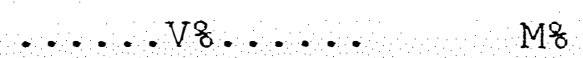

trocável potencial trocável potencial

\begin{tabular}{|c|c|c|c|c|c|}
\hline $\mathrm{SEE}$ & 6,16 & 9,16 & 41 & 60 & 4,5 \\
\hline$S E F$ & 6,16 & 9,16 & 41 & 60 & 4,5 \\
\hline SEG & 6,16 & 9,16 & 41 & 60 & 4,5 \\
\hline SGA & 6,72 & 9,63 & 44 & 61 & 2,5 \\
\hline$S J A$ & 6,57 & 9,21 & 42 & 58 & 2,7 \\
\hline SMA & 6,14 & 9,24 & 44 & 63 & 3,9 \\
\hline SMB & 6,14 & 9,24 & 44 & 63 & 3,9 \\
\hline SMD & 6,34 & 9,44 & 46 & 63 & 3,8 \\
\hline SME & 6,24 & 9,34 & 45 & 63 & 3,8 \\
\hline SPB & 6,41 & 9,48 & 44 & 62 & 4,1 \\
\hline STA & 6,38 & 9,74 & 44 & 63 & 3,8 \\
\hline TAA & 7,00 & 9,91 & 48 & 63 & 4,1 \\
\hline $\mathrm{TAB}$ & 6,92 & 9,83 & 47 & 63 & 4,2 \\
\hline TLA & 6,76 & 9,71 & 47 & 63 & 4,0 \\
\hline TLB & 6,93 & 9,88 & 49 & 64 & 3,9 \\
\hline TLC & 6,73 & 9,68 & 47 & 63 & 4,0 \\
\hline TLD & 6,53 & 9,48 & 45 & 62 & 4,1 \\
\hline TPA & 6,29 & 9,36 & 45 & 63 & 4,5 \\
\hline VBA & 6,45 & 10,39 & 78 & 86 & 2,5 \\
\hline VBB & 4,36 & 5,30 & 72 & 77 & 2,8 \\
\hline WA & 4,59 & 5,39 & 53 & 60 & 8,7 \\
\hline WB & 4,54 & 5,34 & 52 & 60 & 8,8 \\
\hline WC & 4,49 & 7,29 & 52 & 70 & 6,7 \\
\hline
\end{tabular}

Na anàlise dos parâmetros expostos na Tabela 4. pode-se notar que de forma geral, os solos tem uma saturação por bases média e alta, ou seja, epieutróficos, decorrente do manejo a que vem sendo submetidos. A CTC no entanto, revela valores na faixa média. 
Os resultados laboratoriais das análises tecnológicas, ou seja, a leitura do sacarimetro, brix do caldo, peso do bolo úmido e a massa específica, realizadas nos caldos utilizados neste trabalho, encontram-se no Apêndice.

A partir do mesmo caldo extraído para a análise de pagamento de cana, foram feitas as análises de nutrientes no caldo. Estes resultados laboratoriais que compreendem a leitura do fotômetro (K), a transmitância do colorimetro (P) e os volumes das determinações de Ca, $\mathrm{Mg}$ e N, também encontram-se descritos no Apêndice.

A apresentação dos dados laboratoriais visa principalmente a exposição da grandeza dos valores encontrados nas determinações de nutrientes no caldo, já que esta não é ainda, uma prática rotineira nos laboratórios, e poderá facilitar a comparação com outros estudos no futuro.

A partir dos resultados do Sistema PCTS, foram calculados os parâmetros de avaliação da cana-deaçúcar como matéria-prima industrial, em termos de porcentagem de oligossacarídeos (pol) da cana (PC), o teor de açúcar teoricamente recuperável em $\mathrm{kg} / \mathrm{t}$ de cana (ATR), a porcentagem de fibra da cana (FIBRA), e a porcentagem de sacarose em relação ao brix (PUREZA). Estes valores encontram-se na Tabela 5 .

Tabela 5: Parâmetros de qualidade da cana-de-açúcar como matéria-prima industrial.

$\begin{array}{lcccr}\text { BIOCO } & \text { PC } & \text { ATR } & \text { FIBRA } & \text { PUREZA } \\ \text { OID } & 13,12 & 100,98 & 8,93 & 82,56 \\ \text { O1E } & 12,90 & 98,59 & 9,57 & 82,47 \\ \text { O1F } & 12,90 & 98,59 & 9,57 & 82,47 \\ \text { O1G } & 12,90 & 98,59 & 9,57 & 82,47 \\ \text { O1H } & 11,55 & 81,99 & 14,16 & 80,42\end{array}$


Tabela 5: Parâmetros de qualidade da cana-de-açúcar como matéria-prima industrial (continuação) .

\begin{tabular}{lrrrr} 
BLOCO & PC & \multicolumn{1}{c}{ ATR } & FIBRA & PUREZA \\
\hline 01I & 11,59 & 78,06 & 9,57 & 74,10 \\
01J & 11,59 & 78,06 & 9,57 & 74,10 \\
01K & 11,36 & 81,58 & 11,88 & 80,21 \\
01I & 11,81 & 87,58 & 9,51 & 80,85 \\
01M & 13,12 & 100,98 & 8,93 & 82,56 \\
01N & 13,12 & 100,98 & 8,93 & 82,56 \\
010 & 11,81 & 87,58 & 9,51 & 80,85 \\
01P & 13,88 & 108,55 & 11,89 & 85,14 \\
02A & 14,27 & 108,69 & 14,14 & 83,63 \\
02B & 14,27 & 108,69 & 14,14 & 83,63 \\
02C & 14,27 & 108,69 & 14,14 & 83,63 \\
02D & 14,27 & 108,69 & 14,14 & 83,63 \\
02E & 14,47 & 108,92 & 11,64 & 81,12 \\
02F & 14,27 & 108,69 & 14,14 & 83,63 \\
03C & 15,04 & 115,59 & 13,12 & 83,24 \\
O3D & 13,05 & 99,21 & 11,85 & 83,21 \\
03F & 15,04 & 115,59 & 13,12 & 83,24 \\
05B & 15,04 & 115,59 & 13,12 & 83,24 \\
06A & 14,05 & 109,20 & 11,64 & 84,23 \\
06D & 14,05 & 109,20 & 11,64 & 84,23 \\
06E & 14,05 & 109,20 & 11,64 & 84,23 \\
08A & 15,00 & 119,77 & 13,50 & 87,14 \\
08B & 15,72 & 123,33 & 15,27 & 85,73 \\
08C & 15,00 & 119,77 & 13,50 & 87,14 \\
08D & 15,00 & 119,77 & 13,50 & 87,14 \\
08E & 16,10 & 129,27 & 15,27 & 87,78 \\
08E & 14,51 & 114,20 & 11,36 & 84,89 \\
08G & 16,10 & 129,27 & 15,27 & 87,78 \\
08H & 16,10 & 129,27 & 15,27 & 87,78 \\
08I & 14,73 & 110,36 & 15,77 & 82,59
\end{tabular}


Tabela 5: Resultado dos cálculos dos parâmetros de qualidade da cana-de-açúcar como matéria-prima industrial (continuação) .

\begin{tabular}{|c|c|c|c|c|}
\hline BLOCO & $\mathrm{PC}$ & ATR & FIBRA & PUREZA \\
\hline $08 \mathrm{~J}$ & 16,10 & 129,27 & 15,27 & 87,78 \\
\hline $09 A$ & 12,22 & 89,52 & 11,20 & 80,49 \\
\hline $09 G$ & 13,48 & 102,91 & 10,55 & 82,46 \\
\hline $10 \mathrm{~B}$ & 15,55 & 123,01 & 12,95 & 85,47 \\
\hline $10 \mathrm{C}$ & 13,68 & 109,65 & 15,41 & 90,22 \\
\hline $10 \mathrm{E}$ & 11,39 & 77,49 & 14,27 & 77,47 \\
\hline $10 F$ & 11,39 & 77,49 & 14,27 & 77,47 \\
\hline $10 G$ & 13,61 & 104,85 & 13,19 & 84,72 \\
\hline $10 I$ & 11,39 & 77,49 & 14,27 & 77,47 \\
\hline $10 \mathrm{~J}$ & 13,61 & 104,85 & 13,19 & 84,72 \\
\hline $10 \mathrm{~K}$ & 14,19 & 108,86 & 14,25 & 84,39 \\
\hline $10 \mathrm{~L}$ & 12,32 & 89,52 & 12,02 & 80,20 \\
\hline $10 \mathrm{M}$ & 12,32 & 89,52 & 12,02 & 80,20 \\
\hline $10 \mathrm{~N}$ & 12,32 & 89,52 & 12,02 & 80,20 \\
\hline 100 & 12,32 & 89,52 & 12,02 & 80,20 \\
\hline $11 \mathrm{~A}$ & 12,50 & 86,09 & 12,97 & 76,49 \\
\hline $11 B$ & 13,34 & 98,89 & 12,87 & 81,35 \\
\hline $12 \mathrm{~A}$ & 14,73 & 114,37 & 14,43 & 85,18 \\
\hline $12 \mathrm{~B}$ & 14,73 & 114,37 & 14,43 & 85,18 \\
\hline $12 \mathrm{C}$ & 14,73 & 114,37 & 14,43 & 85,18 \\
\hline $13 F$ & 14,51 & 111,75 & 11,72 & 83,07 \\
\hline $13 G$ & 14,51 & 111,75 & 11,72 & 83,07 \\
\hline $13 \mathrm{H}$ & 14,51 & 111,75 & 11,72 & 83,07 \\
\hline $13 \mathrm{~K}$ & 14,34 & 113,05 & 12,81 & 86,06 \\
\hline $\mathrm{ACA}$ & 15,21 & 124,02 & 13,73 & 89,29 \\
\hline $\mathrm{ACB}$ & 15,75 & 124,48 & 11,70 & 84,57 \\
\hline AEA & 15,16 & 120,94 & 12,32 & 86,28 \\
\hline$A E B$ & 15,16 & 120,94 & 12,32 & 86,28 \\
\hline ANB & 15,80 & 132,11 & 10,97 & 89,91 \\
\hline ATA & 16,53 & 131,67 & 14,03 & 86,00 \\
\hline
\end{tabular}


Tabela 5: Parâmetros de qualidade da cana-de-açúcar como matéria-prima industrial (continuação) •

\begin{tabular}{|c|c|c|c|c|}
\hline BLOCO & $\mathrm{PC}$ & ATR & EIBRA & PUREZA \\
\hline ATE & 16,53 & 131,67 & 14,03 & 86,00 \\
\hline ATC & 15,41 & 128,90 & 13,52 & 91,95 \\
\hline $\mathrm{BCA}$ & 12,19 & 87,08 & 12,78 & 79,43 \\
\hline $\mathrm{BCB}$ & 15,44 & 118,03 & 15,21 & 83,51 \\
\hline $\mathrm{BCC}$ & 13,31 & 99,33 & 10,77 & 80,79 \\
\hline$B C D$ & 12,19 & 87,08 & 12,78 & 79,43 \\
\hline $\mathrm{BCE}$ & 14,78 & 113,54 & 15,19 & 84,54 \\
\hline $\mathrm{BCE}$ & 14,92 & 117,76 & 13,10 & 85,84 \\
\hline$B G A$ & 14,26 & 111,62 & 9,72 & 83,64 \\
\hline BNA & 16,11 & 132,67 & 11,51 & 88,37 \\
\hline BNB & 16,11 & 132,67 & 11,51 & 88,37 \\
\hline$B S A$ & 13,80 & 101,28 & 16,70 & 82,16 \\
\hline$B S B$ & 13,11 & 90,27 & 17,39 & 78,11 \\
\hline $\mathrm{BSC}$ & 13,11 & 90,27 & 17,39 & 78,11 \\
\hline CBB & 14,86 & 114,35 & 15,28 & 84,64 \\
\hline $\mathrm{CBC}$ & 14,86 & 114,35 & 15,28 & 84,64 \\
\hline$C M A$ & 14,06 & 107,56 & 12,30 & 83,14 \\
\hline CPA & 13,31 & 102,60 & 11,57 & 84,13 \\
\hline $\mathrm{CPB}$ & 13,08 & 98,56 & 11,28 & 82,09 \\
\hline DMA & 13,16 & 100,71 & 12,96 & 84,38 \\
\hline DMB & 13,16 & 100,71 & 12,96 & 84,38 \\
\hline $\mathrm{DMC}$ & 13,16 & 100,71 & 12,96 & 84,38 \\
\hline DRA & 14,60 & 113,32 & 13,76 & 84,81 \\
\hline$E G A$ & 14,88 & 115,17 & 14,31 & 84,65 \\
\hline EGB & 14,88 & 115,17 & 14,31 & 84,65 \\
\hline$E R A$ & 15,45 & 129,77 & 13,72 & 92,54 \\
\hline ERB & 15,45 & 129,77 & 13,72 & 92,54 \\
\hline ERC & 15,45 & 129,77 & 13,72 & 92,54 \\
\hline FRE & 15,45 & 129,77 & 13,72 & 92,54 \\
\hline FRF & 15,45 & 129,77 & 13,72 & 92,54 \\
\hline
\end{tabular}


Tabela 5: Resultado dos cálculos dos parâmetros de qualidade da cana-de-açúcar como matéria-prima industrial (continuação).

\begin{tabular}{|c|c|c|c|c|}
\hline BLOCO & PC & ATR & EIBRA & PUREZA \\
\hline & - & -2 & & \\
\hline FRG & 15,45 & 129,77 & 13,72 & 92,54 \\
\hline ESA & 14,68 & 116,16 & 9,35 & 84,21 \\
\hline FSB & 14,68 & 116,16 & 9,35 & 84,21 \\
\hline ESC & 14,68 & 116,16 & 9,35 & 84,21 \\
\hline GBA & 14,48 & 114,59 & 13,60 & 86,73 \\
\hline GBB & 14,48 & 114,59 & 13,60 & 86,73 \\
\hline GDA & 13,65 & 100,77 & 14,37 & 81,51 \\
\hline GDB & 12,82 & 92,12 & 14,77 & 80,31 \\
\hline GDC & 12,28 & 89,96 & 14,57 & 82,46 \\
\hline GIA & 14,01 & 109,52 & 11,25 & 84,56 \\
\hline $\mathrm{HBB}$ & 12,47 & 93,38 & 12,23 & 82,69 \\
\hline $\mathrm{HBC}$ & 12,47 & 93,38 & 12,23 & 82,69 \\
\hline $\mathrm{HGA}$ & 16,32 & 134,78 & 12,01 & 88,82 \\
\hline HGB & 16,32 & 134,78 & 12,01 & 88,82 \\
\hline HGC & 16,32 & 134,78 & 12,01 & 88,82 \\
\hline IGA & 15,82 & 126,88 & 12,61 & 86,41 \\
\hline IRA & 13,91 & 103,77 & 13,93 & 81,96 \\
\hline JLA & 13,49 & 103,11 & 12,68 & 83,77 \\
\hline JLB & 13,15 & 99,78 & 11,32 & 82,68 \\
\hline JMA & 13,06 & 95,06 & 15,24 & 81,40 \\
\hline JMB & 13,06 & 95,06 & 15,24 & 81,40 \\
\hline JMC & 13,59 & 102,02 & 14,89 & 83,33 \\
\hline JSA & 13,70 & 104,82 & 13,12 & 83,95 \\
\hline JSB & 14,13 & 110,56 & 10,99 & 84,43 \\
\hline JSC & 14,97 & 117,99 & 10,54 & 84,26 \\
\hline JSD & 13,67 & 106,00 & 11,20 & 84,06 \\
\hline JSE & 12,85 & 95,56 & 9,87 & 80,42 \\
\hline JSG & 13,19 & 98,48 & 11,02 & 81,11 \\
\hline JSH & 14,05 & 109,70 & 10,23 & 83,91 \\
\hline LGA & 12,54 & 93,33 & 12,95 & 82,5 \\
\hline
\end{tabular}


Tabela 5: Parâmetros de qualidade da cana-de-açúcar como matéria-prima industrial (continuação).

\begin{tabular}{lrrrr} 
BLOCO & PC & ATR & FIBRA & PUREZA \\
\hline LGC & 14,42 & 114,35 & 11,84 & 86,02 \\
LZA & 14,23 & 109,20 & 13,62 & 84,04 \\
LZB & 8,04 & 18,73 & 11,63 & 48,42 \\
LZC & 11,55 & 81,99 & 14,16 & 80,42 \\
LZD & 11,59 & 78,06 & 9,57 & 74,10 \\
MAA & 11,55 & 82,63 & 8,09 & 77,50 \\
MAB & 11,55 & 82,63 & 8,09 & 77,50 \\
MGA & 15,22 & 120,14 & 12,91 & 85,51 \\
MIA & 15,41 & 128,90 & 13,52 & 91,95 \\
MIB & 16,53 & 131,67 & 14,03 & 86,00 \\
NRA & 15,61 & 125,95 & 13,90 & 87,93 \\
NRB & 13,51 & 107,70 & 11,04 & 86,87 \\
NRC & 13,43 & 102,42 & 12,05 & 83,28 \\
NZA & 14,55 & 112,11 & 12,69 & 83,60 \\
NZB & 14,55 & 112,11 & 12,69 & 83,60 \\
PDA & 14,49 & 114,01 & 12,48 & 85,50 \\
PDB & 14,49 & 114,01 & 12,48 & 85,50 \\
PDC & 14,49 & 114,01 & 12,48 & 85,50 \\
PLA & 14,91 & 114,78 & 13,98 & 83,92 \\
PWA & 14,78 & 111,99 & 14,09 & 82,68 \\
PXA & 14,86 & 116,51 & 13,31 & 85,34 \\
RCD & 14,10 & 102,91 & 12,18 & 79,11 \\
RCE & 14,22 & 110,59 & 11,86 & 84,32 \\
RPA & 14,06 & 109,83 & 10,76 & 84,20 \\
RPB & 14,06 & 109,83 & 10,76 & 84,20 \\
RVA & 15,94 & 128,19 & 13,27 & 86,95 \\
SAA & 15,14 & 119,63 & 12,03 & 85,17 \\
SEA & 15,46 & 121,67 & 15,20 & 86,26 \\
SFB & 14,78 & 113,95 & 14,50 & 84,43 \\
SFC & 14,78 & 113,95 & 14,50 & 84,43
\end{tabular}


Tabela 5: Parâmetros de qualidade da cana-de-açúcar como matéria-prima industrial (continuação).

\begin{tabular}{|c|c|c|c|c|}
\hline BLOCO & $\mathrm{PC}$ & ATR & EIBRA & PUREZA \\
\hline & --- & --- & ---- & ---- \\
\hline SFD & 14,30 & 106,16 & 18,81 & 83,81 \\
\hline SEE & 14,78 & 113,95 & 14,50 & 84,43 \\
\hline SFE & 15,90 & 126,28 & 13,76 & 85,99 \\
\hline $\mathrm{SEG}$ & 14,73 & 116,32 & 11,88 & 85,30 \\
\hline SGA & 13,13 & 100,25 & 12,22 & 83,78 \\
\hline SJA & 12,85 & 88,77 & 21,88 & 81,19 \\
\hline SMA & 14,57 & 114,29 & 12,48 & 85,15 \\
\hline SMB & 14,57 & 114,29 & 12,48 & 85,15 \\
\hline SMD & 12,94 & 98,49 & 12,07 & 83,60 \\
\hline SME & 13,62 & 105,17 & 10,20 & 83,22 \\
\hline SPB & 14,56 & 112,56 & 13,79 & 84,55 \\
\hline STA & 15,82 & 126,88 & 12,61 & 86,41 \\
\hline TAA & 13,38 & 102,38 & 11,51 & 83,33 \\
\hline $\mathrm{TAB}$ & 12,89 & 97,74 & 11,18 & 82,78 \\
\hline TLA & 13,70 & 104,92 & 12,60 & 83,72 \\
\hline TLB & 13,70 & 104,92 & 12,60 & 83,72 \\
\hline TLC & 13,70 & 104,92 & 12,60 & 83,72 \\
\hline TLD & 13,30 & 99,89 & 12,63 & 82,39 \\
\hline TPA & 14,27 & 108,69 & 14,14 & 83,63 \\
\hline VBA & 12,04 & 87,27 & 12,30 & 80,47 \\
\hline VBB & 12,04 & 87,27 & 12,30 & 80,47 \\
\hline WA & 12,78 & 93,84 & 11,79 & 80,46 \\
\hline WB & 13,75 & 105,72 & 11,86 & 83,61 \\
\hline WC & 15,76 & 126,46 & 14,05 & 87,31 \\
\hline
\end{tabular}

Estes parâmetros tecnológicos apresentam naturalmente variações importantes devido à variedade e à época de colheita (DILLEWIJN, 1952; HUMBERT, 1968; COPERSUCAR， 1980; EERNANDES， 1981， 1982; BEAUCLAIR \& PENTEADO, 1984; PARANHOS, 1987). 
A partir dos resultados das análises de nutrientes no caldo efetuadas, foram calculados os teores de nutrientes no caldo, em função das aliquotas utilizadas nas determinações analíticas descritas anteriormente. os resultados estão expostos na Tabela 6 .

Tabela 6: Resultado da análise de nutrientes presentes no caldo.

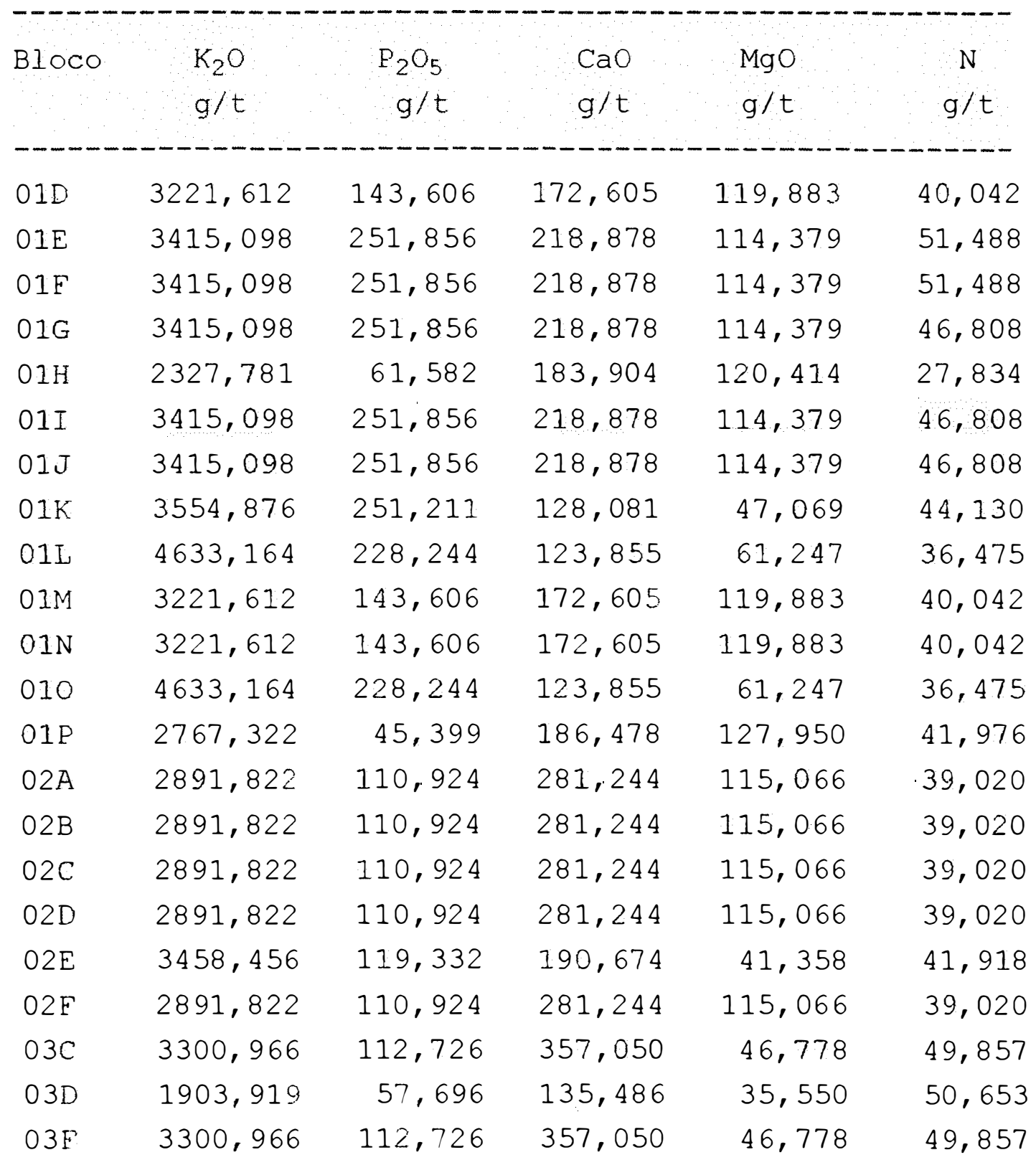


Tabela 6: Resultado da análise de nutrientes presentes no caldo (continuação).

\begin{tabular}{|c|c|c|c|c|c|}
\hline Bloco & $\begin{array}{l}\mathrm{K}_{2} \mathrm{O} \\
\mathrm{g} / \mathrm{t}\end{array}$ & $\begin{array}{l}\mathrm{P}_{2} \mathrm{O}_{5} \\
\mathrm{~g} / \mathrm{t}\end{array}$ & $\begin{array}{l}\mathrm{CaO} \\
\mathrm{g} / \mathrm{t}\end{array}$ & $\begin{array}{l}\mathrm{MgO} \\
g / t\end{array}$ & $\begin{array}{c}N \\
g / t\end{array}$ \\
\hline $05 B$ & 3300,966 & 112,726 & 357,050 & 46,778 & 49,857 \\
\hline 06A & 2523,181 & 89,649 & 182,098 & 69,633 & 34,074 \\
\hline $06 \mathrm{D}$ & 2523,181 & 89,649 & 182,098 & 69,633 & 34,074 \\
\hline $06 \mathrm{E}$ & 2523,181 & 89,649 & 182,098 & 69,633 & 34,074 \\
\hline O8A & 3332,666 & 85,621 & 126,414 & 63,399 & 17,162 \\
\hline $08 \mathrm{~B}$ & 3344,049 & 26,188 & 200,527 & 49,820 & 29,072 \\
\hline O8C & 3332,666 & 85,621 & 126,414 & 63,399 & 17,162 \\
\hline O8D & 3332,666 & 85,621 & 126,414 & 63,399 & 17,162 \\
\hline O8E & 3344,049 & 26,188 & 200,527 & 49,820 & 29,072 \\
\hline O8F & 3696,214 & 166,397 & 89,341 & 44,736 & 27,868 \\
\hline $08 G$ & 3344,049 & 26,188 & 200,527 & 49,820 & 29,072 \\
\hline $\mathrm{OBH}$ & 3344,049 & 26,188 & 200,527 & 49,820 & 29,072 \\
\hline $08 I$ & 2999,301 & 98,536 & 357,802 & 140,813 & 46,655 \\
\hline $08 \mathrm{~J}$ & 3344,049 & 26,188 & 200,527 & 49,820 & 29,072 \\
\hline O9A & 3186,102 & 72,563 & 133,168 & 57,205 & 67,855 \\
\hline $09 G$ & 1887,881 & 210,565 & 129,737 & 45,334 & 44,955 \\
\hline $10 B$ & 1889,981 & 747,840 & 306,405 & 81,511 & 21,639 \\
\hline $10 C$ & 3419,271 & 91,440 & 175,921 & 70,091 & 45,854 \\
\hline 1OE & 1648,895 & 213,235 & 223,820 & 100,160 & 37,744 \\
\hline $10 \mathrm{~F}$ & 1648,895 & 213,235 & 223,820 & 100,160 & 37,744 \\
\hline $10 G$ & 1903,574 & 88,218 & 276,028 & 124,762 & 27,942 \\
\hline $10 I$ & 1648,895 & 213,235 & 223,820 & 100,160 & 37,744 \\
\hline $10 \mathrm{~J}$ & 1903,574 & 88,218 & 276,028 & 124,762 & 27,942 \\
\hline $10 K$ & 3891,588 & 11,462 & 221,563 & 102,328 & 39,011 \\
\hline 101 & 3042,844 & 62,931 & 129,895 & 64,487 & 67,126 \\
\hline $10 \mathrm{M}$ & 3042,844 & 62,931 & 129,895 & 64,487 & 67,126 \\
\hline $10 N$ & 3042,844 & 62,931 & 129,895 & 64,487 & 67,126 \\
\hline 100 & 3042,844 & 62,931 & 129,895 & 64,487 & 67,126 \\
\hline $11 \mathrm{~A}$ & 1665,713 & 163,712 & 198,454 & 103,564 & 58,195 \\
\hline I. $\mathrm{B}$ & 2439,969 & 61,968 & 309,335 & 94,602 & 17,365 \\
\hline
\end{tabular}


Tabela 6: Resultado da análise de nutrientes presentes no caldo (continuação) .

\begin{tabular}{lrrrrc} 
BlOco & $\mathrm{K} \mathrm{O}^{\mathrm{O}}$ & \multicolumn{1}{c}{$\mathrm{P}_{2} \mathrm{O}_{5}$} & $\mathrm{CaO}$ & $\mathrm{MgO}$ & $\mathrm{N}$ \\
& $\mathrm{kg} / \mathrm{t}$ & $\mathrm{g} / \mathrm{t}$ & $\mathrm{g} / \mathrm{t}$ & $\mathrm{g} / \mathrm{t}$ & $\mathrm{g} / \mathrm{t}$ \\
12A & 3668,884 & 122,257 & 138,175 & 36,695 & 45,943 \\
12B & 3668,884 & 122,257 & 138,175 & 36,695 & 45,943 \\
12C & 3668,884 & 122,257 & 138,175 & 36,695 & 45,943 \\
13F & 3269,591 & 180,534 & 125,403 & 37,922 & 51,436 \\
13G & 3269,591 & 180,534 & 125,403 & 37,922 & 51,436 \\
13H & 3269,591 & 180,534 & 125,403 & 37,922 & 51,436 \\
13K & 3906,687 & 25,581 & 198,555 & 98,436 & 47,028 \\
ACA & 3287,363 & 221,736 & 219,207 & 97,780 & 54,144 \\
ACB & 3493,048 & 43,309 & 289,603 & 101,478 & 47,238 \\
AEA & 3336,853 & 237,013 & 194,353 & 56,438 & 47,108 \\
AEB & 3336,853 & 237,013 & 194,353 & 56,438 & 47,108 \\
ANB & 3929,154 & 3,686 & 220,689 & 108,828 & 63,291 \\
ATA & 3307,170 & 85,106 & 343,993 & 80,643 & 51,742 \\
ATB & 3307,170 & 85,106 & 343,993 & 80,643 & 51,742 \\
ATC & 3290,720 & 161,300 & 282,055 & 113,566 & 46,593 \\
BCA & 3393,031 & 3,644 & 218,157 & 105,623 & 32,692 \\
BCB & 2814,304 & 3,481 & 214,494 & 94,666 & 38,228 \\
BCC & 2702,472 & 99,945 & 121,871 & 51,832 & 33,319 \\
BCD & 3393,031 & 3,644 & 218,157 & 105,623 & 32,692 \\
BCE & 1843,389 & 3,498 & 214,717 & 85,136 & 20,565 \\
BCF & 1995,285 & 98,522 & 210,661 & 54,016 & 21,681 \\
BGA & 3609,175 & 67,789 & 197,329 & 91,952 & 80,073 \\
BNA & 3015,752 & 525,679 & 107,914 & 53,565 & 53,084 \\
BNB & 3015,752 & 525,679 & 107,914 & 53,565 & 53,084 \\
BSA & 3507,345 & 106,603 & 388,950 & 102,874 & 43,136 \\
BSB & 4004,623 & 32,725 & 264,951 & 177,041 & 44,332 \\
BSC & 4004,623 & 32,725 & 264,951 & 177,041 & 44,332 \\
CBB & 3205,584 & 27,082 & 104,128 & 50,627 & 25,936 \\
CBC & 3205,584 & 27,082 & 104,128 & 50,627 & 25,936 \\
CMA & 1603,076 & 179,738 & 213,247 & 114,565 & 34,327
\end{tabular}


Tabela 6: Resultado da análise de nutrientes presentes no cald• (continuação) .

\begin{tabular}{|c|c|c|c|c|c|}
\hline Bloco & $\begin{array}{r}\mathrm{K}_{2} \mathrm{O} \\
\mathrm{kg} / \mathrm{t}\end{array}$ & $\begin{array}{l}\mathrm{P}_{2} \mathrm{O}_{5} \\
\mathrm{~g} / \mathrm{t}\end{array}$ & $\begin{array}{l}\mathrm{CaO} \\
\mathrm{g} / \mathrm{t}\end{array}$ & $\begin{array}{l}\mathrm{MgO} \\
\mathrm{g} / \mathrm{t}\end{array}$ & $\begin{array}{c}N \\
g / t\end{array}$ \\
\hline & & & & - & ---1 \\
\hline $\mathrm{CPA}$ & 3211,969 & 52,615 & 109,064 & 109,592 & 53,079 \\
\hline $\mathrm{CPB}$ & 2702,686 & 99,584 & 109,380 & 54,293 & 26,902 \\
\hline DMA & 3390,786 & 80,604 & 350,178 & 140,331 & 28,644 \\
\hline DMB & 3390,786 & 80,604 & 350,178 & 140,331 & 28,644 \\
\hline DMC & 3390,786 & 80,604 & 350,178 & 140,331 & 28,644 \\
\hline DRA & 3768,824 & 59,339 & 331,531 & 146,170 & 46,904 \\
\hline $\mathrm{EGA}$ & 3397,988 & 24,190 & 278,178 & 116,435 & 37,200 \\
\hline EGB & 3397,988 & 24,190 & 278,178 & 116,435 & 37,200 \\
\hline FRA & 3282,642 & 60,031 & 285,031 & 109,480 & 50,367 \\
\hline FRB & 3282,642 & 60,031 & 285,031 & 109,480 & 50,367 \\
\hline FRC & 3282,642 & 60,031 & 285,031 & 109,480 & 50,367 \\
\hline FRE & 3282,642 & 60,031 & 285,031 & 109,480 & 50,367 \\
\hline FRF & 3282,642 & 60,031 & 285,031 & 109,480 & 50,367 \\
\hline FRG & 3282,642 & 60,031 & 285,031 & 109,480 & 50,367 \\
\hline FSA & 3051,004 & 130,040 & 139,434 & 59,219 & 41,887 \\
\hline FSB & 3051,004 & 130,040 & 139,434 & 59,219 & 41,887 \\
\hline FSC & 3051,004 & 130,040 & 139,434 & 59,219 & 41,887 \\
\hline GBA & 4066,034 & 25,328 & 195,693 & 98,103 & 63,192 \\
\hline GBB & 4066,034 & 25,328 & 195,693 & 98,103 & 63,192 \\
\hline GDA & 2246,980 & 43,921 & 193,740 & 78,080 & 21,402 \\
\hline GDB & 3013,212 & 95,366 & 129,603 & 58,968 & 46,044 \\
\hline GDC & 1684,328 & 105,119 & 218,278 & 87,541 & 50,269 \\
\hline GIA & 2735,379 & 118,065 & 126,659 & 71,980 & 99,335 \\
\hline $\mathrm{HBB}$ & 3029,162 & 36,927 & 286,149 & 115,669 & 67,043 \\
\hline$B C$ & 3029,162 & 36,927 & 286,149 & 115,669 & 67,043 \\
\hline HGA & 3151,534 & 34,778 & 209,814 & 99,263 & 38,139 \\
\hline HGB & 3151,534 & 34,778 & 209,814 & 99,263 & 38,139 \\
\hline HGC & 3151,534 & 34,778 & 209,814 & 99,263 & 38,139 \\
\hline IGA & 3463,798 & 95,980 & 388,680 & 166,191 & 57,357 \\
\hline RA & 3889,767 & 3,563 & 187,464 & 83,530 & 52,367 \\
\hline
\end{tabular}


Tabela 6: Resultado da análise de nutrientes presentes no caldo (continuação) .

\begin{tabular}{|c|c|c|c|c|c|}
\hline Bloco & $\begin{array}{r}\mathrm{K}_{2} \mathrm{O} \\
\mathrm{kg} / \mathrm{t}\end{array}$ & $\begin{array}{l}\mathrm{P}_{2} \mathrm{O}_{5} \\
\mathrm{~g} / \mathrm{t}\end{array}$ & $\begin{array}{l}\mathrm{CaO} \\
g / t\end{array}$ & $\begin{array}{l}\mathrm{MgO} \\
g / t\end{array}$ & $\begin{array}{c}N \\
g / t\end{array}$ \\
\hline JLA & 3281,766 & 43,300 & 148,416 & 72,192 & 73,655 \\
\hline JLB & 3100,556 & 129,831 & 113,977 & 85,383 & 96,129 \\
\hline JMA & 3383,297 & 283,063 & 273,447 & 182,718 & 45,754 \\
\hline $\mathrm{JMB}$ & 3383,297 & 283,063 & 273,447 & 182,718 & 45,754 \\
\hline JMC & 3531,813 & 317,933 & 189,351 & 111,234 & 55,184 \\
\hline JSA & 2180,240 & 169,398 & 126,653 & 89,174 & 18,435 \\
\hline JSB & 2981,420 & 200,572 & 126,044 & 85,397 & 53,796 \\
\hline JSC & 3252,466 & 90,392 & 102,932 & 87,432 & 26,913 \\
\hline JSD & 2970,491 & 221,959 & 134,342 & 77,429 & 34,327 \\
\hline JSE & 3904,531 & 143,942 & 141,394 & 82,816 & 29,686 \\
\hline JSG & 3206,772 & 235,638 & 139,279 & 75,609 & 38,989 \\
\hline JSH & 4367,373 & 248,613 & 76,696 & 46,766 & 25,990 \\
\hline LGA & 3334,317 & 28,211 & 103,912 & 56,644 & 48,968 \\
\hline LGC & 3650,756 & 45,323 & 98,129 & 60,921 & 51,534 \\
\hline LZA & 3953,992 & 2,603 & 126,387 & 49,300 & 20,480 \\
\hline LZB & 893,848 & 127,151 & 93,264 & 49,771 & 13,570 \\
\hline LZC & 2327,781 & 61,582 & 183,904 & 120,414 & 27,834 \\
\hline LZD & 3415,098 & 251,856 & 218,878 & 114,379 & 46,808 \\
\hline MAA & 3694,769 & 47,808 & 101,573 & 68,406 & 54,359 \\
\hline $\mathrm{MAB}$ & 3694,769 & 47,808 & 101,573 & 68,406 & 54,359 \\
\hline MGA & 2524,350 & 283,223 & 286,418 & 90,712 & 26,140 \\
\hline MIA & 3290,720 & 161,300 & 282,055 & 113,566 & 46,593 \\
\hline MIB & 3307,170 & 85,106 & 343,993 & 80,643 & 51,742 \\
\hline NRA & 3259,388 & 120,039 & 190,399 & 112,485 & 31,316 \\
\hline NRB & 3716,466 & 117,980 & 370,670 & 137,039 & 55,209 \\
\hline NRC & 2586,304 & 26,723 & 172,491 & 28,181 & 41,925 \\
\hline$N Z A$ & 3076,047 & 205,160 & 378,193 & 180,307 & 37,991 \\
\hline NZB & 3076,047 & 205,160 & 378,193 & 180,307 & 37,991 \\
\hline PDA & 3007,856 & 19,880 & 177,287 & 25,327 & 55,018 \\
\hline $\mathrm{PDB}$ & 3007,856 & 19,880 & 177,287 & 25,327 & 55,018 \\
\hline
\end{tabular}


Tabela 6: Resultado da análise de nutrientes presentes no caldo (continuação).

\begin{tabular}{|c|c|c|c|c|c|}
\hline \multirow[t]{2}{*}{ Bloco } & $\mathrm{K}_{2} \mathrm{O}$ & $\mathrm{P}_{2} \mathrm{O}_{5}$ & $\mathrm{CaO}$ & $\mathrm{MgO}$ & $N$ \\
\hline & $\mathrm{kg} / \mathrm{t}$ & $g / t$ & $g / t$ & $g / t$ & $g / t$ \\
\hline PDC & 3007,856 & 19,880 & 177,287 & 25,327 & 55,018 \\
\hline PLA & 3561,659 & 101,731 & 294,161 & 97,123 & 64,755 \\
\hline PWA & 3402,372 & 305,625 & 155,236 & 66,530 & 52,585 \\
\hline PXA & 2999,301 & 211,514 & 377,982 & 112,869 & 18,850 \\
\hline $\mathrm{RCD}$ & 3328,763 & 87,674 & 289,859 & 66,202 & 26,932 \\
\hline $\mathrm{RCE}$ & 2957,897 & 248,042 & 224,522 & 95,569 & $29,42.6$ \\
\hline RPA & 2400,092 & 92,447 & 112,469 & 83,655 & 59,118 \\
\hline $\mathrm{RPB}$ & 2400,092 & 92,447 & 112,469 & 83,655 & 59,118 \\
\hline RVA & 3805,227 & 110,540 & 195,844 & 122,003 & 46,938 \\
\hline$S A A$ & 3095,916 & 113,491 & 380,636 & 112,526 & 47,233 \\
\hline SFA & 1942,761 & 177,164 & 304,305 & 151,778 & 73,975 \\
\hline$S F B$ & 3810,397 & 26,555 & 305,007 & 107,352 & 51,316 \\
\hline SEC & 3810,397 & 26,555 & 305,007 & 107,352 & 51,316 \\
\hline SFD & 3694,680 & 2,603 & 249,597 & 79,570 & 24,309 \\
\hline SEE & 3810,397 & 26,555 & 305,007 & 107,352 & 51,316 \\
\hline SEF & 3769,353 & 85,689 & 282,409 & 114,181 & 64,161 \\
\hline SEG & 2808,902 & 126,221 & 123,451 & 52,254 & 58,726 \\
\hline SGA & 3657,476 & 45,346 & 134,878 & 35,391 & 47,593 \\
\hline SJA & 2313,745 & 177,462 & 95,400 & 43,888 & 24,462 \\
\hline SMA & 1680,956 & 95,770 & 218,915 & 88,890 & $38,1.42$ \\
\hline $\mathrm{SMB}$ & 1680,956 & 95,770 & 218,915 & 88,890 & 38,142 \\
\hline $\mathrm{SMD}$ & 2534,395 & 109,993 & 80,974 & 27,605 & 28,978 \\
\hline SME & 3156,241 & 32,440 & 72,168 & 30,795 & 50,352 \\
\hline SPB & 4139,440 & 44,148 & 366,253 & 112,939 & 49,645 \\
\hline STA & 3463,798 & 95,980 & 388,680 & 166,191 & 57,357 \\
\hline TAA & 4175,082 & 45,662 & 135,820 & 34,978 & 51,348 \\
\hline $\mathrm{TAB}$ & 1550,437 & 3,711 & 175,718 & 54,455 & 35,020 \\
\hline TLA & 2791,302 & 194,931 & 194,808 & 56,570 & 21,923 \\
\hline TLB & 2791,302 & 194,931 & 194,808 & 56,570 & 21,923 \\
\hline TLC & 2791,302 & 194,931 & 194,808 & 56,570 & 21,923 \\
\hline
\end{tabular}


Tabela 6: Resultado da análise de nutrientes presentes no caldo (continuação) .

\begin{tabular}{lcrccc} 
Bloco & $\mathrm{K}_{2} \mathrm{O}$ & $\mathrm{P}_{2} \mathrm{O}_{5}$ & $\mathrm{CaO}$ & $\mathrm{MgO}$ & $\mathrm{N}$ \\
& $\mathrm{kg} / \mathrm{t}$ & $\mathrm{g} / \mathrm{t}$ & $\mathrm{g} / \mathrm{t}$ & $\mathrm{g} / \mathrm{t}$ & $\mathrm{g} / \mathrm{t}$ \\
\hline & & & & & \\
TLD & 3234,072 & 83,403 & 119,327 & 50,750 & 51,185 \\
TPA & 2891,822 & 110,924 & 281,244 & 115,066 & 39,020 \\
VBA & 2424,516 & 217,121 & 292,494 & 105,776 & 55,661 \\
VBB & 2424,516 & 217,121 & 292,494 & 105,776 & 55,661 \\
WA & 3172,391 & 36,981 & 108,730 & 53,970 & 30,725 \\
WB & 2568,476 & 262,070 & 86,310 & 50,501 & 21,545 \\
WC & 1865,119 & 122,395 & 128,576 & 43,703 & 49,828
\end{tabular}

Uma análise inicial destes dados mostra uma grande variabilidade nos teores de $\mathrm{P}$ absorvido presentes no caldo, contribuindo para aumentar as discussões existentes sobre a absorção e presença deste elemento (MEADE, 1963; SERRA, 1973; ORLANDO \& HAAG, 1976; CESAR et alii, 1987). Observa-se ainda que a ordem de grandeza dos teores de $K$ absorvido presentes no caldo é muito maior que dos demais nutrientes, indicando ser este o nutriente mais exportado no caldo da cana. Esta informação é compatível com dados apresentados na literatura que indicam ser $\circ \mathrm{K}$ ○ nutriente mais exportado pela cana inteira (ORLANDO FILHO et alii, 1980; SAMPAIO \& SAICEDO, 1991). De forma geral, é difícil a comparação com outras referências da literatura, pois não esta incluída a exportação de nutrientes nas demais partes da planta, mas encontra-se perfeitamente dentro dos limites citados (SIIVA \& CASAGRANDE, 1983).

\subsection{Resultados das análises estatisticas}

A partir dos dados expostos nas Tabelas 1 a 6, foi possível obter-se as equações referentes aos modelos de regressão linear múltipla, que expressam as análises das 
relações existentes entre as diferentes variáveis. Todas equações encontradas são estatisticamente significativas pelo teste $F$, ao nivel de 108 de probabilidade de erro. 0 nivel de significância estatistica dos coeficientes de determinação $\left(r^{2}\right)$ é dados pelos asteristicos adjacentes aos valores observados.

$\mathrm{Na}$ avaliação das relações existentes entre a produtividade agrícola e os diversos fatores, obteve-se o número de cortes como a variável mais importante a ser selecionada. Entretanto, a idade não foi incluída como estatisticamente significativa (10\%) na variação da produtividade. Isto indica que durante a safra, o desenvolvimento da cana é de pouca importância, como já indicam trabalhos com crescimento da cana-de-açúcar (RODRIGUES et alii, 1983; MAIA \& BEAUCLAIR, 1986). Em todas as análises pelo método "forward" em que estudou-se a influência da variável EST, ela foi incluída com um coeficiente de determinação $\left(r^{2}\right)$ de 0,4990, ou seja, quase metade da variação dos valores de produtividade podem ser explicados pelo número de cortes efetuados, com probabilidade de erro inferior à $1 \%$, que foi o nível de significância encontrado. A equação relacionando a produtividade e o estágio é a seguinte:

\section{PdtV $=148,01-25,96$ EST $r^{2}=0,499$}

Por esta equação pode-se inclusive calcular - rendimento médio dos diferentes cortes na lavoura da Usina Santa Adélia, que tem uma redução média de aproximadamente 26 t/ha de cana após cada corte.

Como não se pretende confirmar aqui que a produtividade tende a variar fortemente em função do número de cortes, fato já extensivamente conhecido (HUMBERT, 1968; PARANHOS, 1987), foram eliminadas de todas as análises 
subsequientes 0 efeito do corte. A idade também foì eliminada, mas devido a sua não significância estatística.

o efeito da data de corte sobre o rendimento de açucar também foi descartado por não ser interesse deste trabalho elaborar curvas de maturação. Em uma análise preliminar, o efeito desta variável sobre a maturação foi superior a $60 \%\left(\mathrm{r}^{2}=0,605\right)$. Como o modelo utilizado é linear, distorções seriam inevitáveis, contribuindo para a decisão de sua eliminação do rol das variáveis a serem testadas.

4.2.1. Influência dos nutrientes absorvidos sobre a produtividade.

Testando a relação entre os nutrientes absorvidos e suas relações com a produtividade, obteve-se o seguinte resultado:

\section{Pdtv $=92,6348-0,0977 . \mathrm{MGAB}+21,4669 . \mathrm{PCM}$ $r^{2}=0,172$ \\ (2)}

Este resultado mostra a importância da relação do $\mathrm{F}$ com a soma de Ca e Mg. O teor de Mg absorvido tem parâmetro negativo. isto não significa necessariamente que este nutriente exerça influência negativa sobre a produtividade, pois pode estar sendo usado como ajuste, já que esta indiretamente incluído na variável PCM. Por outro lado, pode ser consequiência das baixas relações encontradas no solo entre $\mathrm{Ca}$ e $\mathrm{Mg}$, e este seria um indicio de que esta ocorrendo um excedente de Mg no solo, com absorção excessiva deste elemento. 
4.2.2. Influência dos nutrientes absorvidos, dos parametros do solo e dos fertilizantes aplicados sobre a produtividade.

Apesar de ter sido realizada a análise estatística da relação da produtividade com nutrientes absorvidos e os parâmetros do solo, sem a inclusão da quantidade de fertilizantes aplicados, esta análise foi descartada por tornar-se redundante frente a esta, que considera todos estes fatores em seu conjunto. Foram testadas as variáveis obtidas com extrator $\mathrm{KCl} I \mathrm{~N}$ e com $\mathrm{HCl}$ $0,5 \mathrm{~N}$, mas como nenhuma das variáveis afetadas por esta metodologia de determinação foi selecionada, o resultado foi um só. Também os procedimentos backward e forward não influenciaram o resultado. A equação obtida em todas estas análises foi a seguinte:

\section{Pdtv $=59,0944-21,99 . \mathrm{PCM}+13,20 . \mathrm{PH}-$ $-57,14 . \mathrm{KS}-0,31 . \mathrm{PF}-0,42 . \mathrm{KF}$$$
r^{2}=0,266 \star *
$$

Por esta equação, pode-se confirmar a influência da relação PCM, que agrega teores absorvidos de P, $\mathrm{Ca}$ e $\mathrm{Mg}$. Os parâmetros negativos da equação são justificados pelo ajuste necessário, não significando influências depressivas na produtividade. Isto é particularmente comum em equações com mais de três variáveis independentes (MATTIOLII, 1983). Além disto, é pouco provável que haja redução na produção em função da aplicação de fertilizantes dentro da amplitude observada.

\subsubsection{Influência dos nutrientes absorvidos sobre o teor de açúcar expresso en ATR e em PC.}

$\mathrm{Na}$ análise realizada para determinação das relações entre os nutrientes do caldo e o teor de açúcar da mesma amostra, foram encontradas equações muito semelhantes para ATR e para PC, como seria de se esperar. Aqui também 
os procedimentos backward e forward produziram resultados iguais. As equações encontradas foram:

$\begin{aligned} \operatorname{ATR} & =84,68+5,75 \cdot \mathrm{RAB}+0,23 \cdot \mathrm{CAAB}-0,14 . \mathrm{CM} \\ r^{2}=0,176 * * & \text { (4) }\end{aligned}$

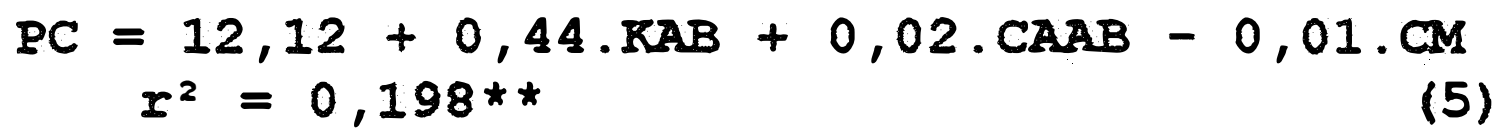

A rápida análise das equações demonstra quão semelhantes elas são, pois alem de terem tido as mesmas variáveis selecionadas, existe muita semelhança entre os parâmetros, já que o PC tem como unidade kg de açúcar em $100 \mathrm{~kg}$ de cana, e o ATR kg de açúcar em $1000 \mathrm{~kg}$ de cana, portanto, em termos de unidades, 10 vezes mais, que é a diferença média geral entre os parâmetros. Porém, como a equação (5), com ○ PC como variável dependente, apresenta maior valor do coeficiente de determinação, ela deve ser a escolhida para representar a relação entre o teor de açúcar e os nutrientes absorvidos.

$A$ escolha do teor de $k$ confirma a importância deste elemento no metabolismo do açúcar (DILLEWI JN, 1952; HUMBERT, 1968; ALEXANDER, 1973; FERNANDES, 1982; KORNDORFER \& MARTINS, 1992). O teor de Ca também selecionado, sofre um ajuste com a soma dos teores de $\mathrm{Ca}$ e Mg, enfatizando a importância destes elementos na nutrição e metabolismo da cana-de-açúcar.

\subsubsection{Influência dos nutrientes absorvidos, dos parâmetros} do solo e dos fertilizantes aplicados sabre o teor de açúcar expresso em ATR e em PC.

Esta análise já revelou efeitos do método analitico na determinação dos teores de $\mathrm{Ca}$ e $\mathrm{Mg}$. Após a análise das equações (4) e (5), isto não causa surpresa, pois estes elementos foram selecionados no caldo, e é natural que os teores no solo também tenham influência. 
Aqui o procedimento do stepwise também teve efeito no resultado final. As equações obtidas foram as seguintes:

- Procedimento forward. Extrator KCl $1 \mathrm{~N}$.

$\mathrm{ATR}=101,62+5,52 . \mathrm{KAB}+0,1743 . \mathrm{CAAB}-$ $-0,1167 . \mathrm{CM}-8,5873 . \mathrm{C}-4,1372 . \mathrm{CAK}+$ $+0,0636 . \mathrm{KV}$

$$
r^{2}=0,271 * *
$$

$\mathrm{PC}=14,8659+0,3914 . \mathrm{KAB}+0,0158 . \mathrm{CAAB}-$ $-0,0102 . \mathrm{CM}-0,7114 . \mathrm{C}-2,3013 . \mathrm{KS}$

$-0,4811$. CAR

$$
r^{2}=0,313 * *
$$

Observando-se as equações (6) e (7) é possivel notar uma grande semelhança entre elas. Praticamente as mesmas variáveis foram selecionadas. Mantiveram-se os efeitos do $K$, do $C a$ e do Mg absorvidos, já analisados nas equações (4) e (5), e houve a entrada do teor de carbono orgânico e do teor de Ca trocável no solo. $\mathrm{Na}$ equação para o ATR, também foi selecionada a quantidade total de K aplicada pela vinhaça, evidenciando a influência deste residuo na maturação. Na equação do PC esta variável não foi selecionada. Em seu lugar, entrou o teor de $K$ trocável do solo, que é afetado pela aplicação de vinhaça IGLÓRIA, 1976; FERNANDES, 1982; GLÓRIA \& ORLANDO FILHO, 1983). Esta equação por sua vez, apresentou um resultado melhor em termos de coeficiente de determinação.

- Procedimento forward. Extrator $\mathrm{HCl} 0,5 \mathrm{~N}$.

ATR $=96,9158+5,4453 . \mathrm{KAB}+0,1934 . \mathrm{CAAB}-$ $-0,1299 . \mathrm{CM}-10,1758 . \mathrm{C}+0,0647 . \mathrm{KV}$

$$
r^{2}=0,253 * \text { * }
$$


$\mathrm{PC}=15,4937+0,0175 \cdot \mathrm{CAAB}+0,0176 \cdot \mathrm{NAB}$

$-0,0744 . \mathrm{NK}-0,0116 . \mathrm{CM}-0,9515 . \mathrm{C}$

$-1,5194 . \mathrm{KS}+0,0034 . \mathrm{KV}$

$$
r^{2}=0,301 * *
$$

As equações (8) e (9), obtidas considerando os teores totais de $\mathrm{Ca}$ e $\mathrm{Mg}$ apresentam algumas diferenças importantes em relação às anteriores (6) e (7). Houve uma redução nos. valores de $r^{2}$, pois os teores de Ca e Mg totais não foram selecionados em nenhuma delas, e a ausência dos teores trocáveis refletiu-se na redução destes valores. Para a equação (8), apenas esta ausência foi observada, mas na equação (9), a variável KAB não foi selecionada, entrando em seu lugar as variáveis NAB e NK. Assim, o teor de $K$ no caldo é mantido mas na relação com o teor de $N$ absorvido, que passa a ser incorporado. A quantidade total de $K$ aplicado na vinhaça também foi incluído, quando antes só tinha sido selecionado para as equações com ATR.

- Procedimento backward. Extrator $\mathrm{KCl} 0,5 \mathrm{~N}$.

$A T R=120,66+0,0977 \cdot \mathrm{PAB}+0,0607 . \mathrm{CAAB}-$ $-0,119 . \mathrm{MGAB}-0,2632 . \mathrm{PK}-7,41 . \mathrm{C}+2,76 \mathrm{HAL}$ $-3,25 . \mathrm{SK}+0,0654 . \mathrm{KV}$

$$
r^{2}=0,305 * *
$$

$\mathrm{PC}=15,29+0.0068 . \mathrm{PAB}+0,006 . \mathrm{CAAB}-$ $-0,01 . \mathrm{MGAB}-0,0187 . \mathrm{PK}-0,61 . \mathrm{C}+0,31 . \mathrm{HAI}-$ $-0,36 . \mathrm{SK}+0,0055 . \mathrm{KV}$

$$
r^{2}=0,330 * *
$$

Com o procedimento backward, os valores de $r^{2}$ foram maiores que com o procedimento forward. Poucas diferenças foram observadas, e a seleção das variáveis para as equações $(10\rangle$ e $\langle 11\rangle$ foi a mesma. Assim, tanto para.PC quanto para ATR, houve efeito do $\mathrm{F}$, do $\mathrm{Ca}$ e do $\mathrm{Mg}$ 
absorvidos presentes no caldo, e da relação entre $\mathrm{P}$ e $K$ absorvidos. Também houve a seleção dos teores de C do solo, do teor de $H+A l$, da soma de bases e da aplicação de vinhaça. A análise com extrator HCl 0,5N foi descartada, já que os teores totais de $\mathrm{Ca}$ e $\mathrm{Mg}$ não foram selecionados, o resultado se repetiu.

4.2.5. Influência dos parânetros do solo e dos fertilizantes aplicados sobre a quantidade de $\mathbf{N}$ absorvido.

- Extrator KCl $1 \mathrm{~N}$.

$\mathrm{NAB}=50,6023-10,3995 . \mathrm{C}-42,2006 . \mathrm{PO}+$ $+6,3436 . \mathrm{CAR}+0,7184 . \mathrm{MGK}$

$$
r^{2}=0,122 * \star
$$

- Extrator $\mathrm{HCl} 0,5 \mathrm{~N}$.

\section{NAB $=50,7438-39,7789$. PO4$$
r^{2}=0,043 * *
$$

As equações (12) e (13) indicam que o teor de $\mathrm{P}$ no solo foi considerado relacionado com $\mathrm{N}$ no caldo. $\mathrm{A}$ equação (13) apresenta um $r^{2}$ muito baixo, ainda que significativo, mas sem poder explicar a variação nos teores de N. Isto também pode ser reflexo da própria metodologia de determinação, que dispensa a digestão da matéria orgânica, e o $\mathrm{N}$ poderia estar desta forma, imobilizado. Já a equação (12) inclui o tesr de $\mathrm{C}$, além dos teores de $\mathrm{Ca}$ e Mg trocáveis. Nenhuma variável relacionada com os insumos aplicados foi selecionada, mostrando que as futuras calibrações do $\mathrm{N}$ através da análise do caldo deverão considerar outros fatores. Neste sentido, incluiu-se no rol das variáveis independentes os demais nutrientes absorvidos. O resultado foi o seguinte: 
- Com extrator $\mathrm{KCl} 1 \mathrm{~N}$.

$\mathrm{NAB}=51,7051+4,8867 . \mathrm{KAB}-9,4136 . \mathrm{C}-$ $-42,6751$. PO4 + 6,2405.CAR - 0,1589.PF $r^{2}=0,154 * \star$

- Com extrator $\mathrm{HCl} 0,5 \mathrm{~N}$.

$\mathrm{NAB}=42,7745+4,6163 . \mathrm{RAB}-5,9331 . \mathrm{C}-$ - $33,7835$. PO4

$$
r^{2}=0,095 * *
$$

De acordo com as equações (14) e (15), podese inferir que o teor de $\mathrm{N}$ no caldo esta relacionado com o teor de $K$ analisado no mesmo material. Houve ainda a inclusão do $C$, independente do extrator utilizado. Isto confirma a importância da matéria orgânica presente no solo no suprimento de $\mathrm{N}$ às plantas. Outra inclusão importante foi a quantidade de $\mathrm{P}$ aplicado via fertilizante na equação (14). Isto pode estar relacionado com maior vigor do sistema radicular.

4.2.6. Influência dos parâmetros do solo e dos fertilizantes aplicados sobre a quantidade de $P$ absorvido.

- Extrator $\mathrm{KCl} 1 \mathrm{~N}$.

$\mathrm{PAB}=232,035-27,5296 . \mathrm{KAB}+68,2785 . \mathrm{C}-$ - 248,8096.AL - 38,8789.MGR - 0,6542. RF

$$
r^{2}=0,131 * \star
$$

- Extrator $\mathrm{HCl} 0,5 \mathrm{~N}$.

$\mathrm{PAB}=229,0567-28,1418 . \mathrm{KAB}+92,8948 . \mathrm{C}-$ - 219,9637.AI - 33,0292.MGH - 0,6331.KF

$$
r^{2}=0,140 * \star
$$


As equações (16) e (17) são bastante parecidas, havendo apenas a substituição do teor de Mg trocável em (16) pelo seu teor total em (17). A influência do $K$ sobre a absorção de $P$ parece ser grande, pois o teor deste elemento no caldo foi selecionado, assim como a quantidade aplicada através de fertilizantes. A influência do Mg no teor de $\mathrm{P}$ no caldo também fica evidente a partir da sua inclusão, seja como teor trocável, seja como teor total. A não seleção das variáveis relativas ao teor de $\mathrm{P}$ no solo ou da quantidade de $P$ aplicada via fertilizante confirma as dúvidas existentes encontradas nos estudos anteriores a respeito da dinâmica de absorção deste elemento pela cana-de-açúcar (SERRA, 1973; SAMPAIO et alii, 1984; CESAR et alii, 1987; PENATTI, 1991), mas indica que talvez trabalhos futuros a este respeito devam considerar também a dinâmica da nutrição relativa ao $\mathrm{Mg}$.

Finalmente, deve-se ainda observar que foram incluídas variáveis relativas ao $\mathrm{C}$ e o teor de Al do solo, que pode estar interferindo com a absorção, influindo no desenvolvimento do sistema radicular.

\subsubsection{Influência dos parânetros do solo e dos} fertilizantes aplicados sobre a quantidade de $K$ absorvido.

A mesma equação foi encontrada utilizando os parâmetros do solo obtidos com extrator $\mathrm{KCl}$ IN e com extrator $\mathrm{HCl} 0,5 \mathrm{~N}$.

\section{$\mathrm{KAB}=2,0018-0,0009 . \mathrm{PAB}+0,0095 . \mathrm{NAB}$}

$-0,8391 . \mathrm{AI}+0,0107 . \mathrm{PF}+0,0207 . \mathrm{NP}$

$$
r^{2}=0,123 * *
$$

$$
\text { Este resultado confirma algumas }
$$

considerações tecidas no item anterior, ou seja, as quantidades de $\mathrm{P}$ e $\mathrm{K}$ presentes no caldo parecem estar relacionadas entre si. A equação (18) apresenta como variáveis selecionadas o teor de $\mathrm{P}$ absorvido e a quantidade 
deste elemento aplicada ao solo através de fertilizantes. Inclui ainda o teor de $N$ absorvido e sua relação com $\circ \mathrm{P}$ absorvido. Assim, o teor de $K$ parece estar bastante relacionado com a dinâmica dos demais macronutrientes primários. O único parâmetro do solo selecionado foi o teor de Al, que deve estar interferindo nos processos de absorção, de forma semelhante ao observado nas equações (16) e (17).

\subsubsection{Influência dos parâmetros do solo e dos} fertilizantes aplicados sobre a quantidade de Ca absorvido.

Eoi observada uma correlação forte entre os teores de $\mathrm{Ca}$ e $\mathrm{Mg}$ absorvidos detectados no caldo. A relação entre estes dois elementos é a seguinte:

\section{CAAB $=77,74+1,52 \cdot \mathrm{MGAB}$}

$$
r^{2}=0,437 \star \star
$$

Esta alta relação entre $\mathrm{Ca}$ e Mg sugere inclusive que estes elementos sejam tratados como um conjunto, $\mathrm{Ca}+\mathrm{Mg}$, eliminando as análises individuais nos trabalhos futuros, reduzindo ainda mais os custos deste procedimento.

Com a inclusão dos demais fatores, foram obtidas as seguintes equações:

- Extrator KCl $1 \mathrm{~N}$.

\section{$\mathrm{CAAB}=283,04+1,5724 . \mathrm{MGAB}-85,2046 . \mathrm{C}-$ - 63,6148.KS - 39,4455.MGK - 8,2595.NF - $-1,171$. NK $r^{2}=0,567 * \star$

- Extrator HCI 0,5N. 
$C A A B=222,86+1,5378 . \mathrm{MGAB}-124,0653 . \mathrm{C}-$ $-148,2739 . \mathrm{AI}+10,5134 . \mathrm{HAL}-56,4271 . \mathrm{KS}+$ $+19,141 . \mathrm{MGH}-1,2485 . \mathrm{NR}$ $r^{2}=0,565 * *$

Nestas duas equações pode-se confirmar a influência do $\mathrm{Mg}$ na absorção do Ca. Esta influência é tão marcante, que o teor trocável e o teor total de Mg também foi selecionado respectivamente nas equações (20) e (21). Verifica-se ainda a presença da relação N/K absorvido, mostrando que estes elementos também tem influência. Entre os parâmetros do solo selecionados nas duas equações estão o teor de C e o teor de K. A diferença entre as equações reside na presença da quantidade de $N$ aplicada via fertilizante em (20), e dos teores de $\mathrm{H}$ e $\mathrm{H}+\mathrm{Al}$ em (21).

4.2.9. Influência dos parâmetros do solo e dos fertilizantes aplicados sobre a quantidade de Mg absorvido.

Como foi encontrada uma relação entre Ca e Mg absorvido no caldo, a relação do Mg em Eunção do Ca é a seguinte:

$$
\begin{aligned}
\operatorname{MGAB} & =26,49+0,29 \cdot \mathrm{CAAB} \\
x^{2} & =0,437 \star \star
\end{aligned}
$$

Esta relação é análoga a descrita em (19). A partir da inclusão das demais variáveis do estudo, foram obtidas as seguintes equações:

- Extrator $\mathrm{KCl} 1 \mathrm{~N}$.

MGAB $=8,0355+0,3075 . C A A B-10,7122 . \mathrm{PH}+$ $+30,8415 . \mathrm{C}+57,0080 . \mathrm{AL}+0,5620 . \mathrm{M}$ $r^{2}=0,534 * \star$ 
- Extrator $\mathrm{HCl} 0,5 \mathrm{~N}$.

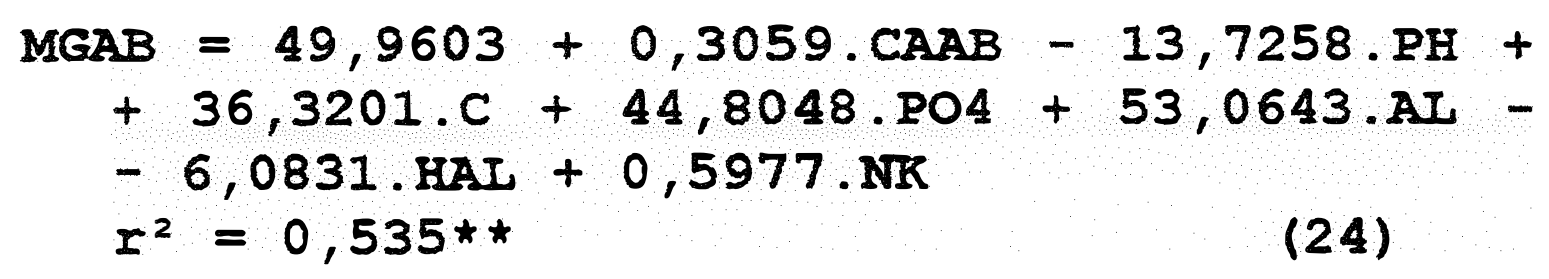

Em função da grande relação existente entre - Ca e o Mg absorvidos, os $r^{2}$ são bastante elevados. Contribuem ainda para esta relação nas duas equações, três parâmetros do solo. São eles o pH, o teor de $\mathrm{C}$ e o teor de Al. O teor de Al geralmente esta associado ao pH, e tende a interferir no desenvolvimento do sistema radicular, e portanto na absorção de nutrientes. O Al encontra-se presente em (23) também na inclusão da variável relativa à saturação de Al (M8), e em (24) na inclusão do teor de $H+A l$. Na equação (24) houve ainda a seleção da relação $N / K$ absorvidos, confirmando a importância das interrelações dos nutrientes absorvidos, e o teor de $\mathrm{P}$ no solo, elemento que esta relacionado com a nutrição de $\mathrm{Mg}$, conforme já discutido. 


\section{CONSIDERAÇÕES GERAIS}

Como o clima é o fator que mais influe na produtividade da cana-de-açúcar (OMETTO, 1978, 1981; IDE \& BANCHI, 1984; IDE \& OIIVEIRA, 1986; BARBIERI, 1993), os modelos que não particularizam este efeito, podem representar no máximo uma fração da variação total. Assim, coeficientes de determinação situados na faixa de 0,2 (20\%) nestes modelos podem ser considerados excelentes, especialmente se forem estatisticamente significativos.

O número de cortes tem um grande efeito depressivo sobre a produtividade agrícola, sendo responsável por uma redução média de $26 \mathrm{t}$ para cada corte. Só este efeito explica quase metade da variação da produtividade $\left(r^{2}=0,499\right)$ de todos os dados utilizados.

Desse modo, a produtividade agrícola passa a ter cerca de apenas 178 de sua variação estatisticamente relacionada com a absorção de nutrientes, que é detectada através da análise do caldo, na metodologia proposta neste trabalho. Ao serem considerados também os parâmetros do solo e dos fertilizantes aplicados, a relação com a variabilidade da produtividade mostra-se superior à $258\left(r^{2}\right.$ = 0,2656), um valor bastante adequado e relativamente alto, considerando-se que nenhum parâmetro climático foi particularizado, com exclusão do número de cortes.

- acúmulo de sacarose ao longo da safra, descrito em termos de $\mathrm{kg}$ de açúcar por tonelada (kg/t), é um processo bastante detalhado em diversos trabalhos relacionados ao manejo de variedades e da cultura em geral (HUMBERT, 1963; NASCIF et alii, 1981; AHMED \& MARIOTTI, 1983; COPERSUCAR, 1983; BEAUCLAIR \& PENTEADO, 1984 ; 
PARANHOS, 1987). Sofre portanto um grande efeito do clima, à semelhança do rendimento agrícola. Também aqui, estes parâmetros climáticos não foram considerados, nem a época de corte. Assim, as relaçŏes encontradas com os valores de ATR e PC são bastante interessantes, pois podem explicar os desvios que normalmente ocorrem no campo, em relação às curvas de maturação apresentadas pelas instituições responsáveis pelo melhoramento de variedades de cana-deaçúcar.

Quando foram considerados os nutrientes absorvidos, os parâmetros do solo e os fertilizantes aplicados, quase um terço da variação do teor de açúcar pode ser relacionado à variação de algumas destas variáveis. Isto significa que é possível a elaboração de trabalhos de modelagem da previsão da maturação futura, a partir desta metodologia de análise.

Os teores dos nutrientes absorvidos tem relação baixa, porém significativa, com os teores do solo, mas estão muito associados entre si. Assim, torna-se necessário em investigações futuras, determinar quais os fatores interferêntes nos níveis de nutrientes no caldo, inclusive sua relação com seu conteúdo total na planta ou em outras de suas partes.

A intima associação entre teores de Ca e Mg no caldo, sugere que eles possam ser determinados em conjunto, eliminando-se uma determinação analítica, diminuindo os custos e o tempo necessário nas análises, de acordo com resultados preliminares obtidos por BITTENCOURT et alii (1992).

Um manejo geral adequado tende a eliminar as limitações à produtividade decorrentes de baixos teores de nutrientes no solo (BEAUCLAIR, 1991). Isto mais uma vez pode ser confirmado através das pequenas interferências dos parâmetros do solo sobre as demais variáveis.

Ocorre ainda uma relação matemática entre os teores no caldo entre si, algumas propriedades químicas do 
solo e alguns insumos aplicados, no caso fertilizantes e vinhaça, indicando que a variação no nivel de nutrientes no caldo não é dependente exclusivamente destes fatores.

O extrator Hcl $0,5 \mathrm{~N}$ não apresentou boas relações com a produtividade de apenas uma safra. Permanece portanto, seu uso limitado aos estudos que consideram vários cortes ou o ciclo completo da cultura (BEAUCLAIR, 1991).

O estudo dos niveis de nutrientes no caldo pode vir a permitir que novas técnicas de diagnose nutricional sejam desenvolvidas. Assim, pode-se sugerir trabalhos futuros de determinaçăo de niveis críticos ou de calibração das relações entre os nutrientes (DRIS), com os teores de nutrientes no caldo, obtidos pelo método descrito neste trabalho. Os resultados aqui expostos provam que a técnica é viável através das determinações das relações existentes.

Portanto, os resultados aqui apresentados, permitem antever com certo otimismo, a possibilidade de obter-se um monitoramento das condições gerais da lavoura, através de investimentos relativamente baixos.

Um método de diagnose nutricional da canade-açúcar, através da análise do caldo, pode ser perfeitamente desenvolvido para ser empregado em lavouras comerciais, sendo que os dados obtidos em uma safra, servirão de base para a tomada de decisão no próximo ano. Assim, através de uma amostragem que não envolve a criação de novas equipes e de uma metodologia analítica simples, o procedimento poderá ser implantado no controle de toda a lavoura da propriedade agrícola.

Sugere-se finalmente, que novos trabalhos neste sentido sejam desenvolvidos à luz dos novos conhecimentos adquiridos, pois os beneficios são claros e marcantes. 


\section{CONCLUSÕES}

Existe uma relação estatisticamente significativa entre os teores de nutrientes detectados no caldo da cana e a produtividade em t/ha e em kg de açúcar / $t$ de cana.

Existe tambèm uma relação estatisticamente significativa entre teores de nutrientes no caldo, parâmetros do solo e fertilizantes aplicados sobre os rendimentos agrícolas e tecnológicos.

A intima associação existente entre o Ca e o Mg no caldo podem permitir a eliminação das análises individuais destes elementos, substituindo-as por uma análise do total de $\mathrm{Ca}+\mathrm{Mg}$.

O extrator $\mathrm{HCl} 0,5 \mathrm{~N}$ apresentou menor relação com a variação da produtividade de uma safra do que o extrator $\mathrm{KCl} 1 \mathrm{~N}$. 


\section{RBFERÊNCIAS BIBLIOGRÁFICAS}

ALEXANDER, A.G. Sugar Cane Physiology. Elsevier Pub. 1973. AHMED, M.A. \& MARIOTTI, J. Caña de azucar: la epoca de corte afecta el rendimento y la produccion. Avance Agroindustrial, 3(12); 5-8, 1983.

BAPTISTELLA, J.R.; LEME, E.J.A.; ROSENEELD, U. Estudos de doses de vinhaça aplicada por aspersão em cana-deaçúcar. In: CONGRESSO NACIONAL STAB, 2. Rio de Janeiro, 1981. Anais. v. 1, p. 215-234.

BARBIERI, V. Condicionamento climatico da produtividade potencial da cana-de-açúcar (sacobarmen spp.): um modelo matemático-fisiológico de estima. Piracicaba, ESALQ/USP, 1993. 142 p. (Tese de Doutorado).

BEAR, F.E. Chemistry of the soil. 2 ed. Rheinhold, New York, 1967. $515 \mathrm{p}$.

BEAUCLAIR, E.G.F.de. Adubação verde e aplicação de matéria orgânica no cultivo da cana-de-açúcar. Reuniảo Técnica Agronômica: manejo da adưbação na cultura da cana-deaçúcar. Copersucar, São Paulo, Abr. 1984. p. 40-7.

BEAUCLAIR, E.G.F.de. Relaçŏes entre algumas propriedades químicas do solo e a produrtividade da cana-de-açúcar 
(Saccharm spp.), através de regressão linear míltipla. Piracicaba, ESALQ/USP, 1991. 96 p. (Tese de Mestrado). BEAUCLAIR, E.G.F.de \& PENTEADO, C.R. Cronograma de corte da cana-de-açúcar através dà programação linear. In: SEMINÁRIO DE TECNOLOGIA AGRONÔMICA, 2. Piracicaba, São Paulo, 1984. Anais. São Paulo, Copersucar, 1984. p.42434 .

BEAUFILS, E.R. Diagnosis and recomendations integrated system (DRIS); a general scheme for experimentatioin and calibration based on principles developed from research in plant nutrition. Soil science Bulletin, (1): 1-32, 1973.

BEAUFILS, E.R. \& SUMNER, M.E. Application of the DRIS approach for calibrating soil, plant yield and plant quality factors on sugarcane. In: ANN. CONG. OF THE SOUTH AFR. SUG. TECH. ASS., 1976, Durban. Rapers, p. 17.

BENEDINI, M.S. Recomendação de calcário para a cultura da cana-de-açúcar. In: SEMINÁRIO DE TECNOLOGIA AGRONÔMICA, 4. Piracicaba, São Paulo, 1988. Anais. São Paulo, Copersucar, 1988. p.99-102.

BERG, R.C. Use of stepwise discriminant analysis to assess soil genesis in Youthfull Sandy Environment. Soil Science, Baltimore, 29: 353-365, 1980.

BITTENCOURT, V.C.de; CARMELLO, Q.A.de C.; CLEMENTE, J.L. Avaliação dos efeitos da calagem da cana-de-açúcar. 
STAB, Açúcar, Álcool e Subprodutos. Piracicaba, 6(3):237, jan/fev, 1988.

BItTENCOURT, V.C.de; CLARET, A.C.; CARMELLO, Q.A.de C.; CARVALHO, A.J.L. Produtividade da cana-de-açúcar e a fertilidade do solo. STAB, Açúcar, Álcool e Subprodutos. Piracicaba, 8(4):10-4, jan/abr, 1990a.

BITTENCOURT, V.C.de; JOÇO, J.; CLEMENTE, J.L.; CARMELLO, Q.A.de C.; BEAUCLAIR, E.G.F.de. Produtividade da canade-açúcar e suas relações com a fertilidade dos solos e - manejo da cultura. STAB, Açúcar, Álcool e subprodutos. Piracicaba, 8(5/6): 10-4, maio/ago, 1990 b.

BITTENCOURT, V.C.de; ORLANDO FILHO, J.; ZAMBELLO JÚNIOR, E. Determinations of available $\mathrm{P}$ for sugarcane in tropical soil by extraction with $\mathrm{H}_{2} \mathrm{SO}_{4}$ 0,5N. In: ISSCT CONGRESS, 16., São Paulo, 1977. Proceedings. São Paulo, I.S.S.C.T., 1978. v.2, p.1175-86.

BITTENCOURT, V.C.de; PAIXÃO, A.C.S.; ALMEIDA, M.J.; BEAUCLAIR, E.G.F.de. Diagnose nutricional da cana-deaçúcar através da análise do caldo. I. Dados preliminares. STAB. Açúcar, Alcool e Subprodutos, Piracicaba, 11(2):12-7, nov./dez. 1992.

BUCKMAN, H.O. \& BRADY, N.C. Natureza e propriedade dos solos. Trad. de A.B.N.FIGUEIREDO FO. 4 ed. Rio de Janeiro, Freitas Bastos, 1976. 594 p.

BURR, G.O. Plant analyses as indexes of ntrient availability and adequacy. The Hawaiian Planters Record. Honolulu, 55(1):103-112. 1955. 
CARMELLO, Q.A.de C. Regressão linear máltipla aplicada à seleção de variáveis de solo e planta mais relacionadas às produçóes de milho e amendoim. Piracicaba, ESALQ/USP, 1991. 94 p. (Tese de Livre-docência).

CESAR, M.A.A., DELGADO, A.A., CAMARGO, A.P., BISSOLI, B.M.A.; SILVA, F.C. Capacidade de fosfatos naturais e artificiais em elevar o teor de fósforo no caldo de cana-de-açúcar (cana-planta), visando o processo industrial. STAB. Açúcar, Alcool e Subprodutos. Piracicaba, 5(5/6): 32-8, 1987 .

CHUI, F. \& SAMUELS, G. Evaluation of $N$ fertilizers efficiency for plant and ratoon crops in irrigated sugarcane. In: ISSCT CONGRESS, 16, São Paulo, 1977. Proceedings. 1978. vol. 2. p.1259-64.

CLEMENTS, H.F. Recent development in the crop-logging of sugarcane. In: ISSCT CONGRESS, 10, Hawaii, 1959. Proceedings. Amsterdam, Elsevier, 1960. p.522-8. CLINE, M.G. Principles of soil sampling. Soil sci., 58: $275-288,1944$.

COELHO, M.B. \& AZEVEDO, H.J. de. Utilização da vinhaça na irrigação da cana-de-açúcar. STAB, Açúcar, Árcool e Subprodutos. Piracicaba, 4(5):49-52, mai/jun, 1986. COLETI, J.T.; LORENZETTI, J.M.; GASPARINI, C.T.; DEMATTE, J.L.I.; FREITAS, E.G.R.de. Efeito da aplicação de vinhaça nas propriedades dos solos da Usina São José Macatuba. STAB, Açúcar, Álcool e subprodutos. Piracicaba, 1(3): 12-7, jan/fev, 1983. 
COOKE, G.W. Valor dos "blueprints" em pesquisa e consultoria. Informaçỏes Agronômicas, 18. Instituto Internacional da Potassa, São Paulo. Junho, 1982. COPERSUCAR. Amostragem e análise da cana-de-açúcar.

Cooperativa Central dos Produtores de Açúcar e Álcool do Estado de São Paulo. São Paulo, 1980. 37 p. COPERSUCAR. Efeitos da aplicação da vinhaça como fertilizante em cana-de-açúcar. Boletim Técnico Copersucar, (7):41-50, 1978 .

COPERSUCAR. Variedades SP: recomendações e manejo. Reuniåo

Técnica Copersucar: variedades de cana-de-açúcar e suas implicaçóes na lavoura canavieira. São Paulo, Copersucar, 1983. p. 44-56. COURY, T., MALAVOLTA, E., VALSECHI, O.; NOVAIS, R.E. diagnose foliar na cana-de-açúcar. I.Resultados preliminares. ESALQ, Piracicaba, 28 p., 1957. COUTO, H.T.Z.do \& MATTIOLLI, C.H. Introduçăo ao sistema SAs. Piracicaba, CIAGRI, USP. 1988. 51 p. (Apostila do cursol.

DILLEWIJN, C. van. Botany of sugarcane. Waltham, Mass., The Chronica Botanica Co., 1952. 371 p.

DRAPER, N.R. \& SMITH, H. Selecting the "best" regression equation. In: DRAPER, N.R. \& SMITH, H. Applied regression analysis. New York, John Wiley, 1966. p. 163215 .

ESPIRONEIO, A.; CAMARGO, A.P.; NAGAI, V.; LEPSCH, I.E. Efeitos de nitrogênio e fósforo como complementação da 
aplicação de vinhaça em soca de cana-de-açúcar. In: CONGRESSO NACIONAL STAB, 2; Rio de Janeiro, 1981. Arais. STAB, Rio de Janeiro, 1981, p. 128-139.

ESPIRONELO, A. \& OLIVEIRA, H.de. orientação geral para adubação da cana-de-açúcar no Estado de são Paulo. Campinas, Instituto Agronômico, 1972. 16 p. (Boletim No. 201).

EERNANDES, A.C. Comportamento agro-industrial de seis variedades de cana-de-açúcar (Saccharm spp.) com e sem fertirrigação. Piracicaba, ESALQ/USP, 1982. 82 p. (Tese de Mestrado).

FERNANDES, A.C. Controle da cana-de-açúcar como matériaprima na fabricação do açúcar e do álcool. Cooperativa Central dos Produtores de Açúcar e Álcool do Estado de São Paulo.São Paulo. 1981. 29 p.

EREUND, R.J. \& MINTON, P.D. Regression methods. A tool for data analysis. New York, Marcel Dekker Inc, 1979. 261 p. FURLANI NETO, V.L.; MAGRO, J.A.; SELAGATO, S.L.; ROSENEELD, U.; STOLF, R.; LUZ, P.H.de C. Formas de cultivo da canasoca - associação à utilização agrícola da vinhaça com adubação mineral. STAB, Açúcar, Álcool e subprodutos. Piracicaba, 3(6):46-52, jul/ago, 1985.

GPILO, J.R., ALVAREZ, R.; ABRAMIDES, E. Amostragem de cana-de-açúcar para fins de análise foliar. Bragantia, 21(54): 899-21, 1962 .

GLórIA, N. A.da. Emprego da vinhaça na fertilização. Piracicaba, SP. Codistil, 1976. s.n.p. 
GLÓRIA, N.A.da; FONTANARI, N.; ALONSO, O.; HENRIQUE, J.L.P.; GERALDI Fo, L.; ALBUQUERQUE, F.C. Complementação nitrogenada de soqueiras de cana-de-açúcar fertilizadas com vinhaça. In: CONGRESSO NACIONAL STAB, 3. São Paulo, 1984. Anais. STAB, São Paulo, 1984, p.74-7.

GLóRIA, N.A.da \& MAGRO, J.A. Utilização agricola de resíduos da cana-de-açúcar e destilaria da Usina da pedra. In: SEMINÁRIO COPERSUCAR DA AGROINDÚSTRIA AÇUCAREIRA. Águas de Lindóia, SP. Arais. 1976. p. 163180 .

GLÓRIA, N.A.da \& ORLANDO FILHO, J. Aplicação da vinhaça como fertilizante. Boletim Técnico PLANAISUCAR, Piracicaba, 5(1):5-38, jan. 1983 .

GOLDEN, L.E. Fertilizer and soil fertility studies with sugarcane. Reports of Projects. Dept. of Agronomy. Louisiana State Univ. 1978. Datilografado. 10p. GOLDEN, L.E. The effect of fertilizers and soil variability on sugarcane yields and its components. Amer. Soc. of Sugar Cane Tech. Proc. vol. 5. p. 37-43. 1976. HAMMOND, L.C., PRICHETT, W.L.; CHEW, V. Soil sampling in relation to soil heterogenety. Soil Sci. Soc. Am. Proc., $22: 548-52,1958$

HOCKING, R.R. The analysis and selection of variables in Iinear regression. Biometrics, Releigh, $32(1): 1-49$, 1976. 
HOFFMANN, R. \& VIEIRA, S. Análise de regressão - Una introdução à econometria. 2 ed. São Paulo, Hucitec, 1977. 379 p.

HUMBERT, H.P. The growing of sugar cane. Amsterdam, Elsevier, 1968. $779 \mathrm{p}$.

IBRAHIM, H.S. Effects of soil properties on sugarcane yield in Sudam. Bxperimental Agriculture, London. 14:273-276, 1978 .

IDE, B.Y. \& BANCHI, A.D. Influência do clima na produtividade da cana-de-açúcar. In: SEMINÁRIO DE TECNOLOGIA AGRONÔMICA, 2, Piracicaba, 1984, Anais. São Paulo, Copersucar, 1984, p.196-204.

IDE, B.Y. \& OLIVEIRA, M.A.de. Efeito do clima na produção de cana-de-açúcar. In: SEMINÁRIO DE TECNOLOGIA AGRONÔMICA, 3, Piracicaba, 1986, Anais. São Paulo, Copersucar, 1986, p.573-583.

KORNDORFER, G.H. \& MARTINS, M. Importância da adubação na qualidade da cana-de-açúcar. STAB, Açúcar, Álcool e Subprodutos. Piracicaba, 10(3):26-31, jan/fev, 1992.

LAIRD, R.J. \& CADY, F.B. Combined analysis of yield data from fertilizer experiments. Agronomy Journal, Madison 61: $829-834,1969$.

LOPES, A.S. \& GUIDOLIN, J.A. Interpretação de análise do solo: conceitos e aplicaçóes. ANDA. São Paulo. 1987. 58 p. (Boletim Técnico No. 2).

LOVEDAY, J. A study of the relationships between the yield of irrigated lucerne and the properties of some grey and 
brown soils of heavy texture in southwest - New Southwest Wales. Australian Journal soil Research, Victoria, 2:96-110, 1964 .

MAAS, S.J. Parameterized model of gramineous crop growth:

I. Leaf area and dry mass simulation. Agronomy Journal. $85: 348-353.1993$

MAIA, N.B. \& BEAUCLAIR, E.G.F.de. Utilização da metodologia do sistema COPI na determinação dos fatores Iimitantes da produtividade. In: SEMINÁRIO DE TECNOLOGIA AGRONÔMICA, 2, Piracicaba, 1984, Anais. São Paulo, Copersucar, 1984. p.151-161.

MARINHO, M.L. \& ALBUQUERQUE, G.A.C. Calagem. In: ORLANDO FILHO, J. Nutrição e adubação da cana-de-açúcar no Brasil. Piracicaba, IAA/Planalsucar, 1983. p.77-99. MARINHO, M.L. \& ALBUQUERQUE, G.A.C. Calibração do Ca+Mg no solo para cana-de-açúcar em Alagoas. In: CONGRESSO NACIONAL STAB. 2. Anais. 1981. p.111-128. MATIOLI, C.S.; MARCONDES, Y.S.; GANDINI, M.O.; GAZON, A.L. Modelo de avaliação técnico-econômico de sistemas de aplicação de vinhaça. In: SEMINÁRIO DE TECNOLOGIA AGRONÔMICA, 4. Anais. Copersucar. p. 151-158. 1988. MATTIOLII, C.H. Métodos de seleção de equaçōes de regressão linear miltipla. Piracicaba, ESALQ/USP. 1983. 104 p. (Tese de Mestrado).

MEADE, G.P. Composition of cane and juice. In: Cane sugar handbook. 9ed. New York, Wiley, 1963, p. 23-26. 
NASCIE, A.E.; TUlLER, V.V.; SOUZA, D; AZEVEDO, A.J. Influência da época de plantio e corte no rendimento agroindustrial da cana-de-açúcar. In: CONGRESSO NACIONAI STAB, 2, Rio de Janeiro, Ago. 1981. Anais. Rio de Janeiro, STAB, 1981. 1: 230-46.

OMETTO, J.C. A equation for the estimation of agroindustrial sugarcane yield in the Piracicaba region. In: ISSCT CONGRESS, 16. Anais. Săo Paulo, 16:899-905. 1978. OMETTO, J.C. Bioclimatologia vegetal. Ceres, São Paulo, $1981,440 \mathrm{p}$.

ORLANDO FILHO, J. \& HAAG, H.P. Influência varietal e do solo no estado nutricional da cana-de-açúcar (Saccharum spp.) pela análise foliar. Boletim Técnico PIANarsucar, Araras, 1976.

ORLANDO FILHO, J. \& RODELLA, A.A. Análise química do solo e recomendação de adubação. In: ORLANDO EILHO, J. Nutrição e adubação da cana-de-açúcar no Brasil. Piracicaba, IAA/Planalsucar, 1983. p.155-178.

ORLANDO EILHO, J. \& ZAMBELLO JÚNIOR, E. Diagnose foliar. In: ORLANDO EILHO, J. Nutrição e adubação da cana-deaçúcar no Brasil. Piracicaba, IAA/Planalsucar, 1983. p. 125-154.

ORLANDO EILHO, J.; ZAMBELLO JÚNIOR, E.; AGUJARO, R. ; ROSSETTO, A.J. Efeito da aplicação prolongada da vinhaça nas propriedades químicas dos solos com cana-de-açúcar. STAB, Açúcar, Álcool e subprodutos. Piracicaba, 1(6):2833, jul/ago, 1983. 
PARANHOS, S.B. (Coord.). Cana-de-açúcar. Cultivo e Utilização. Campinas, Fundação Cargill, 1987, 856 p. PAULER, B. \& NEUMANN, K.H. On the importance of some physical and chemical soil parameters for the characterization of soil fertility by means of multiple linear regression analysis. Bodenkultur, Viena, 40(2): $99-117,1989$.

PEIXOTO, A.A.; DEEELIPO, B.V.; BRAGA, J.M.; NOVAIS, R.F.de. Efeito de $\mathrm{Ca}, \mathrm{Mg}$ e $\mathrm{K}$ e suas relações na produção de cana-de-açúcar (Saccharum spp.) em um solo gley pouco húmico do norte fluminense. In: CONGRESSO NACIONAL STAB, 2. Anais. 1981. p.148-173.

PENATTI, C.P.; FERREIRA, E.da S.; ZOTARELLI, E.M.M.; KORNDORFER, G.H.; BENEDINI, M.S.; CACERES, N.T.; CHALITA, R.; CAMBRIA, S. Recomendação da adubação para a cultura da cana-de-açúcar. In: SEMINÁRIO DE TECNOLOGIA AGRONÔMICA, 4, Anais. São Paulo, Copersucar, 1988 . p. $103-113$

PENATTI, C.P. Uso de ácido fosfórico ou superfosfato triplo camo fonte de fósforo para a cultura da cana-de-açúcar. Piracicaba, ESALQ/USP, 1991. (Tese de Mestrado). PENNA, M.J. ¿ FIGUEIREDO, A.A.M.de. Aquamônia x uréia em soqueiras de cana-de-açúcar fertilizadas com vinhaça. In: SEMINÁRIO DE TECNOLOGIA AGRONOMICA, 2. Anais. Copersucar. p. 180-186. 1984.

PIMENTEI, GOMES, F. Curso de estatistica experimental. Piracicaba. Nobel, 1977. $430 \mathrm{p}$. 
QUAGGIO, J.A. A análise de solo no Brasil. o Agronômico, Campinas, SP, 42(1): 6-17. 1990.

RAIJ. B.van. Fertilidade do solo e adubaçăo. Piracicaba, Associação Brasileira para Pesquisa da Potassa e do Eosfato, 1991. 343 p.

RAIJ, B.van; CANTARELLA, H.; CAMARGO, A.P.; SOARES, E. Perdas de cálcio e magnésio durante cinco anos em ensaio de calagem. Revista Brasileira de Ciência do Solo, Campinas. $7: 269-275,1985$.

RAIJ, B.van \& QUAGGIO, J.A. Métodos de análise de solo para

fins de fertilidade. Campinas, SP, Instituto agronômico, dez. 1983. 31 p. (Boletim técnico, 81).

REED, J.F. \& RIGNEY, J.A. Soil sampling from fields of uniform and nonuniform appearance and soil types. J. Am. soc. Ag., 39: 26-40, 1947 .

RIBEIRO, M.R.; HALSTEAD, E.H.; JONG, E.de. Rendimento da cana-de-açúcar e características das terras da microrregião da Mata Norte de Pernambuco. Revista Brasileira de Ciência do Solo, 8:209-213, 1984. RODELLA, A.A. ¿ EERARI, S.E. A composição da vinhaça e efeitos de sua aplicação como fertilizante na cana-deaçúcar. Brasil Açucareiro, Rio de Janeiro, 90(1): 6-13, jul. 1977.

RODELLA, A.A.; ZAMBELLO JÚNIOR, E.; ORLANDO EILHO, J. Calibraçào das análises de fósforo e potássio no solo em cana-de-açúcar, 2a. aproximaçào. Araras, São Paulo, IAA/PLANALSUCAR. COSUL. 1981, 13 p. ITrabalho 
apresentado na Reunião da Sociedade Brasileira de Ciência do Solo, 18, Salvados, 1981).

RODRIGUES, J.C.S.; BEAUCIAIR, E.G.F.de; RODRIGUES, A.L.C. Integrated control of production applied to sugarcane: the COPI system. In: ISSCT CONGRESS, 18, Cuba, 1983.

Proceedings. Cuba, ISSCT, 1983. Agricultural Commission

1. p. $397-421$.

RODRIGUES, J.C.S. \& PALHARES, A.L. Efeito da aplicação do calcário nas propriedades químicas d• solo e na produtividade da cana-de-açúcar. In: SEMINÁRIO DE TECNOLOGIA AGRONOMICA, 3. Anais. Piraciccaba, Copersucar, 1986. p. 303-320.

RODRIGUES, J.C.S.; PENNA, M.J.; MORAES, R.S. Complementação nitrogenada em àreas fertilizadas com vinhaça. Reuniào Técnica Agronômica: manejo da adubação na cultura da cana-de-açúcar. Copersucar, São Paulo, Abr. 1984. p. 339.

ROSSETto, A.J. Uso de resíduos e produção de alimentos em canaviais. In: Cana-de-açúcar: cultivo e utilização. Campinas, Fundação Cargill, 1987, v.2. p. 433-504. SAMPAIO, E.V.S.B. \& SALCEDO, I.H. Dinâmica de nutrientes em cana-de-açúcar. V. Balanço de $K$ em quatro ćiclos de cultivo. Pesg. agropec. bras., 26(9): 1323-35, 1991. SAMUELS, G. Foliar diagnosis for sugarcane. Chicago, Adams Press, 1969. $232 \mathrm{p}$. 
SANCHEZ, $0 . \&$ CLEMENTS, H.F. Magnesium in sugarcane culture. In: ISSCT CONGRESS, 15. Arais. vol. 2.1974. P. $552-56 ?$.

SASA, Esp. Sta. Methods of sampling for fertilizer advice. BUIL. 16. Mount Edgecombe, 1963. 4 p.

SCHOLZ, A.; SCHOEDER, D.; ZAKOSEK, H. Demonstration of the soil development in high flood loam of the Lower Rhine usirg multiple correlations, regression and cluster analysis. Z. Pflanzenern. Bodenkd, Weinheim, 146: 353$364,1983$.

SERRA, G.E. Efeitos da adubação fosfatada sobre algumas caracteristicas agro-industriais do caldo de cana-deaçúcar, variedade CB41-76. Botucatu, E.C.C.M.B.B. ! UNESP. 1973. (Tese de Doutoramento)

SILVA, G.M.de A. Efeito da aplicação de vinhaça no estado nutricional, produtividade e qualidade tecnológica da cana-de-açúcar (Saccharum spp) en dois tipos de solo. Piracicaba, ESALQ/USP, 1982. 121 p. (Tese de Mestrado). SILVA, L.C.F.da \& CASAGRANDE, J.C. Nutrição mineral da cana-de-açúcar (macronutrientes). In: ORLANDO EILHO, J. Nutrição e adủbação da cana-de-açúcar no Brasil. Piracicaba, IAA/Planalsucar, 1983. p.77-99.

SOLERA, M.A.C. Efeito das relaçóes Ca:Mg, utilizando carbonatos e sulfatos, sobre o crescimento e a nutrição mineral da cana-de-açúcar. Viçosa, univ. Fed. Viçosa, 1988. 186 p. (Tese Mestrado). 
SPIEGEL, M.R. Estatística. São Paulo. McGraw-Hili do Brasil, 1972. $580 \mathrm{p}$.

StUPIELLO, J.P.; PEXE, C.A.; MONTEIRO, H.; SILVA, L.H. Efeitos da aplicação de vinhaça como fertilizante na qualidade da cana-de-açúcar. Brasil Açucareiro, Rio de Janeiro, $90(3): 41-50,1977$.

TISDALE, S.L.; NELSON, W.L.; BEATON, J.D. Soil fertility and fertilizers. 4 ed. New York, Macmillian, 1984. 694 p.

TOMANENG, A.A. A parametric approach to evaluation of soil productivity for land use, planning and crop development. Sugarland, 14(5):10, 1977.

TRIVELIN, P.C.O.; RODRIGUES, J.C.S.; VITÓRIA, R. Aproveitamento pela soqueira da cana-de-açúcar do nitrogênio dos adubos uréia $\left(15_{N}\right)$ e aquamônia $\left(15_{N}\right)$ incorporados ao solo em área fertilizada com vinhaça. In: SEMINÁRIO DE TECNOLOGIA AGRONÔMICA, 3. Anais. Copersucar. p. 287-301. 1986.

ZAMBEILO JÚNIOR, E. \& ORLANDO FILHO, J. Adubação da canade-açúcar na região Centro-Sul do Brasil. Boletim Técnico planausucar, Piracicaba, 3(3): 1-26, 1981.

ZAMBELLO JÚNIOR, E. \& ORLANDO EILHO, J. Aplicação do sistema integrado de diagnose e recomendação (DRIS) em soqueiras de 3 variedades de cana-de-açúcar. Saccharum, $3(10): \quad 23-28,1979$.

ZAMBELLO JÚNIOR, E. \& ORLANDO EILHO J. Diagnosis and recommendations integrated system (DRIS) applied to 
various sugarcane tissues. In: ISSCT CONGRESS, 17 Manila, 1980. Proceedings, V. 1, p. 446-57. 